\title{
Coupled 3-d numerical simulation of proppant transport and fluid flow in hydraulic fracturing
}

\author{
Bing Kong \\ West Virginia University
}

Follow this and additional works at: https://researchrepository.wvu.edu/etd

\section{Recommended Citation}

Kong, Bing, "Coupled 3-d numerical simulation of proppant transport and fluid flow in hydraulic fracturing" (2014). Graduate Theses, Dissertations, and Problem Reports. 237.

https://researchrepository.wvu.edu/etd/237

This Thesis is protected by copyright and/or related rights. It has been brought to you by the The Research Repository @ WVU with permission from the rights-holder(s). You are free to use this Thesis in any way that is permitted by the copyright and related rights legislation that applies to your use. For other uses you must obtain permission from the rights-holder(s) directly, unless additional rights are indicated by a Creative Commons license in the record and/ or on the work itself. This Thesis has been accepted for inclusion in WVU Graduate Theses, Dissertations, and Problem Reports collection by an authorized administrator of The Research Repository @ WVU. For more information, please contact researchrepository@mail.wvu.edu. 


\title{
Coupled 3-D numerical simulation of proppant transport and fluid flow in hydraulic fracturing
}

\author{
Bing Kong \\ Thesis submitted \\ to the Benjamin M. Statler College of Engineering and Mineral Resources \\ at West Virginia University \\ in partial fulfillment of the requirements for the degree of \\ Master of Science in \\ Petroleum and Natural Gas Engineering \\ Ebrahim Fathi, PhD., Chair \\ Kashy Aminian, $\mathrm{PhD}$. \\ Ali Takbiri Borujeni, PhD. \\ Department of Petroleum and Natural Gas Engineering
}

Morgantown, West Virginia

2014

Keywords: numerical simulation, proppant transport, fracture production simulation, hydraulic fracture performance optimization

Copyright 2014 Bing Kong 


\begin{abstract}
Coupled 3-D Numerical Simulation of Proppant Transport and Fluid Flow in Hydraulic Fracturing

By Bing Kong
\end{abstract}

Hydraulic fracturing is one of the most common and important stimulation techniques used in oil and gas industry to create high conductivity flow paths for hydrocarbons to flow from the reservoir matrix to the wellbore. Hydraulic fracturing is a complex process including different physical and chemical phenomena. It involves rock mechanics for the part of fracture propagation and involves fluid mechanics for the part of slurry injection, fluid flow, fluid leakoff, proppant transport, proppant settling and interaction between fluid and proppant particles. In this study, the focus is on fluid and proppant motion within hydraulic fractures. The effectiveness of hydraulic fracturing treatment is highly dependent on the fracture geometry and conductivity after flow back. Fracture geometry is a function of proppant placement while fracture conductivity is determined by both proppant placement and proppant pack permeability. Advanced understanding of these properties is essential for optimization of hydraulic fracturing treatment.

For proppant placement, the proppant jamming principles are considered based on sphere packing theory while for proppant pack permeability, correlations based on published experimental data have been implemented. Navier-Stokes equation describing fluid flow in the fracture is coupled with mass conservation equation governing the proppant transport, and solved using finite difference approach based on staggered grid to avoid checkerboard solution while fracture propagation is simulated using in house 3D hydraulic fracturing simulator (HFWVU, Dr Bao). Slippage between proppant and fracturing fluid induced by gravity and affected by fracture width, particle interaction and non-Newtonian effect are considered in our formulation to obtain precise proppant distribution profile in the hydraulic fracture during the injection. 
Next, Fracture-Production model simulating fluid flow in a non-uniform-conductivity fracture is established for the evaluation of fracture performance, where the fracture geometry after flow back follows proppant concentration profile considering proppant pack contraction due to effective closure stress. Sensitivity analysis and optimization of parameters such as initial proppant concentration, proppant size and injection rate, fluid viscosity and reservoir permeability has been performed using Plackett-Burman design.

This study is a unique approach for the further understanding of the hydraulic fracturing process to allow for possible enhancements of hydraulic fracture performance. 
DEDICATION

To my parents 


\section{TABLE OF CONTENTS}

DEDICATION.

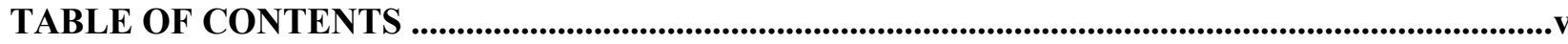

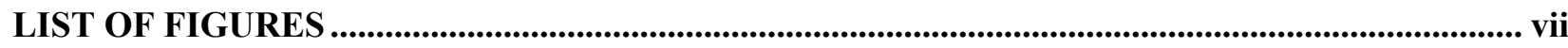

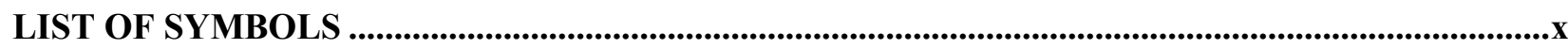

INTRODUCTION

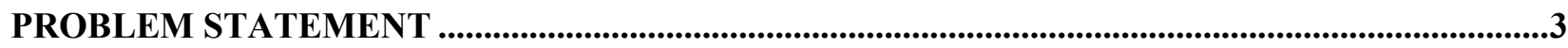

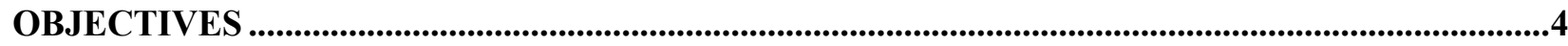

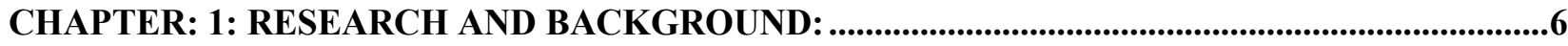



1.1.1: Mechanics of hydraulic fracturing .....................................................................................................6

1.1.2: Hydraulic fracturing propagation models and fracture geometry ..........................................8

1.2 : Fluid flow and proppant transport in hydraulic fractures ....................................................11

1.2.1. Fluid flow in hydraulic fractures ....................................................................................................12

1.2.2. Proppant transport in hydraulic fractures .................................................................................13

1.2.3. Proppant settling in hydraulic fractures....................................................................................14

1.2.4. Proppant pack in hydraulic fractures ................................................................................................16

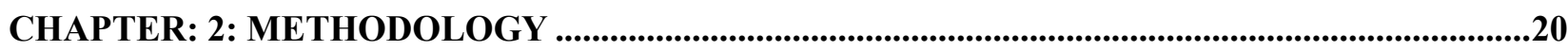

2.1: Governing equations of fluid flow and proppant transport ......................................................20

2.2: Numerical solution of governing equations for fluid flow and proppant transport ....................24

2.2.1. Formulation of numerical solver of Navier-Stokes equation ..................................................25

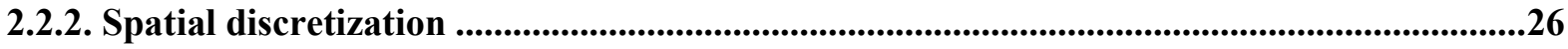

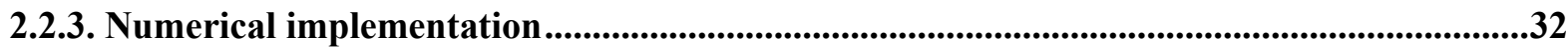

2.2.4. Fluid leak-off and proppant transport................................................................................................34

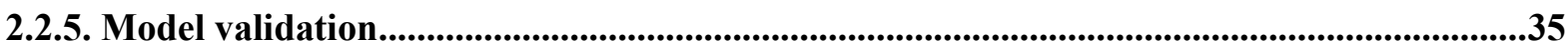

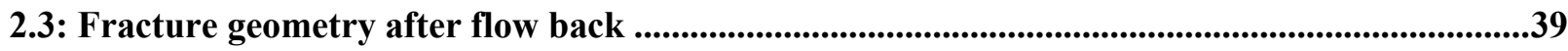

2.4: Numerical simulation of fluid flow in fractures during production..........................................41 
2.4.1 Slightly compressible system ...............................................................................................................43

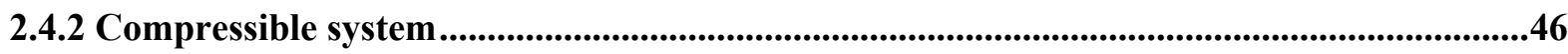

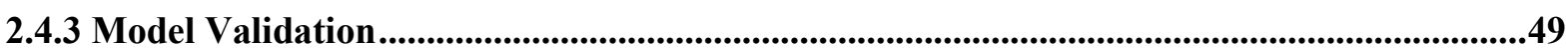

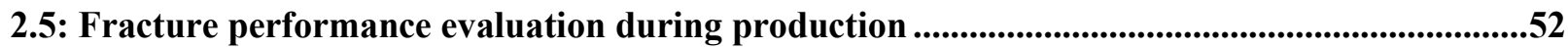

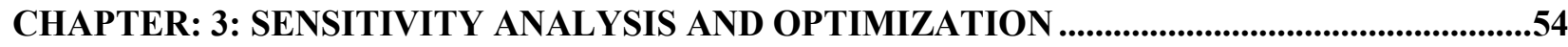

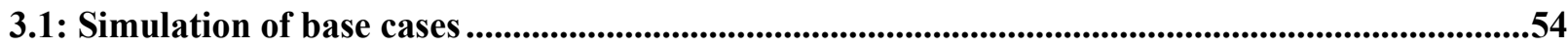

3.1.1 Base case …...................................................................................................................................................54

3.1.2 Effect of proppant settling on gas transport in hydraulic fractures.....................................60

3.1.3 Effect of Non-Darcy flow on reservoir performance .......................................................61

3.1.4 Different proppant size injection effects on hydraulic fracturing performance ...................62

3.2: Single variable sensitivity analysis ........................................................................................................64

3.2.1 Proppant size sensitivity analysis....................................................................................................64

3.2.2 Fracture width sensitivity analysis .......................................................................................66

3.2.3 Fracturing fluid viscosity sensitivity analysis .......................................................................67

3.2.4 Two size proppant combination optimization ...................................................................68

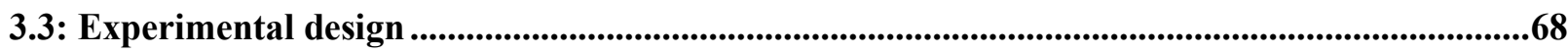

3.3.1 Design of experiments ................................................................................................................................69

3.3.2 Experiment design analysis .............................................................................................................70

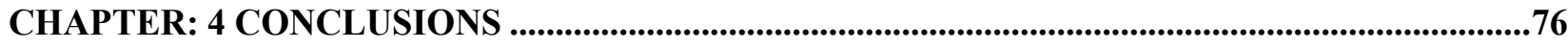

REFERENCES............................................................................................................................................................77 


\section{LIST OF FIGURES}

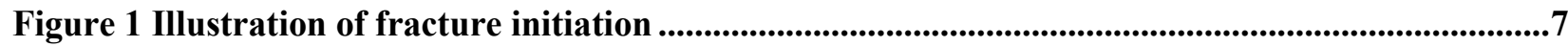

Figure 2 Fracture geometry of PKN model .....................................................................................................9

Figure 3 Fracture geometry of KGD model ......................................................................................................9

Figure 4 Fracture geometry of horizontal fracture model ....................................................................10

Figure 5 Cross section of fracture geometry considering non-settling of proppant (left) and

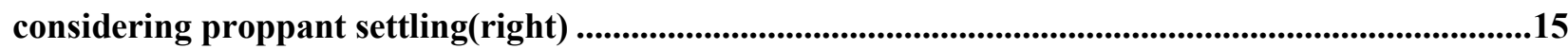

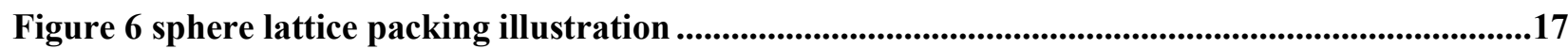

Figure 7 irregular packing of different size sphere..........................................................................18

Figure 8 mass conservation of fracturing fluid in 3D ...............................................................................21

Figure 9 Mass conservation of proppant in 2D ...........................................................................................22

Figure 10 Polynomial correlation for the effects of fracture wall width on settling velocity (Phani, et

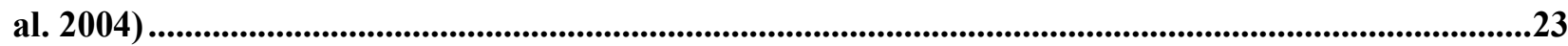

Figure 11 Polynomial correlation for the effects of proppant concentration on settling velocity

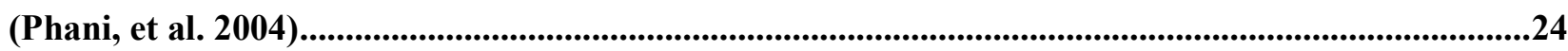

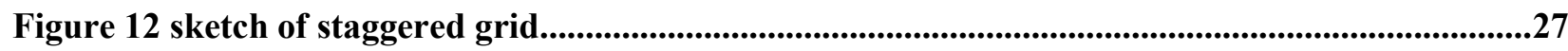

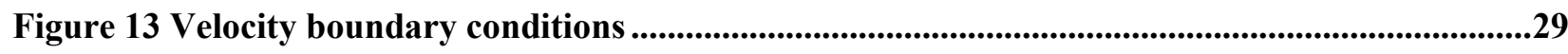

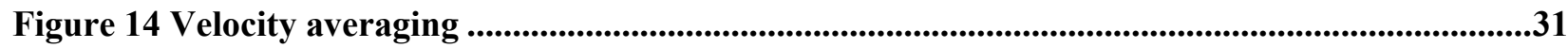

Figure 15 Lid-driven cavity model .................................................................................................36



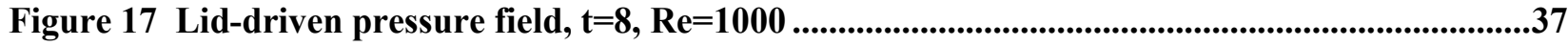

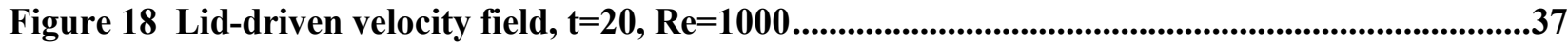

Figure 19 Lid-driven pressure field, $t=20, R e=1000$.................................................................................38

Figure 20 Pack width versus stress for 16/30 white sand (Barree, 2003) ...................................................39

Figure 21 Pack width versus stress for 20/40 white sand (Barree, 2003) ................................................40

Figure 22 Mass conservation of porous media flow ..........................................................................................41

Figure 23 illustration of finite volume coefficients ...........................................................................................46

Figure 24 Material balance of a gas reservoir. the results show an agreement with the theory..........52

Figure 25 Overlook of the gas reservoir model for simulation ...................................................................55

Figure 26 Permeability of reservoir and hydraulic fracture, considering non-settling of proppant, proppant is distributed uniformly in the hydraulic fracture ...............................................................56

Figure 27 pressure field of reservoir and hydraulic fracture during production, considering nonsettling of proppant. 
Figure 28 Permeability of reservoir and hydraulic fracture, considering settling of proppant, proppant is distributed non-uniformly in the hydraulic fracture.

Figure 29 pressure field of reservoir and hydraulic fracture during production, considering settling of proppant

Figure 30 the ratio of apparent permeability over absolute permeability considering non-Darcy flow

Figure 31 Influence of proppant settling on dimensionless productivity index, the proppant size is

$0.6 \mathrm{~mm}$. . .61

Figure 32 Influence of Non-Darcy flow on dimensionless productivity index, the proppant size is

$0.6 \mathrm{~mm}$. . .62

Figure 33 Permeability distribution of reservoir and hydraulic fracture of Two-proppant size( $0.2 \mathrm{~mm}$ and $0.6 \mathrm{~mm}$ ) combination .

Figure 34 the effect of proppant size on dimensionless productivity for different permeability reservoir.

Figure 35 the effect of original fracture width on dimensionless productivity for different permeability reservoir .66

Figure 36 The effect of base fluid viscosity on dimensionless productivity for different permeability reservoir

Figure 37 The effect of proppant size and volume portion combination on dimensionless productivity Figure 38 Pareto chart shows the importance of parameters evaluated on the t-value of original case

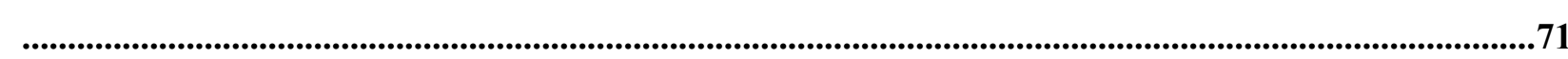

Figure 39 Normal plot of the standardized effects of original case shows the importance of parameters. .72

Figure 40 Pareto chart shows the importance of parameters evaluated on the t-value of fold-over case . .74

Figure 41 3D surface generated to visualize the magnitude and trend of the effect of proppant size and relative density on dimensionless productivity . .75 


\section{LIST OF TABLES}

Table 1 Comparison of PKN, KGD and penny-shaped model ............................................................11

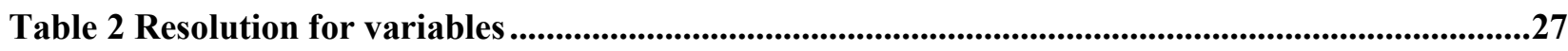

Table 3 Model parameters used for validation ....................................................................................51

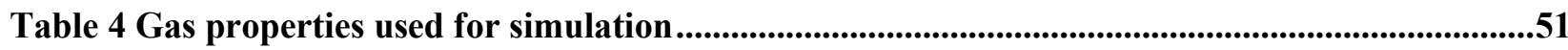

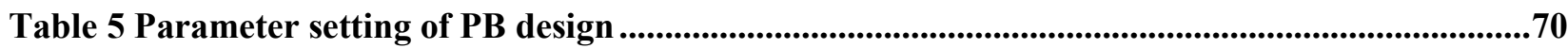

Table 6 PB matrix for 7 variables, $-1=$ low value;+1=high value ......................................................70

Table 7 full fold-over PB matrix for 7 variables, $-1=10$ value; +1=high value .......................................73 


\section{LIST OF SYMBOLS}

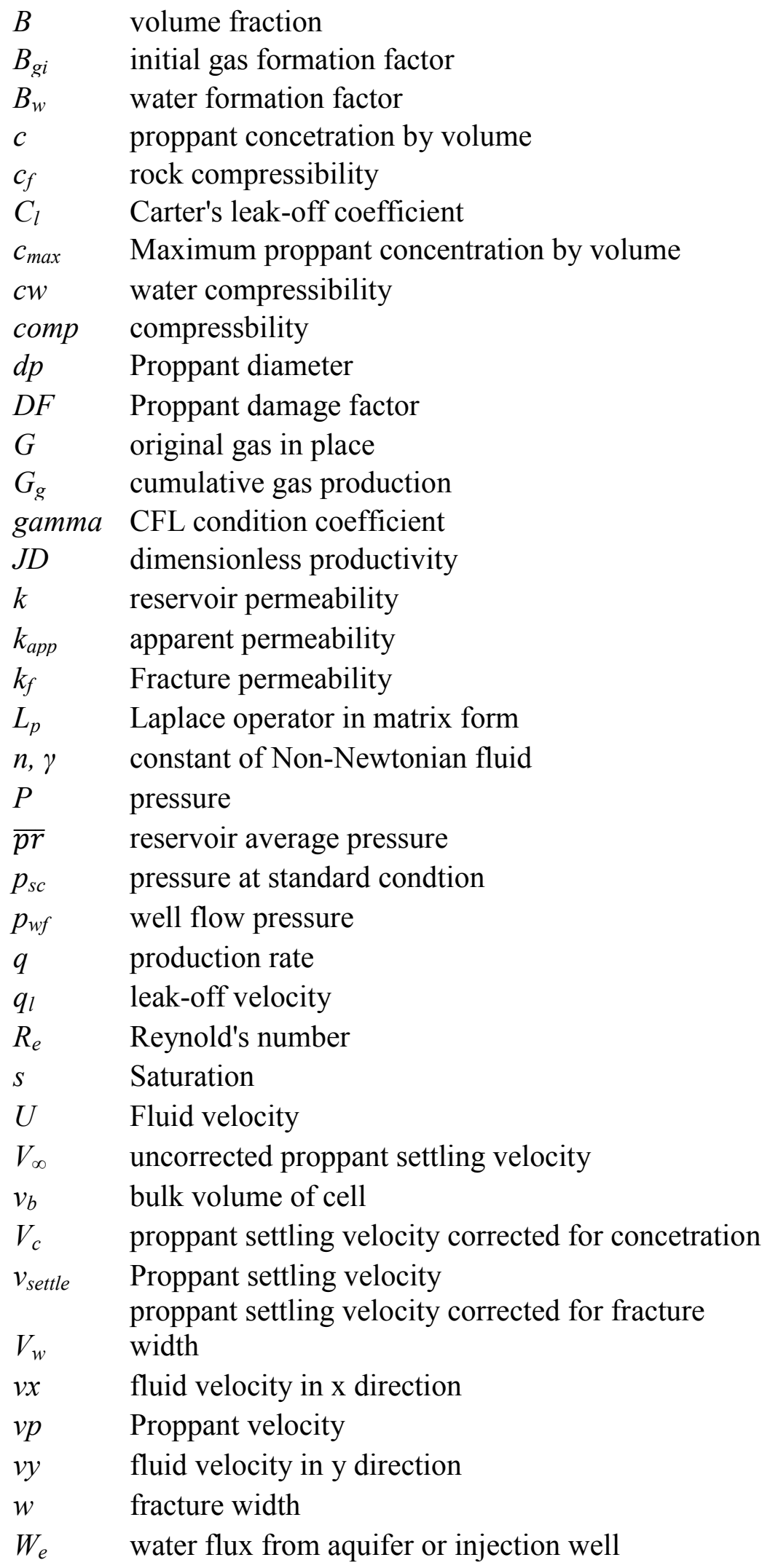




$\begin{array}{ll}w_{f^{\prime}} & \text { Final fracture width after flow back } \\ W_{p} & \text { cumulative water production } \\ z & \text { gas compressibility factor } \\ \beta & \text { Forchheimer factor } \\ \mu & \text { fluid viscosity } \\ \mu_{0} & \text { viscosity of Newtonian fluid without proppant } \\ \rho_{f} & \text { fluid density } \\ \rho_{p} & \text { proppant density } \\ \rho_{s c} & \text { density at standard condition } \\ \Phi & \text { proppant sphericity } \\ \varnothing & \text { Porosity }\end{array}$




\section{INTRODUCTION}

Hydraulic fracturing is now been broadly used in petroleum industry to enhance hydrocarbons production especially in unconventional reservoirs like shale gas and coal bed methane. In order to produce trapped gas/oil from underground formation, significant amount of frac fluid that is a mixture of liquid (usually water), acid, friction reducer and proppant will be pumped into the wells at very high pressure leading to fracture propagation into the formation. When required fracture developed the injection stops and fluid will be produced out of the fracture "flow back". Injected proppant will prop the fracture open after flow back to provide high-conductive pathway for gas and oil to flow from reservoir to the wells. Hydraulic fracturing greatly increases the flow area and makes it economically viable to develop low porosity, low permeability reservoir. The performance of hydraulic fractures is highly dependent on proppant distribution inside the fracture. However, it is always a controversial subject to study the distribution of proppant in hydraulic fractures. Commonly, uniform proppant distribution in fractures is assumed to estimate fracture geometry. However, proppant distribution in hydraulic fractures is very sensitive to different factors, including injection rate, pump schedule, proppant size and density, fluid viscosity and density. A better understanding of proppant transport and distribution in fractures is vital to make better decision of hydraulic fracturing design.

In this study, a 3D computational fluid dynamics model is developed to simulate the process of proppant transport and placement in an elliptic hydraulic fracture. Unlike conventional approach in simulation of hydraulic fracturing that assumes fluid will be injected in whole cross section area of the formation (Mobbs 2001, Yamamoto 1999, Phani 2004, Daneshy 1978), here, a narrow injection inlet comparable to perforation hole is assumed to best reflect the reality a fluid injection. Governing equations describing the fluid and proppant motion in hydraulic fracture is coupled and to avoid checkerboard solution staggered grid system is adopted.. For the slip velocity between proppant and fluid, only gravity induced settling is considered due to insignificant diffusion of proppant particles. The hydraulic fracture represents the pseudo-3D flow domain where fracture length and height dimensions are significantly larger than its width dimension. Therefore, the variation of proppant concentration in width direction is neglected and replaced by an average value. This model handles wide range of Newtonian and non-Newtonian 
fluids with different viscosity and density, considers different injection rates, initial fracture geometry and different proppant size, density and pump scheduling. For each case proppant settling pattern is obtained and compared for sensitivity analysis purposes.

While significant effort has been put on simulation of fracture propagation and fluid flow during injection (Mobbs 2001, Yamamoto 1999, Phani 2004), fracture geometry after flow back is merely studied. Fracture geometry after flow back is a function of proppant distribution and closure stress that significantly different than fracture geometry after injection stops. Thus, in this study final fracture geometry is obtained based on mechanical properties of proppant pack and proppant concentration distribution during injection.

Finally, a Fracture-Production model simulating single phase fluid flow from reservoir through hydraulic fracture to well bottom is developed. This model calculates fluid flow rate and pressure difference between reservoir matrix and bottom hole pressure. Then, a dimensionless productivity index is defined as an indicator of the hydraulic fracturing performance. Next, Experimental design technique "Plackett burman "has been used to perform the sensitivity analysis and obtain the most important factors impacting the hydraulic fracturing performance. 


\section{PROBLEM STATEMENT}

Proppant transport in hydraulic fractures involves different physical phenomena, which make this process hard to simulate. Frac fluid leak off into the formation impacts the dynamics of proppant distribution in hydraulic fracture. Fractures also have complex geometry (fracture width and height varies with fracture length) that leads to different fluid velocity thus different proppant settling. Proppant settling velocity is also affected by proppant concentration, relative density and non-Newtonian effect. Current literature on proppant transport simulation, either assume highly simplified fracture geometry, or they neglect fluid leak-off, or uncorrected Stokes law is used for poppant settling. However, experimental studies show that these parameters are highly correlated and vital for determining settling velocity; ignoring any of them will lose the reality of proppant transport physics that leads to inaccurate prediction of hydraulic fracturing performance.

Conductivity or dimensionless conductivity is commonly used to evaluate the performance of hydraulic fracturing stimulation. But this technique doesn't take into account the importance of proppant distribution and flow area (fracture length and height). Therefore different evaluation method is required to evaluate the performance of hydraulic fracturing stimulation considering all the physical phenomena involved in the process.

Finally, to do the sensitivity analysis and optimization of the process, impact of different properties like proppant size, proppant density, proppant concentration, fluid viscosity and injection rate, and their interactions need to be considered employing a valid experiment design technique. 


\section{OBJECTIVES}

The objectives of this study are:

1) To model pseudo $3 \mathrm{D}$ fluid flow and proppant transport in hydraulic fractures considering fluid leak-off and slippage between fluid and proppant.

2) To calculate fracture geometry after flow back based on proppant distribution and stress field.

3) To simulate fluid production from fractured reservoir and evaluate fracture performance using dimensionless productivity.

4) To conduct sensitivity analysis and optimization on fracture performance of proppant, fluid and reservoir properties. 


\section{CHAPTER: 1: RESEARCH AND BACKGROUND:}

\section{1: Hydraulic fracturing}

Hydraulic fracturing is a popular well stimulation treatment usually used on oil and gas wells in low permeability reservoirs to improve productivity. During the treatment, fracturing fluids will be injected into well at high pressure to create fracture. The fractures extend away from the wellbore in opposite directions depending on the formation geomechanical properties and formation stress. Hydraulic fractures are normally in the direction of maximum horizontal stress. Proppant will be mixed with fracturing fluid and pumped together into the fractures to keep them open after flow back the fluid. Proppant pack left in hydraulic fractures will become high conductivity flow channel for underground hydrocarbons. According to statistics, over $70 \%$ of gas wells and $50 \%$ of oil wells in North America are stimulated using hydraulic fracturing treatment (Valko and Economides, 1995).

\subsection{1: Mechanics of hydraulic fracturing}

Hydraulic fracturing in deep reservoirs tends to be suppressed by confining pressure, due to the immense load caused by the overlying rock strata and hydrostatic pressure. Hydraulic fracturing occurs when the effective stress overcomes sufficiently by an increase in the pressure of fluids within the rock, such that the minimum principal stress becomes tensile and exceeds the tensile strength of the material. Fractures formed in this way will be oriented in the least resistance. The fracture will finally propagate in the direction normal to the smallest principal stress. When the formation is deep enough, the smallest principal stress is in horizontal plane, thus vertical fracture will be created. Ideally, two symmetric fracture wings will be created normal to the smallest principal stress as shown in Figure 1(Fjaer E., 2008). 


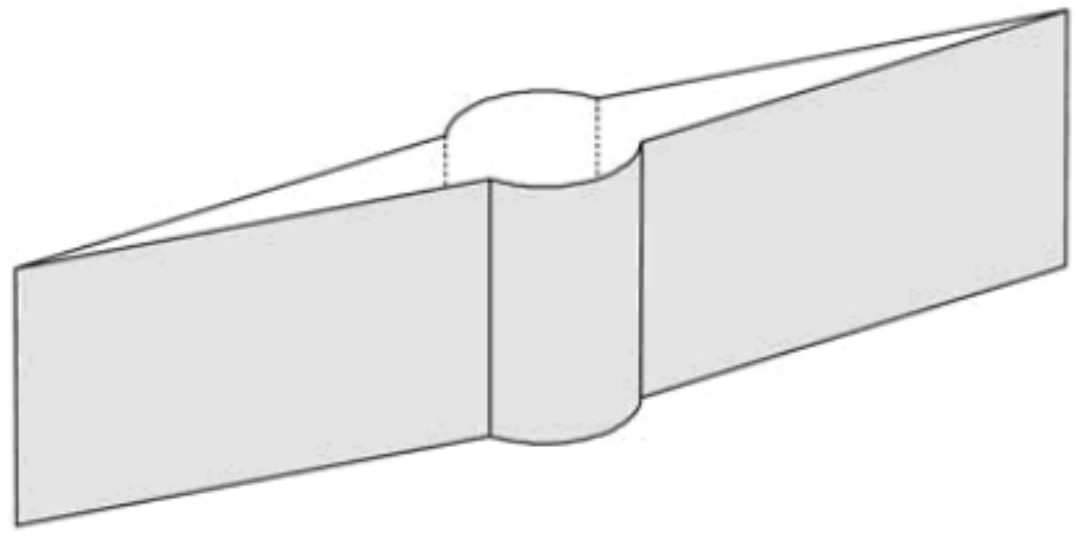

Figure 1 Illustration of fracture initiation

The fracturing fluid is usually considered to be Newtonian or Power law fluid. During the injection, fracturing fluid may flow into porous formation through fracture walls under the pressure difference between fracturing fluid and reservoir fluid. This is referred to as leak-off of fracturing fluid. The standard leak-off theory was developed by Carter and Settari (Carter,1957; Settari, 1985). This leak-off theory is also known as Carter's leak-off model. In this model, a constant fluid leak-off coefficient is used to characterize the fluid leak-off rate. Also, the leak-off rate of fracturing fluid is independent of pressure difference between fracture and reservoir and only is a function of time since the beginning of fracturing fluid leaking into reservoir. Carter's leak-off model provides a simple tool to evaluate the loss of fracturing fluid in the process of hydraulic fracturing, but neglect of the effect of pressure difference is major flaw. In this model, improved Carter's leak-off model with a leak-off coefficient which is function of pressure difference between fracture and reservoir is employed (Abousleiman 1991).

Most of the modern hydraulic fracturing propagation models are based on linear elastic fracture mechanics (LEFM). Griffith (Griffith, 1921) built the foundation for LEFM. He applied the energy balance theory to fracture propagation for the first time. He brought up that the total energy consumed in different parts of the fracturing process is constant. According to Griffiths' theory, the critical stress $\sigma_{c}$ needed for mode I crack to propagate is,

$$
\sigma_{c}=\sqrt{\frac{2 E \gamma}{\pi a}}
$$


Where $E$ is the formation's Young's modulus and $\gamma$ is the surface energy per unit area of the crack, $a$ is crack half length.

\subsection{2: Hydraulic fracturing propagation models and fracture geometry}

Knowing the dimensions and propagation characteristics of a hydraulic fracture is critical for optimum hydraulic fracturing design. Numerous works have been done to study the propagation of hydraulic fracture and fracture geometry in 2 and 3 dimensions. 2D models include PerkinsKern-Nordgren model, which is also known as PKN model, and Khristianovic-Geertsma-de. Klerk model, which can be shorten as KGD model. 3D models include pseudo 3D model (P3D) and fully 3D model. Each model has different assumptions for fracture propagation process and different fracture geometry.

Perkins and Kern (Perkins and Kern, 1961) firstly developed equations to calculate fracture length and fracture width with a constant fracture height. Then Nordgren (Nordgren, 1972) added fluid leak-off to their model. This modified model is called PKN model. PKN model has elliptical cross section both in vertical and horizontal directions as shown in Figure 2. In this model, the height of the fracture is constant and is much smaller than the fracture length. So this problem can be reduced to $2 \mathrm{D}$ by using plane-strain assumption. The plane-strain is in vertical direction (considering vertical fracture) and each vertical plane-strain section perpendicular to fracture propagation direction is independent. PKN model only considers energy dissipation due to fluid flow along fracture, while energy consumption due to fracture propagation "toughness" is ignored. In PKN fracture model, fluid pressure in each vertical section perpendicular to the direction of fracture propagation is constant. Therefore, fluid flow can be simplified to channel flow in elliptical fracture. 


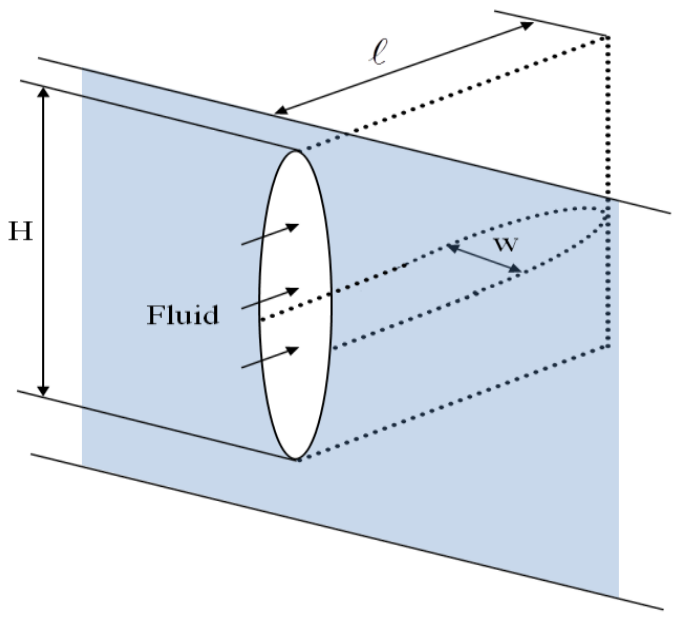

Figure 2 Fracture geometry of PKN model

Khristianovitch and Zheltov (Khristianovitch and Zheltov, 1955) and Geertsma and de Klerk (Geertsma and de Klerk, 1969) developed KGD model. In KGD model, the fracture geometry is assumed to have elliptical cross section in horizontal direction and rectangular in vertical direction as shown in Figure 3. This model holds when fracture height is larger than fracture length. In this model, flow rate and fluid pressure is assumed to be constant except for the fracture tip region. Fluid flow and fracture propagation is only in one direction. Plane-strain model is also applied to KGD model but in horizontal direction, where each horizontal cross section is independent.

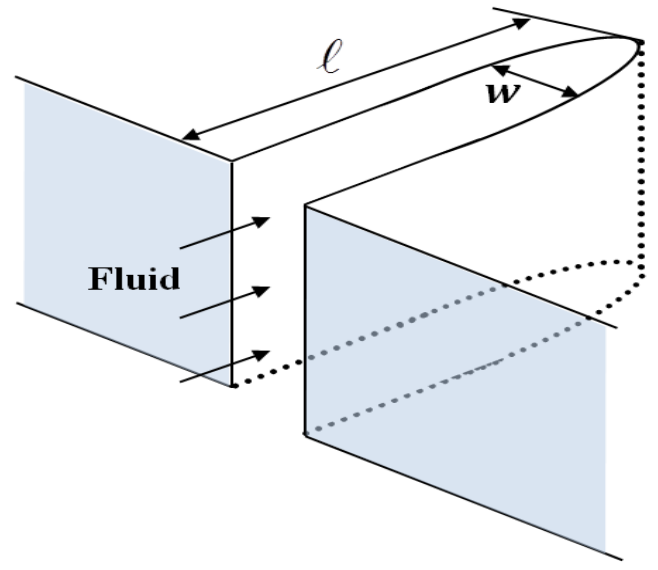

Figure 3 Fracture geometry of KGD model 
When the formation is shallow enough, minimum stress is equal overburden stress, thus, hydraulic fracturing will create horizontal fractures. Abé et al. (Abé et al., 1976) introduced penny-shaped fracture model for this case, in which fracture geometry is symmetric to the injection point. This model assumes constant fluid injection rate and the pressure within the fracture is constant.

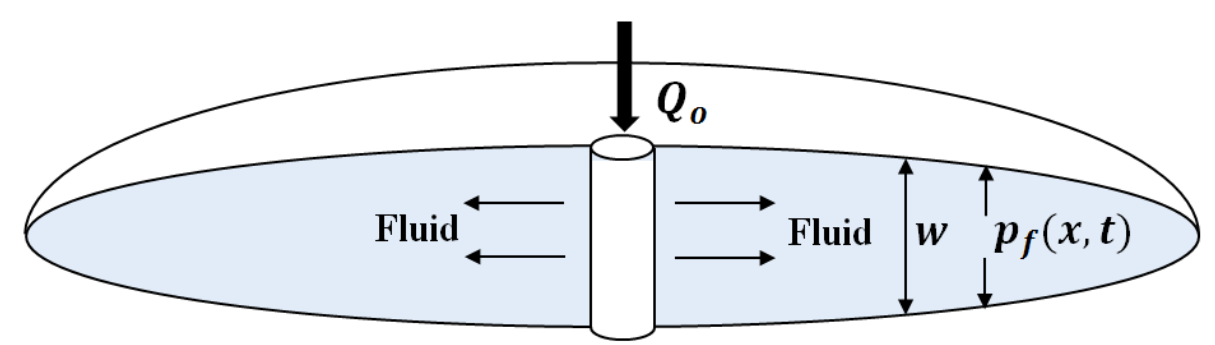

Figure 4 Fracture geometry of horizontal fracture model 
The comparison of PKN, KGD and penny-shaped model is shown in the Table 1

Table 1 Comparison of PKN, KGD and penny-shaped model

\begin{tabular}{|c|c|c|c|}
\hline Model & Assumption & Fracture shape & Application \\
\hline PKN & $\begin{array}{l}\text { Fixed fracture height } \\
\text { Vertical plane strain }\end{array}$ & Elliptical cross section & $\begin{array}{c}\text { Length is larger than } \\
\text { height }\end{array}$ \\
\hline KGD & $\begin{array}{l}\text { Fixed fracture height } \\
\text { horizontal plane strain }\end{array}$ & $\begin{array}{l}\text { Rectangular cross } \\
\text { section }\end{array}$ & $\begin{array}{c}\text { Length is smaller than } \\
\text { height }\end{array}$ \\
\hline $\begin{array}{l}\text { Penny- } \\
\text { shaped }\end{array}$ & $\begin{array}{c}\text { Symmetric to injection point, } \\
\text { propagate in a plane }\end{array}$ & Circular & Horizontal fracture \\
\hline
\end{tabular}

Application of aforementioned 2D models is to simulate fracture propagation in a simplified problems, for example, hydraulic fracturing in a homogeneous shale formation confined by limestone. In this case, the fracture height is equal to the thickness of the shale formation. However, for more complicated problems, 3D models were developed. Morales (Morales, 1989) and Settari and Cleary (Settari and Cleary, 1980) introduced pseudo-3D model, where fracture height is not assumed constant, but varies with fracture length and time. The fluid flow in this model is in two directions, i.e. fracture height and length. In this model, fracture propagation path is pre-defined. Fully 3D models have not been developed that can simulate hydraulic fractures of any shape that can propagate in any orientation depending on geomechanical properties and in situ stress conditions.

\section{2 : Fluid flow and proppant transport in hydraulic fractures}

For hydraulic fracturing treatment, wells need to be perforated. These perforations act as initial paths of fractures to propagate. Fracturing fluid is then injected into the wells at high pressure. The injected fluid initiates fractures from well perforations. Initially fracturing fluid does not contain any proppant, this fluid is known as pad and its volume is called 'pad volume' (Daneshy, 1978). Injected path initiates fractures and makes fracture width large enough to allow proppant travel through, that avoids proppant bridge and sudden pressure increase at early stage of 
hydraulic fracturing. The minimum fracture width must be at least two or three times larger than proppant diameter (Daneshy, 1978, Novotny, 1977). Then, fracturing fluid with certain concentration of proppant will be pumped in to further enlarge the fracture. After the injection, fracturing fluid will be produced and reservoir is ready to produce hydrocarbon reservoir fluid.

\subsubsection{Fluid flow in hydraulic fractures}

Fluid flow in hydraulic fractures can be modeled using lubrication theory, represented by a nonlinear partial differential equation that relates the fluid flow velocity, the fracture width and the gradient of pressure. This is due to the fact that fracture width is commonly very small in compare to fracture height and length. Fluid film lubrication is a hydrodynamic phenomenon characterized by a lubricant flowing in the narrow gap between two closely spaced surfaces (San Andrés, 2012).

Fluid flow in a general physical domain is governed by the principles of: conservation of mass, conservation of linear momentum, and conservation of energy. By employing equations of conservation of mass and momentum and scaling analysis, we can derive Reynolds equation of classical lubrication theory,

$$
\frac{\partial}{\partial \mathrm{t}}\{\rho \mathrm{h}\}+\frac{1}{2} \frac{\partial}{\partial \mathrm{x}}\{\rho \mathrm{hU}\}=\frac{\partial}{\partial \mathrm{x}}\left\{\frac{\rho \mathrm{h}^{3}}{12 \mu} \frac{\partial \mathrm{P}}{\partial \mathrm{x}}\right\}+\frac{\partial}{\partial \mathrm{z}}\left\{\frac{\rho \mathrm{h}^{3}}{12 \mu} \frac{\partial \mathrm{P}}{\partial \mathrm{z}}\right\}
$$

Where $\rho$ is the fluid density, $\mathrm{h}$ is layer thickness, $\mu$ is viscosity and $\mathrm{U}$ is velocity

By considering gravity effect in transport and slurry as incompressible fluid, fluid density can be assumed constant. One can re-write equation (2) as follow including the source/sink term for injection/production from fracture:

$$
\frac{\partial \mathrm{w}}{\partial \mathrm{t}}=\nabla[\mathrm{D}(\mathrm{w})(\nabla \mathrm{p}-\rho \mathrm{g})]+\delta(\mathrm{x}, \mathrm{y}) \mathrm{Q}
$$

Where $\mathrm{D}(\mathrm{w})=w^{3} / 12 \mu, \delta$ is the Dirac delta function and $\mathrm{Q}$ is the source injection rate.

Application of equation (3) is limited to low viscosity fracture fluid and low proppant concentration (Adachia, 2007). Therefore, different models like large eddy simulation are proposed by Kuochen Tsai's, 2012, for fluid flow in hydraulic fractures. Large eddy simulation leads to more accurate results simulating large scale eddy behavior in compare to Reynolds averaged Navier-stock's turbulence model. However, eddy behavior due to high velocity jetting 
area behind perforation holes are neglected assuming fracturing fluid flows through perforation holes and then expands over the entire fracture height in a negligible distance(Novotny, 1977). Ouyang et al., 1997, investigated fluid flow in hydraulic fractures releasing the assumption of Newtonian fluid. They introduced the apparent viscosity of incompressible non-Newtonian fluid " $\eta$ " using power law model as follow:

$$
\eta([D])=\mathrm{k}\left[2 \operatorname{tr}\left([\mathrm{D}]^{2}\right)\right]^{(\mathrm{n}-1) / 2}
$$

where [D] is the rate of strain tensor of fluid velocity, $\mathrm{n}$ is the power law index and $\mathrm{k}$ is the consistency coefficient of the fluid, where, $\mathrm{k}$ and $\mathrm{n}$ depend on the proppant concentration as:

$$
\mathrm{n}=\mathrm{Ae}^{\mathrm{Bc}}, \mathrm{k}=\mathrm{Pe}^{\mathrm{Qc}}
$$

$\mathrm{A}, \mathrm{B}, \mathrm{P}, \mathrm{Q}$ depend on the properties of fluid and proppant and need to be determined using experimental approach.

The slurry continuity equation considering fluid leak-off is,

$$
\frac{\partial}{\partial \mathrm{t}}(\rho \mathrm{w})+\nabla \cdot(\mathrm{vw} \rho)=-\mathrm{q}_{\mathrm{l}} \rho_{\mathrm{f}}
$$

Where $\rho$ is slurry density, $\rho_{f}$ is fluid density, $q_{l}$ is the leak-off rate which can be determined using Carter leak off model:

$$
q_{l}=2 c_{l} / \sqrt{[t-\tau(x, y)]}
$$

In which, $c_{l}$ is leak-off coefficient and $\tau(x, y)$ is the time when leak-off starts at a certain location.

\subsubsection{Proppant transport in hydraulic fractures}

Proppant pumped in hydraulic fractures moves in two directions. Horizontal movement of proppant is caused by fluid flow, and usually no slippage between proppant and fluid in horizontal direction will be concerned. Vertical motion of proppant is induced both by fluid flow and gravity. Vertical velocity of proppant is usually referred to as settling velocity and is influenced by fluid properties, particle size, and particle density (Daneshy, 1978). During injection, proppant tends to migrate to the center of the fracture, causing a close-packed sheet in the middle of the fracture width, which is called sheet flow (Mobbs, 2001). Proppant will stop to settle down when the proppant particles forms a bank at the bottom of the fracture, or the proppant concentration in the slurry becomes so high that it can no longer move, or the fracture 
width becomes so small that proppant particles stuck by fracture walls (Novotny, 1977)..Fluid leak off into the formation occurs during the injection and after injection stops and fracture walls start to close up after the injection stops. Final width of fracture depends on the local amount of proppant "proppant distribution" which can stop fracture walls from closing completely.

Proppant transport in hydraulic fractures involves different physical phenomena, which make this process hard to simulate. Formation rock is a porous media, thus fracturing fluid leaks off into the formation continuously leading to dynamic change in proppant concentration profile across the fracture. Fractures also have complex geometry (fracture width and height varies with fracture length) that alters fluid velocity further influencing proppant settling velocity. Moreover, proppant settling velocity is affected by proppant concentration, fracture width, and non-Newtonian effects. Therefore, conventional Stokes law needs to be corrected for aforementioned effects. However, recent publications on proppant transport simulation in hydraulic fracturing use uncorrected Stokes law to determine poppant settling velocity. They also either use highly simplified fracture geometry, or neglect fluid leak-off into the formation. All these simplifying assumptions leads to inaccurate proppant transport and displacement prediction in hydraulic fractures (Novotny, 1977, Adachia, 2007).

\subsubsection{Proppant settling in hydraulic fractures}

Proppant settling is inevitable phenomenon during the hydraulic fracturing treatment, and it will largely determine the fracture geometry as shown in Figure 5. Because of density difference between fluid and particle, a solid particle will settle down once dropped into the fluid. The accelerating period is fairly short, and a uniform settling velocity will be obtained very soon. Equality between effective weight of a single spherical particle in an infinitely large space with viscous drag force of fluid results in a general settling velocity equation known as Stocks' law (Rubey, 1933).

$$
\frac{\pi C_{D} V^{2} \rho_{f} d_{p}{ }^{2}}{8}=\frac{\pi d^{3} g\left(\rho_{p}-\rho_{f}\right)}{6}
$$

Where $\rho_{p}$ is proppant density and $\rho_{f}$ is fluid density, $d$ is proppant diameter and $C_{D}$ depends on Reynolds' number

For $\mathrm{N}_{\mathrm{Re}} \leq 2$ (Stokes law region), $\mathrm{C}_{\mathrm{D}}=24 / \mathrm{N}_{\mathrm{Re}}$ and 


$$
\mathrm{V}_{\infty}=\frac{\mathrm{g}\left(\rho_{\mathrm{p}}-\rho_{f}\right) d_{p}{ }^{2}}{18 \mu}
$$

For $2<\mathrm{N}_{\mathrm{Re}}<500$ (intermediate region), $\mathrm{C}_{\mathrm{D}}=18.5 / \mathrm{N}_{\mathrm{Re}}{ }^{0.6}$ and

$$
\mathrm{V}_{\infty}=\frac{20.34\left(\rho_{\mathrm{p}}-\rho_{\mathrm{f}}\right)^{0.71} \mathrm{~d}_{\mathrm{p}}^{1.14}}{\rho_{\mathrm{f}}^{0.29} \mu^{0.43}}
$$

For $\mathrm{N}_{\mathrm{Re}} \geq 500$ (Newton's law region), $\mathrm{C}_{\mathrm{D}}=0.44$ and

$$
\mathrm{V}_{\infty}=1.74 \sqrt{\frac{\mathrm{g}\left(\rho_{\mathrm{p}}-\rho_{f}\right) d_{p}}{\rho_{f}}}
$$

For most proppant density values, settling is in the Stokes region.

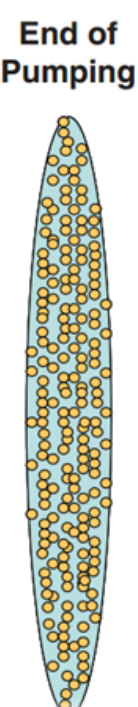

Fracture geometry without considering proppant settling

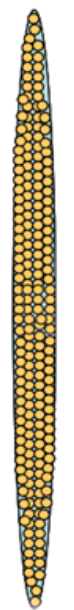

\section{End of \\ Pumping}

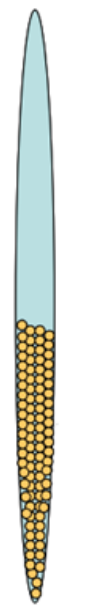

During

Production

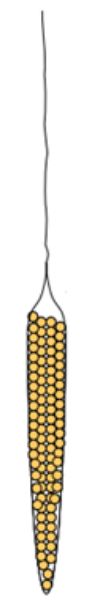

Fracture geometry considering proppant settling

Figure 5 Cross section of fracture geometry considering non-settling of proppant (left) and considering proppant settling(right)

Stokes law the way described above carries significant simplifying assumptions, eg., there is only one single particle, the surrounding space is relatively large enough, and the fluid should be Newtonian fluid, that do not include the real physics of proppant transport in hydraulic fractures. Numerous numerical and experimental studies have been conducted on the proppant settling velocity among which empirical corrections based on experiment results are the most 
common(Daneshy, 1978, Novotny, 1977, Roodhart, 1985). Phani B., 2004, accounted for the influence of proppant concentration, wall effect and turbulence on proppant settling velocity.

When the fluid Reynolds number is large, the settling velocity is affected by the turbulent created behind the particle. The following correction is used for $2<\operatorname{Re}<500$ (Phani B., 2004)

$$
V_{R e}=\frac{20.34\left(\rho_{p}-\rho_{f}\right)^{0.71} d_{p}^{1.14}}{\rho_{f}^{0.29} \mu^{0.43}}
$$

For including the effect of proppant concentration on settling velocities several correlations have been introduced earlier by Phani B., 2004, evaluated and compared in this work. Finally best empirical correlation for set of parameters in this study is selected for unbounded flows.

$$
V_{\varphi}=V_{S}\left(2.37 c^{2}-3.08 c+1\right)
$$

Effect of fracture width on settling velocities is considered by Phani B., 2004, assuming impermeable confining walls. The average settling velocity then is a function of Stokes settling velocity and the ratio of the radius of the particle to fracture width.

$$
V_{w}=V_{s}\left[0.563\left(\frac{d_{p}}{w}\right)^{2}-1.563\left(\frac{d_{p}}{w}\right)+1\right]
$$

Nicholas A. Petty, 2011, summarized different methods dealing with non-Newtonian effect of slurry in hydraulic fracturing. The author concludes that Eiler's equation is the best to predict slurry viscosity.

$$
\mu=\mu_{0}\left\{1+\left[0.75\left(e^{1.5 n}-1\right) e^{-\frac{\gamma(1-n)}{1000}}\right] \frac{1.25 c}{1-1.5 c}\right\}^{2}
$$

Where $\mu_{0}$ is the viscosity of Newtonian fluid without proppant, $\mathrm{c}$ is proppant volumetric concentration, $\mathrm{n}$ and $\gamma$ are properties of the non-Newtonian fluid with proppant where maximum concentration is 0.66 .

\subsubsection{Proppant pack in hydraulic fractures}

It's common to assume all proppant particles are sphere, in that case the packing density of proppant in fractures can be determined by theoretical models. Generally, there are two kinds of sphere packing are assumed, i.e., regular and irregular packing. 
Regular packing, also known as lattice packing, is a pattern in which all spheres form a certain symmetric configuration as shown in Figure 6. In a three-dimensional space, different types of close regular packing structures such as, cubic lattice, hexagonal lattice, and tetrahedral lattice are common. Gauss, 1831, proved that the closest regular packing structure has a density of 0.74048 .
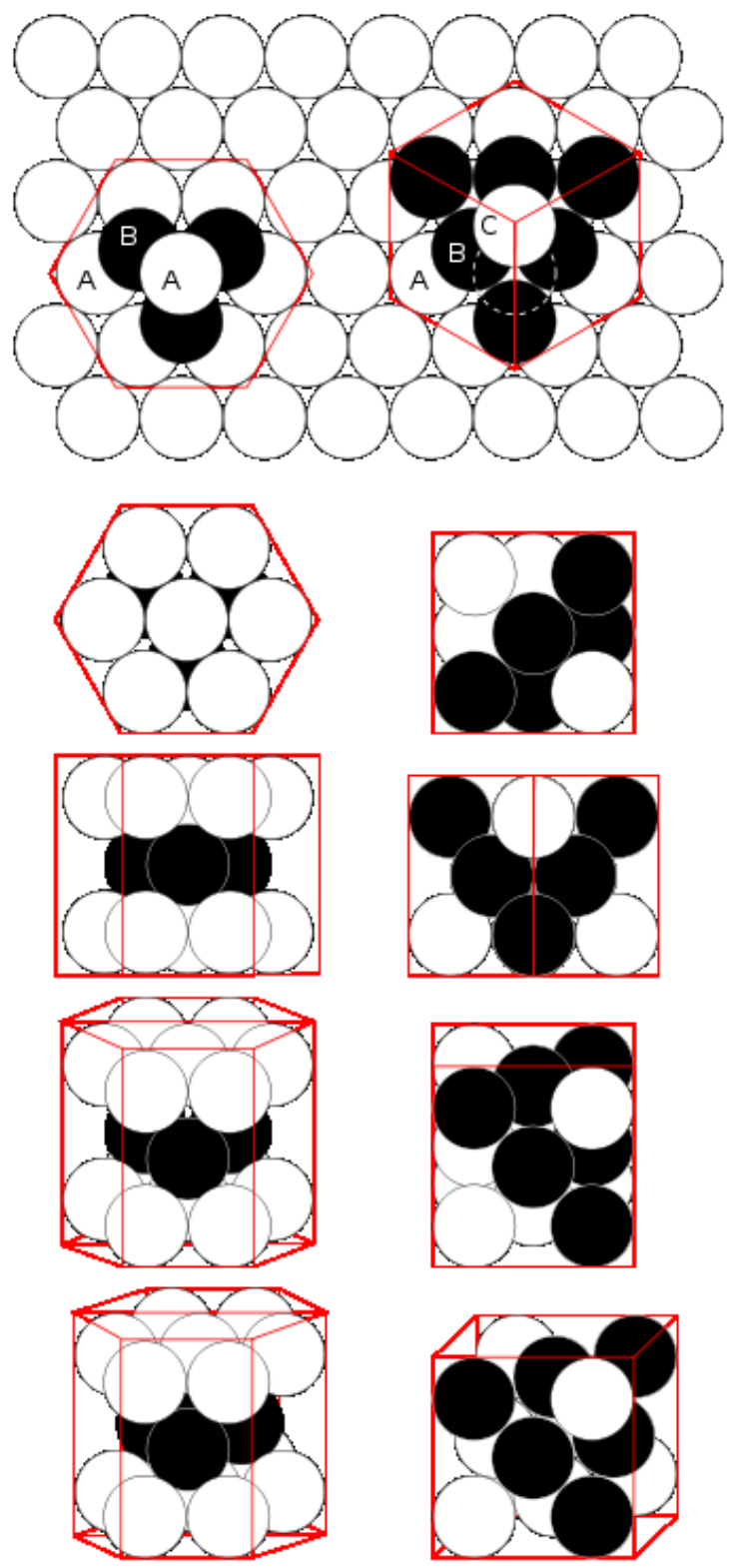

Figure 6 sphere lattice packing illustration 
When proppant concentration reaches a certain value, it will jam in fracture. According to Gardner, 1966, this concentration is 0.55536 , which is actually the lowest jammed regular sphere packing density.

Instead of placing every sphere particle in the order regularly, if all particles are placed randomly into a container and compressed, irregular sphere packing can be obtained. Irregular dense sphere packing is stable against compression (Chaikin P, 2007). And according to Song's, 2008, the highest density of irregular sphere packing is equal to 0.634 .

If there is more than one size of proppants in the system, the packing pattern would be more complex, i.e., unequal sphere packing as is shown in Figure 7. If the ratio of smaller to larger sphere particles radius is less than 0.2999, then, the smaller spheres can be arranged within the larger spheres' gaps, (Zong C., 2002). In that case the density increment can reach to 0.13025 (Hudson D R., 1949). When the ratio exceeds 0.41421, the smaller spheres cannot be arranged into the gaps of dense packed larger spheres; therefore, both large and small spheres need to be rearranged for which densities of different size combinations can be found in Marshall G W, 2010 .

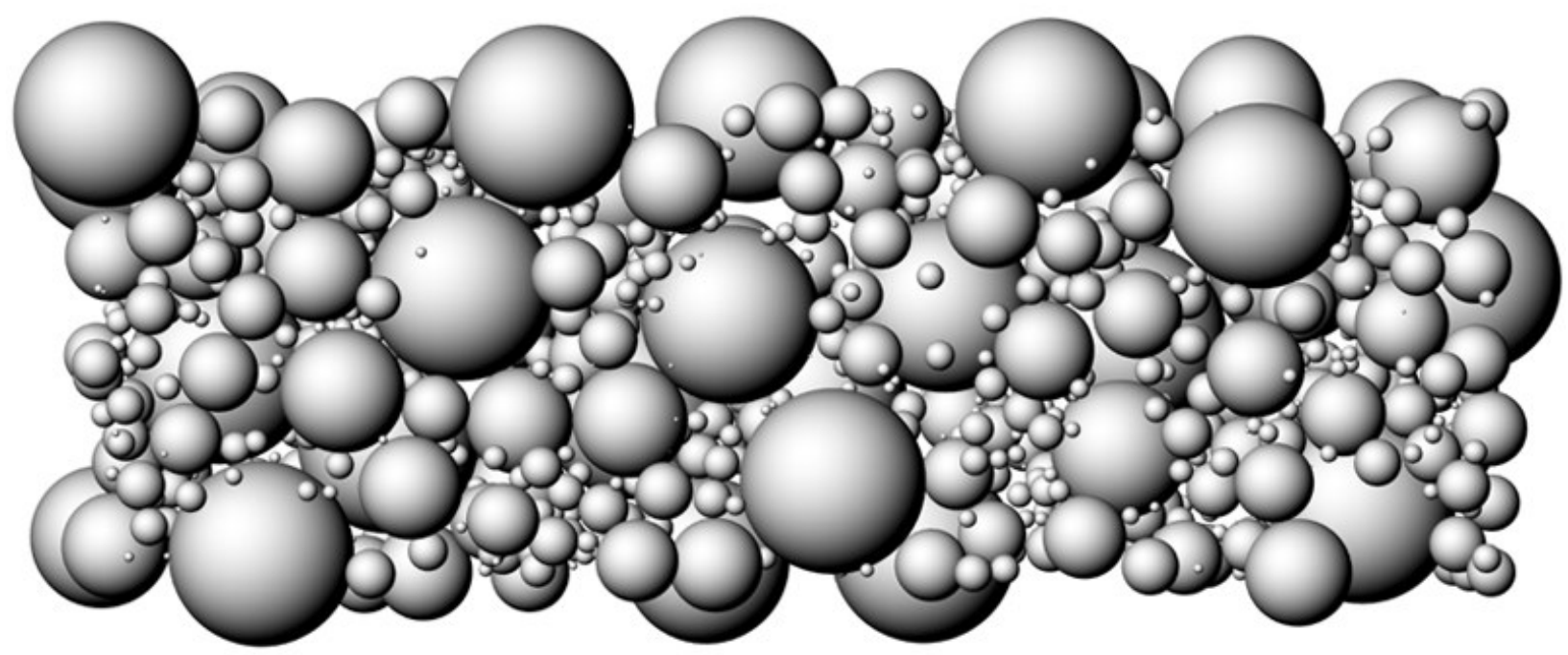

Figure 7 irregular packing of different size sphere

The key to the success of hydraulic fracturing is the creation of highly conductible fluid flow pathway which depends mostly on the permeability of proppant pack. Proppant pack permeability 
is a function of proppant size, shape and reservoir net stress. Since all the proppant particles are assumed to be sphere, only the effect of proppant size and stress will be discussed in this research.

When the concentration of proppant in fracture reaches threshold value, proppant particles will jam and form irregular packing. Because of fluid leak-off or flow back, the fluid pressure will decrease and thus the proppant pack will be compacted by fracture walls. CE C., 1971, using experimental data showed that this effect will decrease the proppant pack porosity and permeability. It is also shown that when the net pressure is under 4,000 psi, the permeability change is not important in the same work. Usually in a hydraulic fracturing, the pressure difference between formation and fracture fluid is not under 4000 psi except special cases such as Haynesville shale.

It is widely accepted that porosity impacts permeability and high porosity formation usually inferred as high permeability too. However, permeability also depends on the shape and size of the voids between particles. As discussed earlier, the highest irregular packing density is $63.4 \%$ and the highest regular packing density is $74 \%$ (Song C, 2008; Gauss, 1831). Therefore, the corresponding porosity range can be obtained between $26 \%$ and $36.6 \%$. This is similar to the data reported by CE C., 1973 , which is $32-35 \%$ for large proppant and $25-30 \%$ for small proppant sizes.

Furthermore, smaller proppant particles change size and curvature of pores and throats that leads to change in permeability. The theoretical fracture permeability, $k_{f}$, is calculated in terms of the proppant diameter, $d_{p}$, porosity, $\emptyset$, proppant sphericity, $\Phi$, propped fracture width, $w$, and damage factor, $D F$, using the equation given below (Bird, 1960),

$$
\mathrm{k}_{\mathrm{f}}=\frac{\emptyset^{3}\left(\mathrm{~d}_{\mathrm{p}} \Phi\right)^{2}}{72 \lambda_{\mathrm{m}}\left(1-\emptyset^{2}\right)}\left(1+\frac{\mathrm{d}_{\mathrm{p}} \Phi}{3(1-\emptyset) \mathrm{w}}\right)^{-2}(1-\mathrm{DF})
$$

Where $\lambda_{m} \approx 25 / 12$ for most of the porosity ranges in hydraulic fractures.

Under effective fracture closure stress, proppant particles can be crushed or embedded into formation. The permeability of proppant pack can be compromised by closure stress, which is verified by R.D. Barree 2003 and A. Takbiri, 2013. Takbiri showed that when the closure stress is $12 \mathrm{Kpsi}$, depending on the proppant material, the permeability can be reduced by less than $16 \%$ and the reduction is less than $7 \%$ when the stress is $4 \mathrm{Kpsi}$. Following his discussion, if the closure 
stress is less than 4000 psi, the effect of closure stress on proppant pack permeability can be neglected.

\section{CHAPTER: 2: METHODOLOGY}

\section{1: Governing equations of fluid flow and proppant transport}

Velocity and pressure fields for an incompressible fluid can be obtained solving Navier-stokes equations using different numerical techniques. Under the assumption of constant density, the mass and momentum conservation equations can be simplified as:

$$
\begin{gathered}
\frac{\partial \mathrm{v}_{\mathrm{x}}}{\partial \mathrm{x}}+\frac{\partial \mathrm{v}_{\mathrm{y}}}{\partial \mathrm{y}}=0 \\
\frac{\partial \mathrm{v}_{\mathrm{x}}}{\partial \mathrm{t}}+\frac{\partial \mathrm{P}}{\partial \mathrm{x}}=-\frac{\partial\left(\mathrm{v}_{\mathrm{x}}^{2}\right)}{\partial \mathrm{x}}-\frac{\partial\left(\mathrm{v}_{\mathrm{x}} \mathrm{v}_{\mathrm{y}}\right)}{\partial \mathrm{y}}+\frac{1}{\mathrm{Re}}\left(\frac{\partial^{2} \mathrm{v}_{\mathrm{x}}}{\partial \mathrm{x}^{2}}+\frac{\partial^{2} \mathrm{v}_{\mathrm{x}}}{\partial \mathrm{y}^{2}}\right) \\
\frac{\partial \mathrm{v}_{\mathrm{y}}}{\partial \mathrm{t}}+\frac{\partial \mathrm{P}}{\partial \mathrm{y}}=-\frac{\partial\left(\mathrm{v}_{\mathrm{x}} \mathrm{v}_{\mathrm{y}}\right)}{\partial \mathrm{x}}-\frac{\partial\left(\mathrm{v}_{\mathrm{y}}{ }^{2}\right)}{\partial \mathrm{y}}+\frac{1}{\mathrm{Re}}\left(\frac{\partial^{2} \mathrm{v}_{\mathrm{y}}}{\partial \mathrm{x}^{2}}+\frac{\partial^{2} \mathrm{v}_{\mathrm{y}}}{\partial \mathrm{y}^{2}}\right)
\end{gathered}
$$

The mass conservation equation is time-independent for incompressible flow that makes it an additional constraint for the momentum conservation equations. To capture the dynamics of flow, a common used projection method is preferred to solve discrete equations. The key advantage of the projection method is to decouple velocity and the pressure fields. Nonlinear convection term, viscous diffusion term and pressure correction can be calculated in different steps: evolve the momentum equations neglecting the pressure, then project onto the subspace of divergence-free velocity fields.

In this study, different numerical treatment methods for nonlinear convection term, viscous diffusion and pressure correction will be discussed. The discretization will be based on staggered grid. The features of the model are:

- $2 \mathrm{D}$ incompressible Navier-stokes equations solver

- Second order finite difference on a staggered grid

- Explicit time integration for both advection and viscous term

- Sparse matrices for the Poisson equation for the pressure correction

- Visualization of pressure field and velocity field 
We consider all fluid leak-off happens in $\mathrm{z}$ direction in a 3D control volume, therefore the mass conservation can be written as:

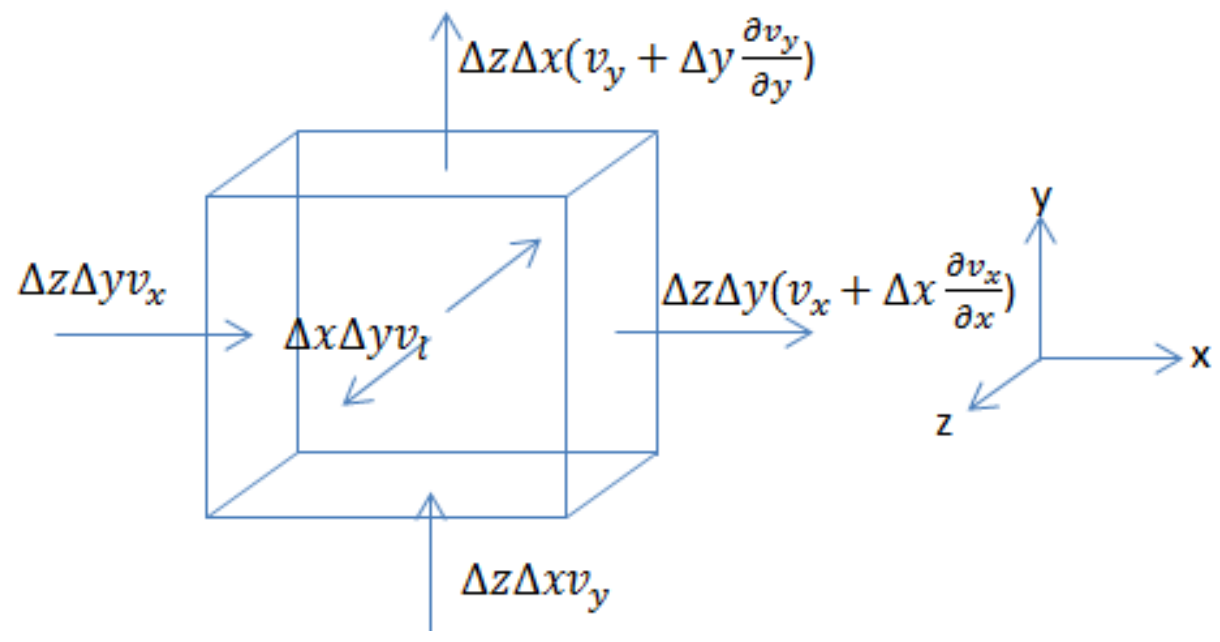

Figure 8 mass conservation of fracturing fluid in 3D

$$
\Delta \mathrm{z} \Delta \mathrm{yv}_{\mathrm{x}}+\Delta \mathrm{z} \Delta \mathrm{xv}_{\mathrm{y}}=\Delta \mathrm{z} \Delta \mathrm{x}\left(\mathrm{v}_{\mathrm{y}}+\Delta \mathrm{y} \frac{\partial \mathrm{v}_{\mathrm{y}}}{\partial \mathrm{y}}\right)+\Delta \mathrm{z} \Delta \mathrm{y}\left(\mathrm{v}_{\mathrm{x}}+\Delta \mathrm{x} \frac{\partial \mathrm{v}_{\mathrm{x}}}{\partial \mathrm{x}}\right)+2 \Delta \mathrm{x} \Delta \mathrm{y} q_{l}
$$

Equation 20 can be re-organized as

$$
\begin{gathered}
\Delta \mathrm{z} \Delta \mathrm{x} \Delta \mathrm{y} \frac{\partial \mathrm{v}_{\mathrm{y}}}{\partial \mathrm{y}}+\Delta \mathrm{z} \Delta \mathrm{y} \Delta \mathrm{x} \frac{\partial \mathrm{v}_{\mathrm{x}}}{\partial \mathrm{x}}+2 \Delta \mathrm{x} \Delta \mathrm{y} q_{l}=0 \\
\frac{\partial \mathrm{v}_{\mathrm{y}}}{\partial \mathrm{y}}+\frac{\partial \mathrm{v}_{\mathrm{x}}}{\partial \mathrm{x}}+\frac{2 q_{l}}{\Delta \mathrm{z}}=0
\end{gathered}
$$

Where $q_{l}$ is leak off velocity, which is a function of pressure and formation permeability.

The leak off velocity is also a function of pressure and can be described by Carter's leak off model, as follow:

$$
q_{l}=\frac{2 \mathrm{c}_{\mathrm{l}}}{\sqrt{\mathrm{t}-\tau(\mathrm{x}, \mathrm{y})}}
$$

Where

$$
\mathrm{C}_{\mathrm{l}}=\sqrt{\mathrm{K} \Delta \mathrm{p} \emptyset / 2 \mu}
$$


The proppant motion is highly depends on fracturing fluid flow. Horizontal velocity of proppant is the same as fluid velocity. However, the vertical velocity of proppant is a combination of fluid vertical velocity and settling velocity of proppant. The settling velocity of proppant can be determined by the equivalent of viscous drag force and gravity, when neglecting the interaction of solid particles and the interaction between particle and fracture walls, which is known as Stokes' law. The settling velocity comes from Stokes' law is constant, which will be corrected for concentration effect, fracture wall effect and non-Newtonian effect. The mass conservation of proppant is:

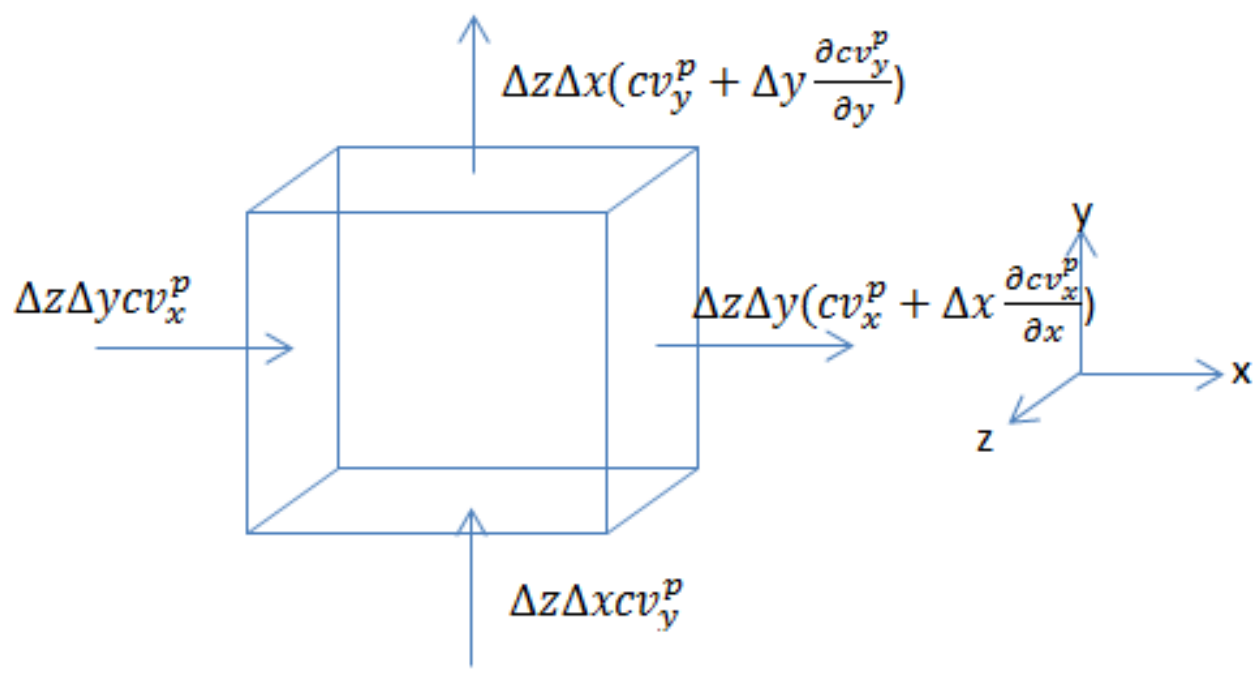

Figure 9 Mass conservation of proppant in 2D

$$
\begin{gathered}
\left(\Delta \mathrm{z} \Delta \mathrm{ycv}_{\mathrm{x}}^{\mathrm{p}}+\Delta \mathrm{z} \Delta \mathrm{xcv}_{\mathrm{y}}^{\mathrm{p}}-\Delta \mathrm{z} \Delta \mathrm{x}\left(\mathrm{cv}_{\mathrm{x}}^{\mathrm{p}}+\Delta \mathrm{y} \frac{\partial \mathrm{cv}_{\mathrm{y}}^{\mathrm{p}}}{\partial \mathrm{y}}\right)-\Delta \mathrm{z} \Delta \mathrm{y}\left(\mathrm{cv}_{\mathrm{y}}^{\mathrm{p}}+\Delta \mathrm{x} \frac{\partial \mathrm{cv}_{\mathrm{x}}^{\mathrm{p}}}{\partial \mathrm{x}}\right)\right) \Delta \mathrm{t} \\
=\Delta \mathrm{x} \Delta \mathrm{y} \Delta \mathrm{z}\left(\mathrm{c}_{\left.\mathrm{t}+\Delta \mathrm{t}-\mathrm{c}_{\mathrm{t}}\right)}\right. \\
\frac{\partial \mathrm{cv_{ \textrm {y } } ^ { \mathrm { p } }}}{\partial \mathrm{y}}+\frac{\partial \mathrm{c} \mathrm{v}_{\mathrm{x}}^{\mathrm{p}}}{\partial \mathrm{x}}=\frac{\partial \mathrm{c}}{\partial \mathrm{t}}
\end{gathered}
$$

Where $\mathrm{c}$ is the proppant concentration by volume, $\mathrm{v}_{\mathrm{x}}^{\mathrm{p}}$ and $\mathrm{v}_{\mathrm{y}}^{\mathrm{p}}$ are proppant velocities

$$
\begin{gathered}
\mathrm{v}_{\mathrm{x}}^{\mathrm{p}}=\mathrm{v}_{\mathrm{x}} \\
\mathrm{v}_{\mathrm{y}}^{\mathrm{p}}=\mathrm{v}_{\mathrm{y}}+\mathrm{v}_{\text {settle }}
\end{gathered}
$$


Where $\mathrm{v}_{\text {settle }}$ is settling velocity

Settling velocity can be calculated using Stokes law, which describes a single spherical particle settling in an infinitely large environment. The following equation holds when Reynolds number is less than 2 that is valid for most hydraulic fracturing treatments.

$$
\mathrm{V}_{\infty}=\frac{\mathrm{g}\left(\rho_{\mathrm{p}}-\rho_{f}\right) \mathrm{d}_{\mathrm{p}}^{2}}{18 \mu}
$$

During the injection of proppant in hydraulic fractures, the settling velocity of proppant can be affected by different parameters like fracture wall, proppant concentration, and Non-Newtonian effect. These effects are mostly accounted by using empirical correlations (Asmolov, 2002, Biswas, 2002, Brucato, 1998, Clark, 1981, Daneshy, 1978, Ouyang, 1994). Phani et al., 2004, presented a summary and comparison of those corrections and used polynomial equation for the corrections as is shown in Figure 10.

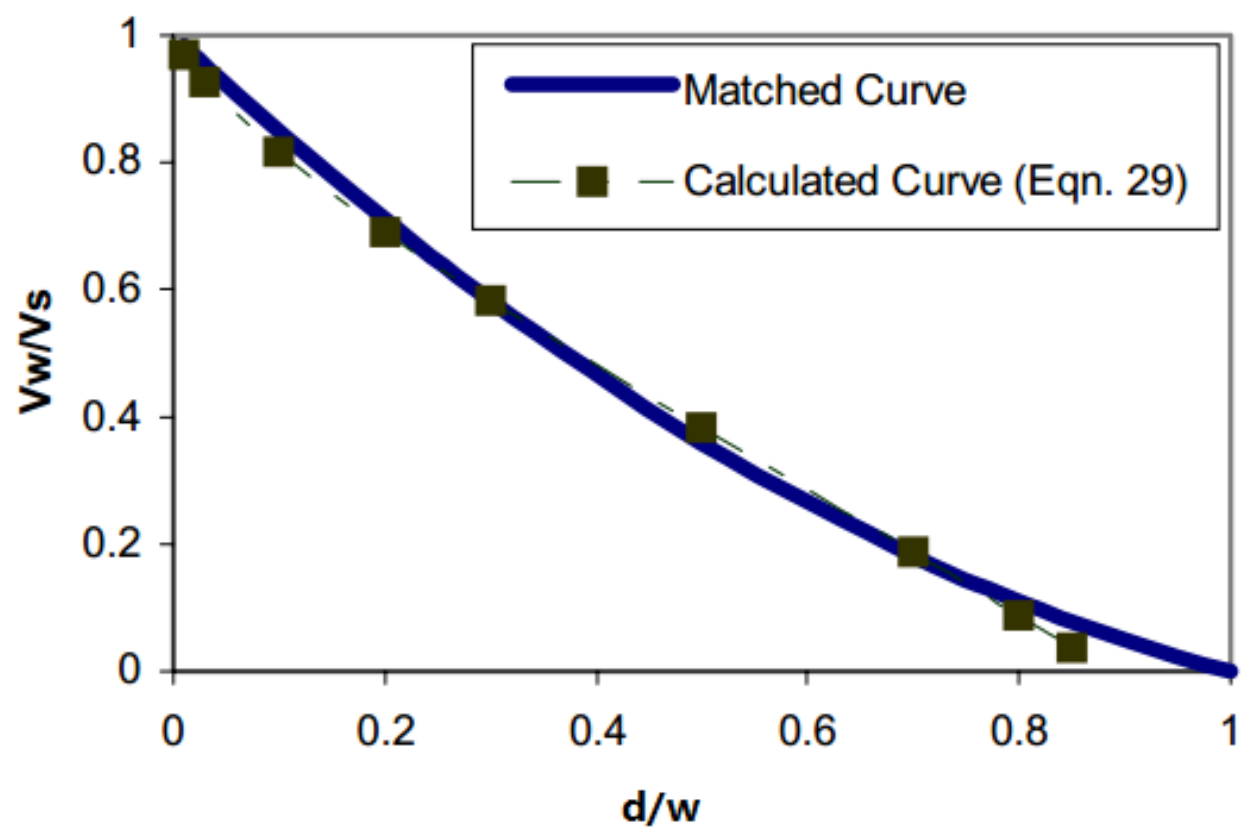

Figure 10 Polynomial correlation for the effects of fracture wall width on settling velocity (Phani, et al. 2004)

For the fracture wall effect, the following polynomial equation is introduced,

$$
V_{w}=V_{\infty}\left[0.563\left(\frac{\mathrm{d}_{\mathrm{p}}}{w}\right)^{2}-1.563\left(\frac{\mathrm{d}_{\mathrm{p}}}{w}\right)+1\right]
$$


Where $V_{w}$ is settling velocity corrected for fracture wall effect, $V_{\infty}$ is uncorrected settling velocity, $d_{p}$ is proppant particle diameter, $w$ is fracture width.

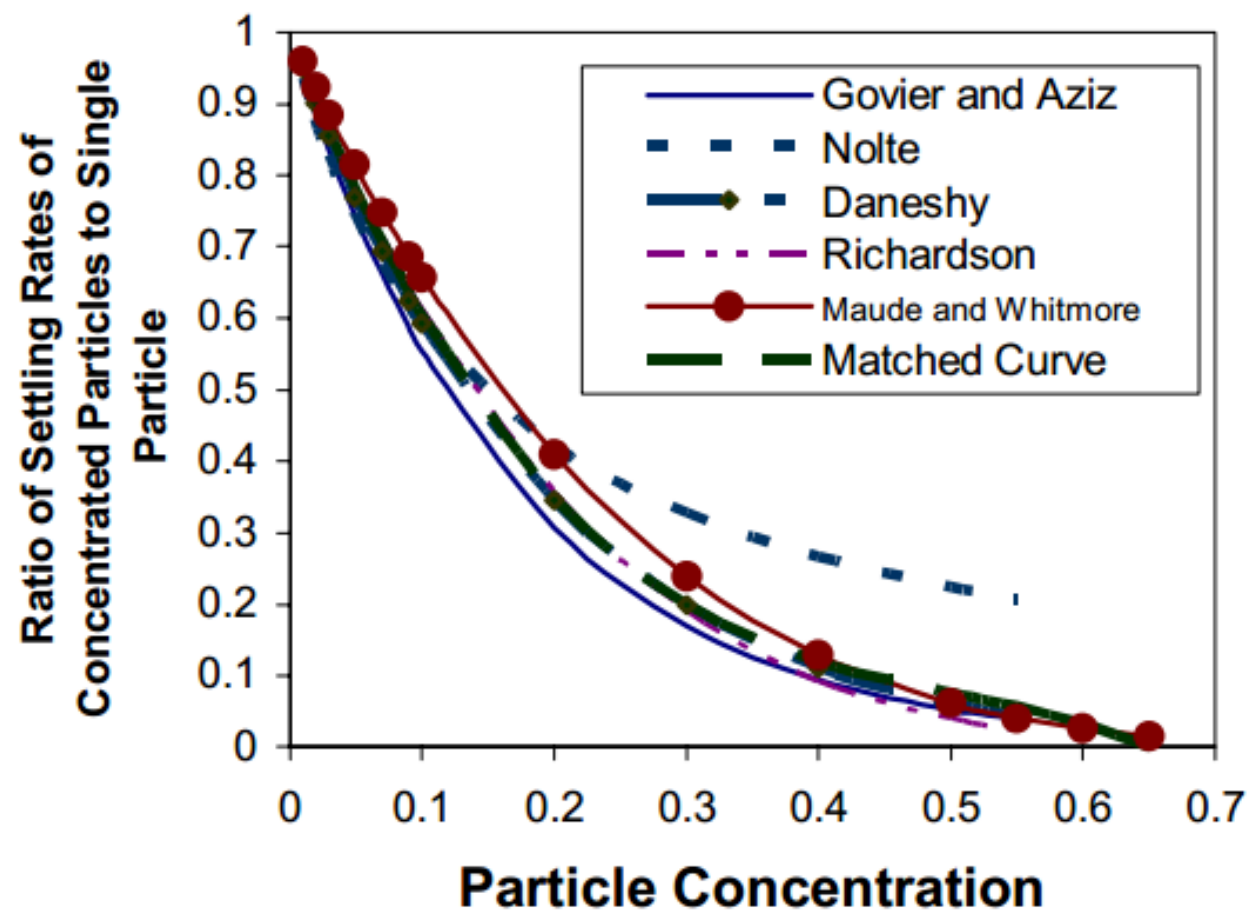

Figure 11 Polynomial correlation for the effects of proppant concentration on settling velocity (Phani, et al. 2004)

Proppant concentration effect on settling velocity is quantified by following polynomial equation,

$$
V_{c}=\mathrm{V}_{\infty}\left(2.37 c^{2}-3.08 c+1\right)
$$

Where $V_{c}$ is settling velocity corrected for proppant concentration effect, $V_{\infty}$ is uncorrected settling velocity, $c$ is proppant concentration.

\section{2: Numerical solution of governing equations for fluid flow and proppant transport}

Governing equations of proppant transport is coupled with Navier-Stokes equation governing incompressible fluid flow considering fluid leak-off. Navier-Stokes equation is solved using projection method based on staggered grid system. At each time step, first fluid pressure and velocity is updated, and then proppant velocity and concentration will be calculated. First, numerical solver of NS equation is presented. 


\subsubsection{Formulation of numerical solver of Navier-Stokes equation}

Numerical approximations of $\mathrm{v}_{\mathrm{x}}, \mathrm{v}_{\mathrm{y}}$ and $\mathrm{P}$ are denoted by capital letters. Assume we already know the velocity field $v_{x}{ }^{n}$ and $v_{y}{ }^{n}$ at the $n$ time level and mass conservation condition is satisfied, then we can find the velocity and pressure fields, $\mathrm{v}_{\mathrm{x}}{ }^{\mathrm{n}+1}, \mathrm{v}_{\mathrm{y}}{ }^{\mathrm{n}+1}$ and $\mathrm{P}^{\mathrm{n}+1}$ by following steps:

The nonlinear terms are treated explicitly which avoids the solution of a nonlinear system with additional constraint on time step to assure stability of the solution. The condition considered here is CFL condition which will be discussed in subsection (2.2.2).

$$
\begin{aligned}
& \frac{\mathrm{v}_{\mathrm{x}}{ }^{*}-\mathrm{v}_{\mathrm{x}}{ }^{\mathrm{n}}}{\Delta \mathrm{t}}=-\left(\left(\mathrm{v}_{\mathrm{x}}{ }^{\mathrm{n}}\right)^{2}\right)_{\mathrm{x}}-\left(\mathrm{v}_{\mathrm{x}}{ }^{\mathrm{n}} \mathrm{V}^{\mathrm{n}}\right)_{\mathrm{y}} \\
& \frac{\mathrm{v}_{\mathrm{y}}{ }^{*}-\mathrm{v}_{\mathrm{y}}{ }^{\mathrm{n}}}{\Delta \mathrm{t}}=-\left(\mathrm{v}_{\mathrm{x}}{ }^{\mathrm{n}} \mathrm{v}_{\mathrm{y}}{ }^{\mathrm{n}}\right)_{\mathrm{x}}-\left(\left(\mathrm{v}_{\mathrm{y}}{ }^{\mathrm{n}}\right)^{2}\right)_{\mathrm{y}}
\end{aligned}
$$

The viscosity term can be treated implicitly or explicitly. If treated implicitly, two linear systems will be solved in an additional step. But no additional requirement on time step is needed.

$$
\begin{aligned}
& \frac{\mathrm{v}_{\mathrm{x}}{ }^{* *}-\mathrm{v}_{\mathrm{x}}{ }^{*}}{\Delta \mathrm{t}}=\frac{1}{\operatorname{Re}}\left(\mathrm{v}_{\mathrm{x}_{\mathrm{xx}}}^{* *}+\mathrm{v}_{\mathrm{x} \mathrm{y} y}^{* *}\right) \\
& \frac{\mathrm{v}_{\mathrm{y}}{ }^{* *}-\mathrm{v}_{\mathrm{y}}{ }^{*}}{\Delta \mathrm{t}}=\frac{1}{\operatorname{Re}}\left(\mathrm{v}_{\mathrm{y}_{\mathrm{xx}}}^{* *}+\mathrm{v}_{\mathrm{y}_{\mathrm{yy}}^{* *}}\right)
\end{aligned}
$$

On the other hand if viscosity is treated explicitly, no additional calculation step is needed but time step restriction needs to be imposed.

$$
\begin{aligned}
& \frac{v_{x}{ }^{*}-v_{x}}{\Delta t}=-\left(\left(v_{x}{ }^{n}\right)^{2}\right)_{x}-\left(v_{x}{ }^{n} v_{y}{ }^{n}\right)_{y}+\frac{1}{R e}\left(v_{x_{x x}}^{n}+v_{x y y}^{n}\right) \\
& \frac{v_{y}{ }^{*}-v_{y}^{n}}{\Delta t}=-\left(v_{x}{ }^{n} v_{y}{ }^{n}\right)_{x}-\left(\left(v_{y}{ }^{n}\right)^{2}\right)_{y}+\frac{1}{R e}\left(v_{y_{x x}}^{n}+v_{y_{y y}}^{n}\right)
\end{aligned}
$$

Here explicit method is used for our purpose.

To enforce incompressibility, the intermediate velocity field needs to be corrected by pressure gradient. 


$$
\begin{aligned}
& \frac{\mathrm{v}_{\mathrm{x}}^{\mathrm{n}+1}-\mathrm{v}_{\mathrm{x}}{ }^{*}}{\Delta \mathrm{t}}=-\left(\mathrm{P}^{\mathrm{n}+1}\right)_{\mathrm{x}} \\
& \frac{\mathrm{v}_{\mathrm{y}}^{\mathrm{n}+1}-\mathrm{v}_{\mathrm{y}}{ }^{*}}{\Delta \mathrm{t}}=-\left(\mathrm{P}^{\mathrm{n}+1}\right)_{\mathrm{y}}
\end{aligned}
$$

Applying divergence to both sides gives:

$$
\begin{aligned}
& \mathrm{v}_{\mathrm{x}_{\mathrm{x}}}^{\mathrm{n}+1}-\mathrm{v}_{\mathrm{x}_{\mathrm{x}}}^{*}=-\Delta \mathrm{t}\left(\mathrm{P}^{\mathrm{n}+1}\right)_{\mathrm{xx}} \\
& \mathrm{v}_{\mathrm{y}_{\mathrm{y}}}^{\mathrm{n}+1}-\mathrm{v}_{\mathrm{y}_{\mathrm{y}}^{*}}^{*}=-\Delta \mathrm{t}\left(\mathrm{P}^{\mathrm{n}+1}\right)_{\mathrm{yy}}
\end{aligned}
$$

Applying divergence free condition on summation of Equation 29 and 30

$$
\mathrm{v}_{\mathrm{x}_{\mathrm{x}}}^{*}+\mathrm{v}_{\mathrm{y}_{\mathrm{y}}}^{*}-\Delta \mathrm{t}\left(\left(\mathrm{P}^{\mathrm{n}+1}\right)_{\mathrm{xx}}+\left(\mathrm{P}^{\mathrm{n}+1}\right)_{\mathrm{yy}}\right)=\mathrm{v}_{\mathrm{x}_{\mathrm{x}}}^{\mathrm{n}+1}+\mathrm{v}_{\mathrm{y}_{\mathrm{y}}}^{\mathrm{n}+1}=0
$$

The Poisson equation for pressure can be obtained:

$$
\left(\mathrm{P}^{\mathrm{n}+1}\right)_{\mathrm{xx}}+\left(\mathrm{P}^{\mathrm{n}+1}\right)_{\mathrm{yy}}=\frac{\mathrm{v}_{\mathrm{x}_{\mathrm{x}}}^{*}+\mathrm{v}_{\mathrm{y}_{\mathrm{y}}}^{*}}{\Delta \mathrm{t}}
$$

Solve the Poisson equations and substitute pressure gradient into pressure correction Equation 27 and 28 , then velocity field can be updated.

\subsubsection{Spatial discretization}

In order to avoid spurious checkerboard solution, governing equations are discretized on staggered grid which is demonstrated in Figure 12. Pressure is defined in cell centers and the velocities are defined in the centers of vertical and horizontal cell faces respectively. The filled and open symbols denote interior and boundary points respectively.

Consider having $\mathrm{n}_{\mathrm{x}} \times \mathrm{n}_{\mathrm{y}}$ cells, number of unknowns for each variable is given in Table 2 . 
Table 2 Resolution for variables

\begin{tabular}{|c|c|c|}
\hline Variable & Interior resolution & Boundary conditions included \\
\hline $\mathrm{P}$ & $\mathrm{Nx} \times \mathrm{Ny}$ & $(\mathrm{Nx}+2) \times(\mathrm{Ny}+2)$ \\
\hline $\mathrm{v}_{\mathrm{x}}$ & $(\mathrm{Nx}-1) \times \mathrm{Ny}$ & $(\mathrm{Nx}+1) \times(\mathrm{Ny}+2)$ \\
\hline $\mathrm{v}_{\mathrm{y}}$ & $\mathrm{Nx} \times(\mathrm{Ny}-1)$ & $(\mathrm{Nx}+2) \times(\mathrm{Ny}+1)$ \\
\hline
\end{tabular}

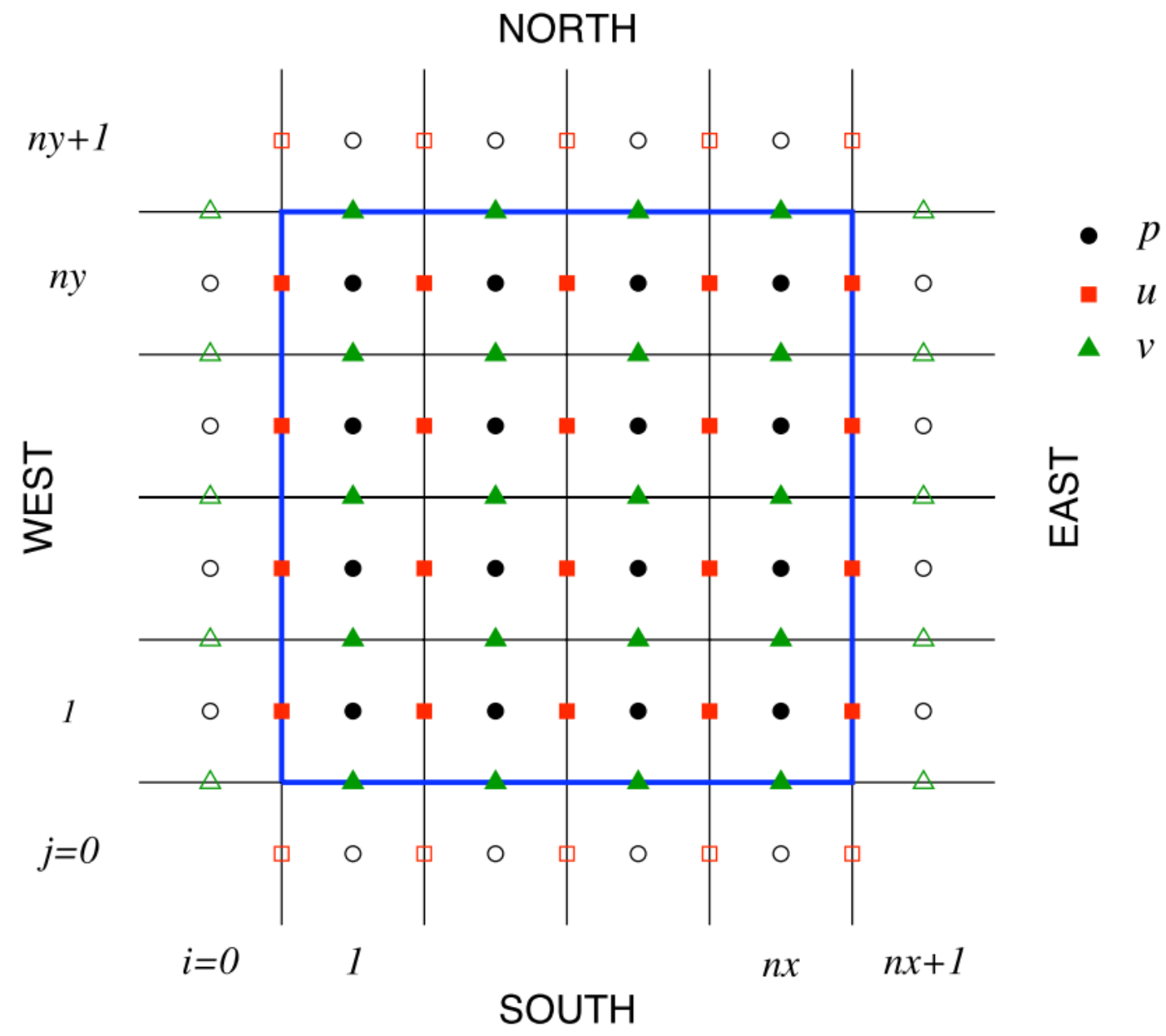

Figure 12 sketch of staggered grid 
Boundary conditions for both velocity components are given all around the rectangular domain. In this study, the vectors are defined as $\mathrm{v}_{\mathrm{x}} \mathrm{s}$ for $\mathrm{v}_{\mathrm{x}}$ at south boundary, $\mathrm{v}_{\mathrm{y}} \mathrm{w}$ for $\mathrm{v}_{\mathrm{y}}$ at west boundary, etc. Thus, on each side, a total of $(n x+1)$ or $(n y+1)$ boundary values are specified on the cell corners. The Dirichlet boundary conditions on west and east side can be applied directly because the velocity nodes lie on the boundaries. The same is valid for $v_{y}$ on south and north boundaries. The boundary conditions of $\mathrm{v}_{\mathrm{x}}$ on north and south boundaries need to be imposed using linear interpolation, i.e.,

$$
\begin{aligned}
& \frac{v_{x_{i, j}}+v_{x_{i, j}+1}}{2}=v_{x_{N}} \\
& v_{x_{i, j+1}}=2 v_{x_{N}}-v_{x_{i, j}}
\end{aligned}
$$

This expression corresponds to taking the average between the interior and exterior points. Similarly for V on west and east boundaries.

For boundary condition of pressure, the common approach is to use homogeneous Neumann boundary conditions. To avoid singularity pressure at one point is fixed and only pressure gradients are used to correct the velocity field.

$$
\frac{\partial \mathrm{P}}{\partial \mathrm{n}}=0
$$

This means pressure at boundaries is equal to the values at interior points, for example,

$$
\frac{P_{i, j+1}-P_{i, j}}{h y}=0
$$




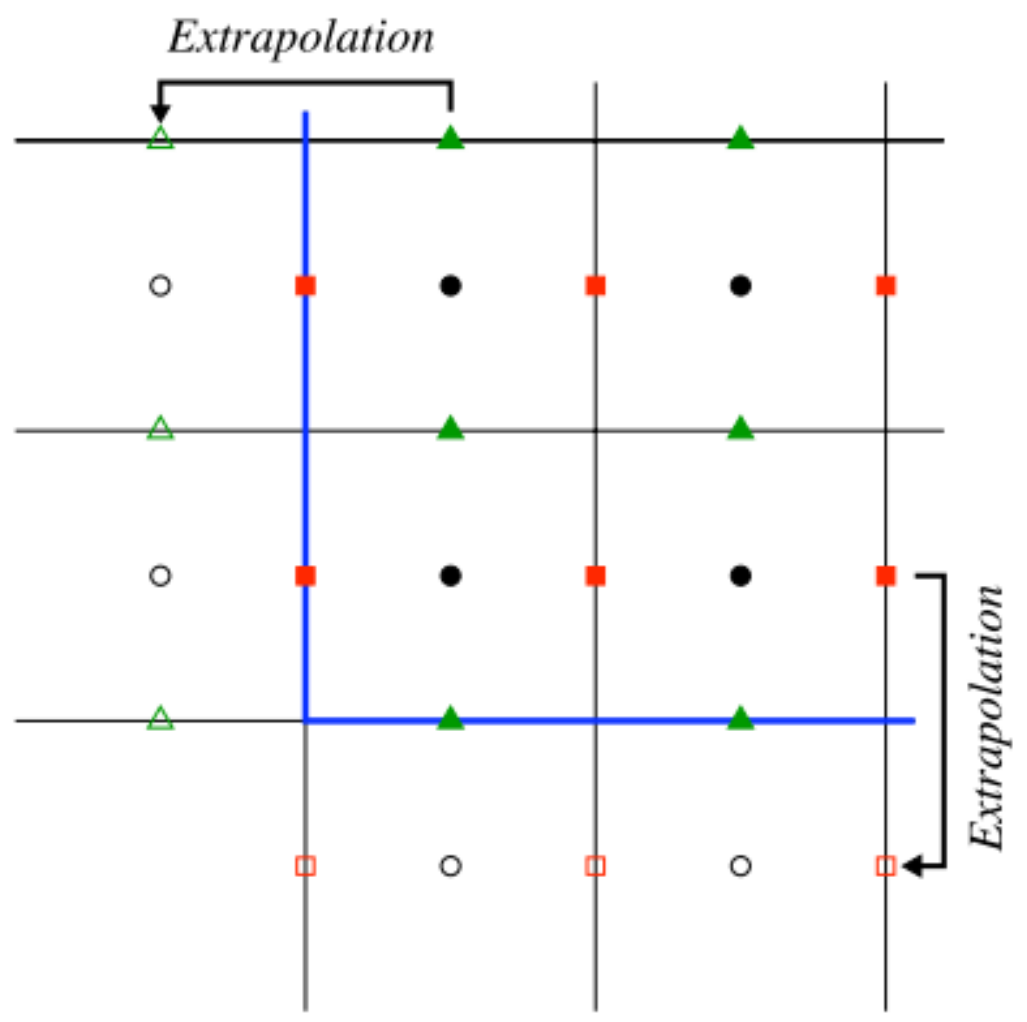

Figure 13 Velocity boundary conditions

Second derivatives can be approximated by finite difference method using central difference technique. This can be applied to second derivatives of pressure and velocity, for example,

$$
\begin{aligned}
& \left(v_{x_{x x}}^{n}\right)_{i, j} \approx \frac{v_{x_{i}-1, j}^{n}-2 v_{x_{i, j}}^{n}+v_{x_{i}+1, j}^{n}}{h_{x}^{2}} \\
& \left(v_{x_{y y}}^{n}\right)_{i, j} \approx \frac{v_{x_{i, j}-1}^{n}-2 v_{x_{i, j}}^{n}+v_{x_{i, j}+1}^{n}}{h_{y}^{2}}
\end{aligned}
$$

Our approach leads to second order accuracy for the solutions.

First derivatives can be approximated by central difference approximation at a grid point, and to avoid instability or checkerboard effect we use staggered grid in this study. Solutions can meet the stability criteria if we evaluate first derivatives in the middle of two grid points using central difference approximation. For example, 


$$
\left(v_{x_{x}}^{n}\right)_{i+\frac{1}{2}, j} \approx \frac{v_{x_{i}+1, j}^{n}-v_{x_{i, j}}^{n}}{h_{x}}
$$

Finite difference approximation of first order is used for both pressure correction and nonlinear convection terms. As stated before, the velocities lie in the center of cell faces, so the divergences of the velocity field lie in the cell centers. The second derivative of pressure also lies in the cell centers. So, those two are matched in space. For the velocity correction, the divergence of pressure lies in the middle of cell faces, where exactly the velocities are.

However, for the nonlinear convection terms, special care needs to be taken. If direct derivative of $\left(\left(v_{x}{ }^{n}\right)^{2}\right)_{x}$ is conducted, corresponding value will lie at grid points which is different from velocity point, i.e. at the center. Also, $\mathrm{v}_{\mathrm{x}}{ }^{\mathrm{n}} \mathrm{v}_{\mathrm{y}}{ }^{\mathrm{n}}$ lies at different locations, they cannot be calculated directly. Here, we average the velocity values in horizontal and vertical directions to solve the problem as follow:

$$
\begin{aligned}
& \left(\left(v_{x}\right)^{2}\right)_{x}=\left(\left(v_{x}{ }^{h}\right)_{x}^{2}\right. \\
& v_{x_{i+\frac{1}{2}, j}}^{h}=\frac{v_{x_{i}+1, j}^{h}+v_{x_{i, j}}^{h}}{2} \\
& \left(v_{x} v_{y}\right)_{y}=\left(v_{x} v_{y}{ }^{h}\right)_{y} \\
& v_{x_{i, j}+\frac{1}{2}}^{v}=\frac{v_{x_{i, j}}^{h}+v_{x_{i, j}}^{h}}{2} \\
& v_{y_{i+\frac{1}{2}, j}^{h}}^{h}=\frac{v_{y_{i+1, j}}^{h}+v_{y_{i, j}}^{h}}{2}
\end{aligned}
$$

Similarly for $\left(\mathrm{v}_{\mathrm{x}} \mathrm{n}_{\mathrm{y}}{ }^{\mathrm{n}}\right)_{\mathrm{x}}$ and $\left(\left(\mathrm{v}_{\mathrm{y}}{ }^{\mathrm{n}}\right)^{2}\right)_{\mathrm{y}}$, demonstration of velocity averaging can be found in Figure 14. 


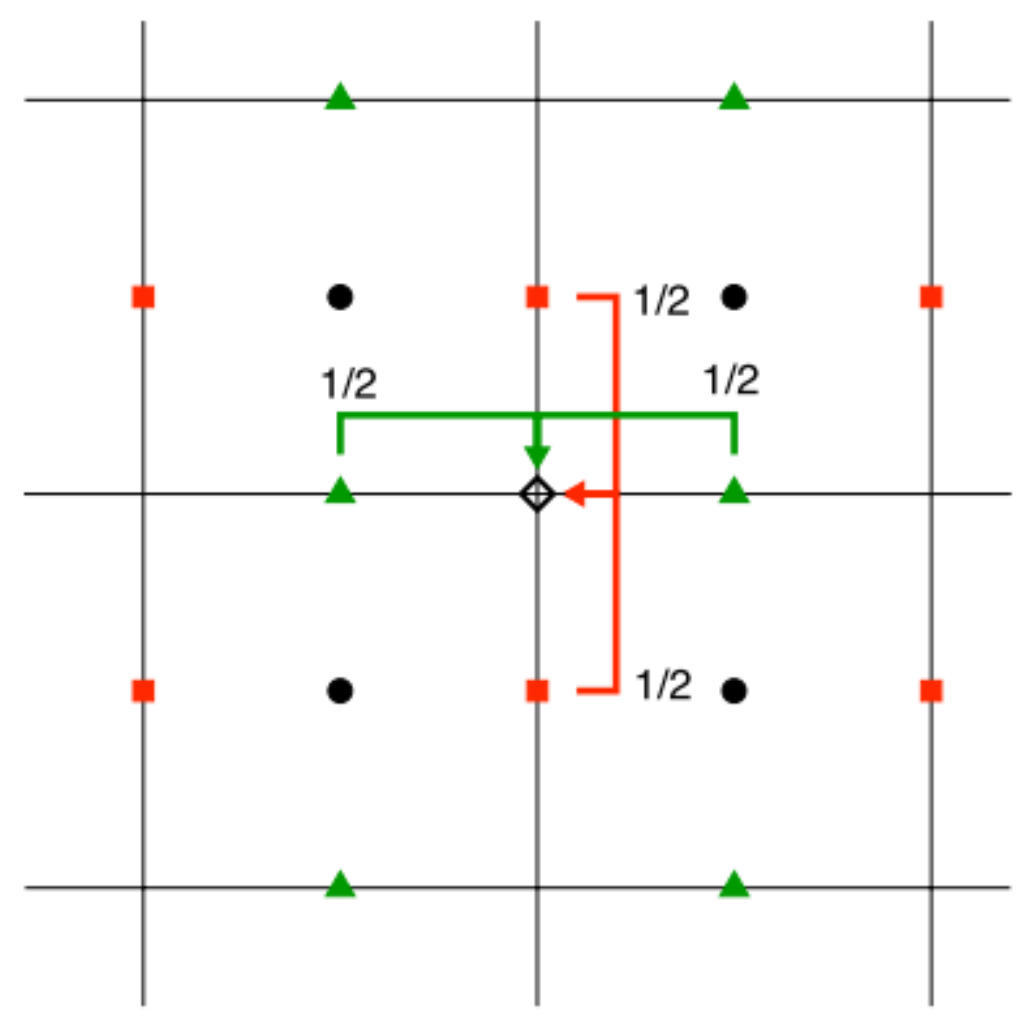

Figure 14 Velocity averaging

As discussed before, since we are using explicit scheme for nonlinear terms, additional restriction for time step needs to be imposed. If the time step is too large, or velocity is too large, quantities will travel beyond our calculation domain which is not appropriate and may cause instability. CFL condition is employed here in this research. The purpose of this condition is to switch central difference to upwind difference approximation when the time step is too large or velocity is too large. We define several new parameters for this purpose.

$$
\begin{aligned}
& \operatorname{gamma}=\min \left(\Delta \mathrm{t} * \max \left(\max \left|\mathrm{v}_{\mathrm{x}_{\mathrm{i}, \mathrm{j}}}\right|, \max \left|\mathrm{v}_{\mathrm{y}_{\mathrm{i}, \mathrm{j}}}\right|\right), 1\right) \\
& {\widetilde{v_{x_{i}}, j}}_{{ }^{\prime}, j}=\frac{v_{x_{i+1, j}}^{h}-v_{x_{i, j}}^{h}}{2} \\
& {\widetilde{v_{x}}}_{x_{i, j}+\frac{1}{2}}^{v}=\frac{v_{x_{i, j+1}}^{h}-v_{x_{i, j}}^{h}}{2}
\end{aligned}
$$

Using gamma as a linear combination coefficient for nonlinear terms and we have: 
$\frac{\mathrm{v}_{\mathrm{x}}{ }^{*}-\mathrm{v}_{\mathrm{x}}{ }^{\mathrm{h}}}{\Delta \mathrm{t}}=-\left(\left(\mathrm{v}_{\mathrm{x}}{ }^{\mathrm{h}}\right)^{2}-\text { gamma }\left|\mathrm{v}_{\mathrm{x}}{ }^{\mathrm{h}}\right|{\widetilde{v_{x}}}^{\mathrm{h}}\right)_{\mathrm{x}}-\left(\mathrm{v}_{\mathrm{x}} \mathrm{v}_{\mathrm{y}}^{\mathrm{h}}-\text { gamma }\left|\mathrm{v}_{\mathrm{y}}{ }^{\mathrm{h}}\right|{\widetilde{v_{x}}}_{\mathrm{v}}^{\mathrm{v}}\right)_{\mathrm{y}}+\frac{1}{\operatorname{Re}}\left(\mathrm{v}_{\mathrm{x}_{\mathrm{xx}}}^{\mathrm{n}}+\mathrm{v}_{\mathrm{x} \mathrm{yy}}^{\mathrm{n}}\right)$

$\frac{\mathrm{v}_{\mathrm{y}}{ }^{*}-\mathrm{v}_{\mathrm{y}}{ }^{\mathrm{n}}}{\Delta \mathrm{t}}=-\left(\mathrm{v}_{\mathrm{x}}{ }^{\mathrm{n}} \mathrm{v}_{\mathrm{y}}{ }^{\mathrm{n}}-\text { gamma }\left|\mathrm{v}_{\mathrm{x}}{ }^{\mathrm{v}}\right|{\widetilde{\mathrm{v}_{\mathrm{y}}}}^{\mathrm{h}}\right)_{\mathrm{x}}-\left(\left(\mathrm{v}_{\mathrm{y}}{ }^{\mathrm{n}}\right)^{2}-\text { gamma }\left|\mathrm{v}_{\mathrm{y}}{ }^{\mathrm{v}}\right|{\widetilde{v_{\mathrm{y}}}}^{\mathrm{v}}\right)_{\mathrm{y}}+\frac{1}{\operatorname{Re}}\left(\mathrm{v}_{\mathrm{y}_{\mathrm{xx}}}^{\mathrm{n}}+\mathrm{v}_{\mathrm{y}_{\mathrm{yy}}}^{\mathrm{n}}\right)$

gamma $=1$, change the system to upwind scheme and gamma $=0$ leads to central difference.

\subsubsection{Numerical implementation}

In a $\mathrm{n}_{\mathrm{x}} \times \mathrm{n}_{\mathrm{y}}$ grid system, define matrices of $\mathrm{v}_{\mathrm{x}}, \mathrm{v}_{\mathrm{y}}$ and $\mathrm{P}$ which contain only the interior points. All three matrices have same size as the interior point of each unknown as is shown in table 1. The Drichlet boundary conditions are defined as $v_{x} N$ as $v_{x}$ velocity at north boundary, $v_{y} E$ as $v_{y}$ velocity at east boundary, etc. the Neumann boundary conditions are defined as zero gradient at boundaries.

Also, the approximation of derivatives and average value of two neighboring points are done in the form of matrix using defined functions "diff" and "avg". $\operatorname{diff}(\mathrm{P}, 1,1)$ will do first order derivative in $\mathrm{x}$ direction and $\operatorname{diff}(\mathrm{P}, 1,2)$ will do first order derivative in y direction. $\operatorname{Avg}(\mathrm{P}, 1)$ will calculate the average value of two neighboring points in $\mathrm{x}$ direction and $\operatorname{avg}(\mathrm{P}, 2)$ will calculate the average value of two neighboring points in y direction.

Nonlinear convection terms include $\left(v_{x}{ }^{n} v_{y}{ }^{n}\right)_{x},\left(\left(v_{y}{ }^{n}\right)^{2}\right)_{y},\left(\left(v_{x}{ }^{n}\right)^{2}\right)_{x}$ and $\left(v_{x}{ }^{n} v_{y}{ }^{n}\right)_{y}$ terms.

First we define $\mathrm{v}_{\mathrm{x}} \mathrm{e}$ and $\mathrm{v}_{\mathrm{y}} \mathrm{e}$ which include both exterior and interior points for velocities in $\mathrm{x}$ and $y$ directions, respectively, then we obtain each term as follow:

$$
\left(v_{x}{ }^{n} v_{y}{ }^{n}\right)_{x} \approx d v_{x} v_{y} d x=\operatorname{diff}\left(v_{x} a \cdot * v_{y} a-\operatorname{gamma} * \operatorname{abs}\left(v_{x} a\right) \cdot * v_{y} d, 1,1\right) / h x
$$

Where $\mathrm{v}_{\mathrm{x}} \mathrm{a}=\operatorname{avg}\left(\mathrm{v}_{\mathrm{x}} \mathrm{e}, 2\right), \mathrm{v}_{\mathrm{y}} \mathrm{a}=\operatorname{avg}\left(\mathrm{v}_{\mathrm{y}} \mathrm{e}, 1\right), \mathrm{v}_{\mathrm{y}} \mathrm{d}=\operatorname{diff}\left(\mathrm{v}_{\mathrm{y}} \mathrm{e}, 1,1\right) / 2$

$$
\left(v_{x}{ }^{n} v_{y}{ }^{n}\right)_{y} \approx d v_{x} v_{y} d y=\operatorname{diff}\left(v_{x} a \cdot * v_{y} a-\operatorname{gamma} * \operatorname{abs}\left(v_{y} a\right) * v_{x} d, 1,2\right) / h y
$$

Where $v_{x} a=\operatorname{avg}\left(v_{x} e, 2\right), v_{y} a=\operatorname{avg}\left(v_{y} e, 1\right), v_{x} d=\operatorname{diff}\left(v_{x} e, 1,2\right) / 2$

$$
\left(\left(v_{x}{ }^{n}\right)^{2}\right)_{x} \approx d v_{x} 2 d x=\operatorname{diff}\left(v_{x} a \cdot * v_{x} a-\operatorname{gamma} * \operatorname{abs}\left(v_{x} a\right) . * v_{x} d, 1,1\right) / h x
$$


Where $\mathrm{v}_{\mathrm{x}} \mathrm{a}=\operatorname{avg}\left(\mathrm{v}_{\mathrm{x}} \mathrm{e}(:, 2:\right.$ end -1$\left.), 1\right), \mathrm{v}_{\mathrm{x}} \mathrm{d}=\operatorname{diff}\left(\mathrm{v}_{\mathrm{x}} \mathrm{e}(:, 2\right.$ : end -1$\left.), 1,1\right) / 2$,

$$
\left(\left(v_{\mathrm{y}}{ }^{\mathrm{n}}\right)^{2}\right)_{\mathrm{y}} \approx \mathrm{dv}_{\mathrm{y}} 2 \mathrm{dy}=\operatorname{diff}\left(\mathrm{v}_{\mathrm{y}} \mathrm{a} \cdot * \mathrm{v}_{\mathrm{y}} \mathrm{a}-\operatorname{gamma} * \operatorname{abs}\left(\mathrm{v}_{\mathrm{y}} \mathrm{a}\right) \cdot * \mathrm{v}_{\mathrm{y}} \mathrm{d}, 1,2\right) / \mathrm{hy}
$$

Where $\mathrm{v}_{\mathrm{y}} \mathrm{a}=\operatorname{avg}\left(\mathrm{v}_{\mathrm{y}} \mathrm{e}(2:\right.$ end $\left.-1,:), 2\right), \operatorname{Vd}=\operatorname{diff}\left(\mathrm{v}_{\mathrm{y}} \mathrm{e}(2:\right.$ end $\left.-1,:), 1,2\right) / 2$,

The viscous terms include second derivatives which can be approximated by

$$
\begin{aligned}
& \mathrm{v}_{\mathrm{x}_{\mathrm{xx}}}^{\mathrm{n}} \approx \mathrm{dv}_{\mathrm{x}} \mathrm{dxx}=\operatorname{diff}\left(\mathrm{v}_{\mathrm{x}} \mathrm{e}(:, 2: \text { end }-1), 2,1\right) / \mathrm{hx}^{\wedge} 2 \\
& \mathrm{v}_{\mathrm{x}_{\mathrm{yy}}}^{\mathrm{n}} \approx \mathrm{dv}_{\mathrm{x}} \mathrm{dyy}=\operatorname{diff}\left(\mathrm{v}_{\mathrm{x}} \mathrm{e}(:, 2: \text { end }-1), 2,2\right) / \mathrm{hy}^{\wedge} 2 \\
& \mathrm{v}_{\mathrm{y}_{\mathrm{xx}}}^{\mathrm{n}} \approx \mathrm{dv}_{\mathrm{y}} \mathrm{dxx}=\operatorname{diff}\left(\mathrm{v}_{\mathrm{y}} \mathrm{e}(2: \text { end }-1,:), 2,1\right) / \mathrm{hx}^{\wedge} 2 \\
& \mathrm{v}_{\mathrm{y}_{\mathrm{yy}}}^{\mathrm{n}} \approx \mathrm{dv}_{\mathrm{y}} \operatorname{dyy}=\operatorname{diff}\left(\mathrm{v}_{\mathrm{y}} \mathrm{e}(2: \text { end }-1,:), 2,2\right) / \mathrm{hy}^{\wedge} 2
\end{aligned}
$$

The two side of Poisson equation for pressure can be expressed as

$$
\operatorname{Lp}(\mathrm{P})=\left(\mathrm{P}^{\mathrm{n}+1}\right)_{\mathrm{xx}}+\left(\mathrm{P}^{\mathrm{n}+1}\right)_{\mathrm{yy}}
$$

Right hand side of Laplace Equation 32 is:

$$
\text { rhs }=\frac{\mathrm{v}_{\mathrm{x}_{\mathrm{x}}}^{*}+\mathrm{v}_{\mathrm{y}_{\mathrm{y}}}^{*}}{\Delta \mathrm{t}}
$$

Where Lp is Laplace operator

$$
\operatorname{Lp}=\frac{\partial^{2}}{\partial \mathrm{x}^{2}}+\frac{\partial^{2}}{\partial \mathrm{y}^{2}}
$$

Lp can be implemented in the form of matrix by code as

$$
\mathrm{Lp}=\operatorname{kron}(\operatorname{speye}(\mathrm{Ny}), \mathrm{DD}(\mathrm{Nx}, \mathrm{hx}))+\operatorname{kron}(\mathrm{DD}(\mathrm{Ny}, \mathrm{hy}), \text { speye }(\mathrm{Nx}))
$$

Where "kron" is Kronecker tensor product, "speye" is sparse matrix generator and "DD" is a function defined to generate tridiagonal matrix. $\mathrm{DD}(\mathrm{Nx}, \mathrm{hx})$ is for $\frac{\partial^{2}}{\partial \mathrm{x}^{2}}$ while $\mathrm{DD}(\mathrm{Ny}, \mathrm{hy})$ is for $\frac{\partial^{2}}{\partial \mathrm{y}^{2}}$.

$$
\text { rhs }=\operatorname{diff}\left(\left[v_{x} W ; v_{x} ; v_{x} E\right], 1,1\right) / h x+\operatorname{diff}\left(\left[v_{y} S^{\prime} v_{y} v_{y} N^{\prime}\right], 1,2\right) / h y ;
$$


Then the Poisson Equation 32 can be expressed as,

$$
[\mathrm{Lp}]\{\mathrm{P}\}=\{\text { rhs }\}
$$

This equation is solved using Gauss-Seidel iteration method. Then for the pressure correction, we have

$$
\begin{array}{r}
\mathrm{v}_{\mathrm{x}}=\mathrm{v}_{\mathrm{x}}-\mathrm{dt} * \operatorname{diff}(\mathrm{P}, 1,1) / \mathrm{hx} ; \\
\mathrm{v}_{\mathrm{y}}=\mathrm{v}_{\mathrm{y}}-\mathrm{dt} * \operatorname{diff}(\mathrm{P}, 1,2) / \mathrm{hy}
\end{array}
$$

\subsubsection{Fluid leak-off and proppant transport}

Considering fluid leak-off in $\mathrm{z}$ direction, the implicit pressure Equation 31 can be written as:

$$
\begin{gathered}
\mathrm{v}_{\mathrm{x}_{\mathrm{x}}}^{*}+\mathrm{v}_{\mathrm{y}_{\mathrm{y}}}^{*}-\Delta \mathrm{t}\left(\left(\mathrm{P}^{\mathrm{n}+1}\right)_{\mathrm{xx}}+\left(\mathrm{P}^{\mathrm{n}+1}\right)_{\mathrm{yy}}\right)=\mathrm{v}_{\mathrm{x}_{\mathrm{x}}}^{\mathrm{n}+1}+\mathrm{v}_{\mathrm{y}_{\mathrm{y}}}^{\mathrm{n}+1}=-\frac{2 \mathrm{q}_{\mathrm{l}}^{\mathrm{n}}}{\Delta \mathrm{z}} \\
\left(\mathrm{P}^{\mathrm{n}+1}\right)_{\mathrm{xx}}+\left(\mathrm{P}^{\mathrm{n}+1}\right)_{\mathrm{yy}}=\frac{\mathrm{v}_{\mathrm{x}_{\mathrm{x}}}^{*}+\mathrm{v}_{\mathrm{y}_{\mathrm{y}}}^{*}+\frac{2 \mathrm{q}_{\mathrm{l}}^{\mathrm{n}}}{\Delta \mathrm{z}}}{\Delta \mathrm{t}}
\end{gathered}
$$

Pressure field can be obtained from Poisson Equation 33 and then used for velocity corrections.

Leak off velocity is a function of pressure, and can be defined as:

$$
q_{1}^{n}=\frac{2 c_{l}}{\sqrt{t-\tau(x, y)}}
$$

Where

$$
\mathrm{C}_{\mathrm{l}}=\sqrt{\mathrm{K} \Delta \mathrm{p} \emptyset / 2 \mu}
$$

Here, $K, \emptyset$, and $\mu$ are properties of rock and fluid, they are constant; $t-\tau(x, y)$ is the time of leak off.In this case, the leak off velocity can be simplified as

$$
q_{1}^{n}=\alpha \sqrt{\frac{p-p_{\text {matrix }}}{t-\tau(x, y)}}
$$




$$
\alpha=2 \sqrt{\mathrm{K} \emptyset / 2 \mu}
$$

$\alpha$ is considered to be constant here.

Since only convection is involved, central difference approximation is no longer appropriate. So, here the space discretization is made based on upwind method.

$$
\begin{aligned}
& \frac{\partial \mathrm{cv}_{\mathrm{x}}^{\mathrm{p}}}{\partial \mathrm{x}} \approx \frac{\left(\mathrm{cv}_{\mathrm{x}}^{\mathrm{p}}\right)_{\mathrm{i}+\frac{1}{2}, \mathrm{j}}-\left(\mathrm{cv}_{\mathrm{x}}^{\mathrm{p}}\right)_{\mathrm{i}-\frac{1}{2}, \mathrm{j}}}{\Delta \mathrm{x}} \\
& \left(c v_{x}^{p}\right)_{i+\frac{1}{2}, j}=c_{i+\frac{1}{2}, j}\left(0.5 *\left(v_{x_{i+1, j}}^{p}+v_{x_{i, j}}^{p}\right)-\frac{\left|v_{x_{i, j}}^{p}\right|}{v_{x_{i, j}}^{p}} * 0.5 *\left(v_{x_{i+1, j}}^{p}-v_{x_{i, j}}^{p}\right)\right)
\end{aligned}
$$

This can be expressed as

$$
\begin{aligned}
&\left(v_{\mathrm{x}}^{\mathrm{p}}\right)_{\mathrm{i}+\frac{1}{2}, \mathrm{j}} \approx \mathrm{v}_{\mathrm{x}} \text { aa } \\
&=\left[\mathrm{v}_{\mathrm{x}} \mathrm{W} ; \operatorname{avg}\left(\operatorname{avg}\left(\mathrm{v}_{\mathrm{x}} \mathrm{ee}, 1\right), 1\right)-\operatorname{abs}\left(\mathrm{v}_{\mathrm{x}}\right) \cdot /\left(\mathrm{v}_{\mathrm{x}}\right) \cdot * \operatorname{diff}\left(\operatorname{avg}\left(\mathrm{v}_{\mathrm{x}} \mathrm{ee}, 1\right), 1,1\right) / 2 ; \mathrm{v}_{\mathrm{x}} \mathrm{E}\right] ; \\
& \qquad \mathrm{v}_{\mathrm{x}} \mathrm{ee}=\left[\mathrm{v}_{\mathrm{x}} \mathrm{W} ; \mathrm{v}_{\mathrm{x}} ; \mathrm{v}_{\mathrm{x}} \mathrm{E}\right] ;
\end{aligned}
$$

\subsubsection{Model validation}

After implementing the above model, a lid-driven cavity problem is simulated using this code. The sketch and boundary conditions are shown in Figure 15. 


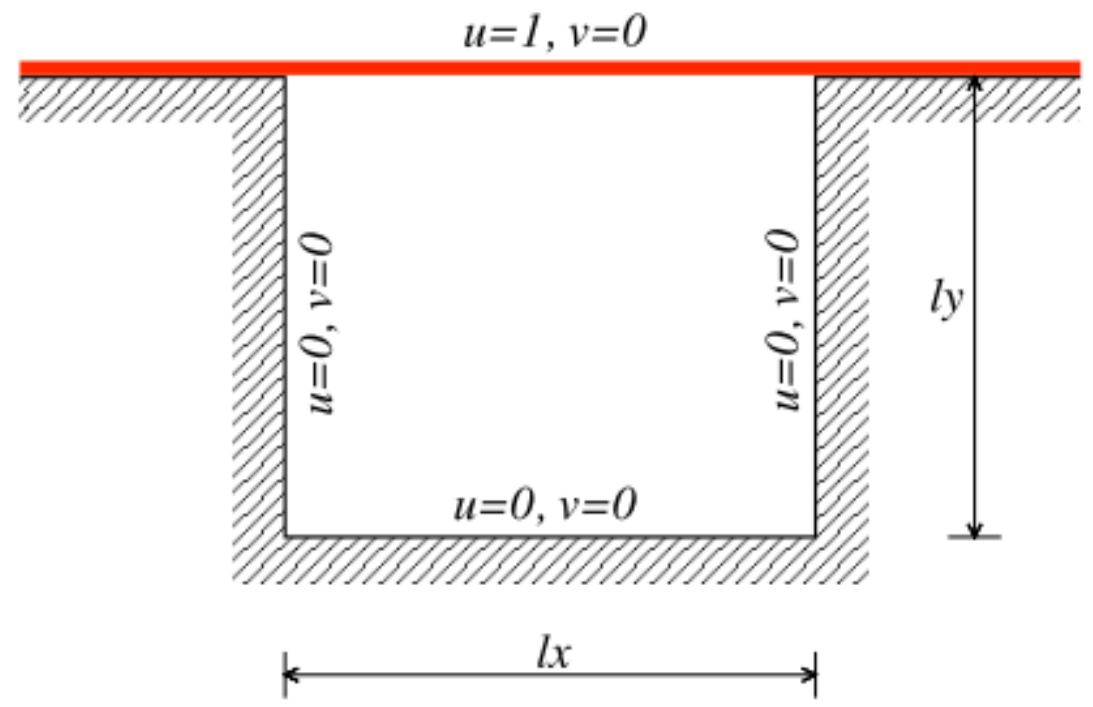

Figure 15 Lid-driven cavity model

The test runs of lid-driven cavity uses Reynolds number of 1000 , the results are reasonable as are shown in the following figures.

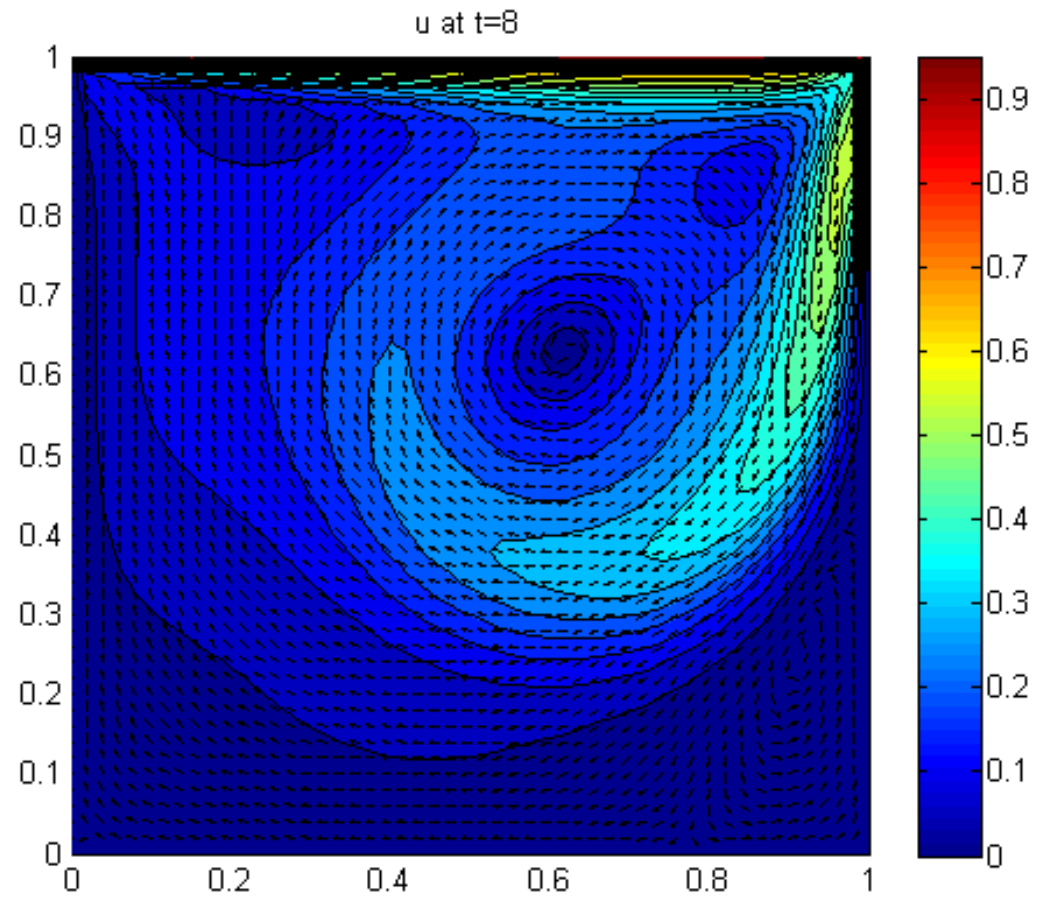

Figure 16 Lid-driven velocity field, $t=8, R e=1000$ 


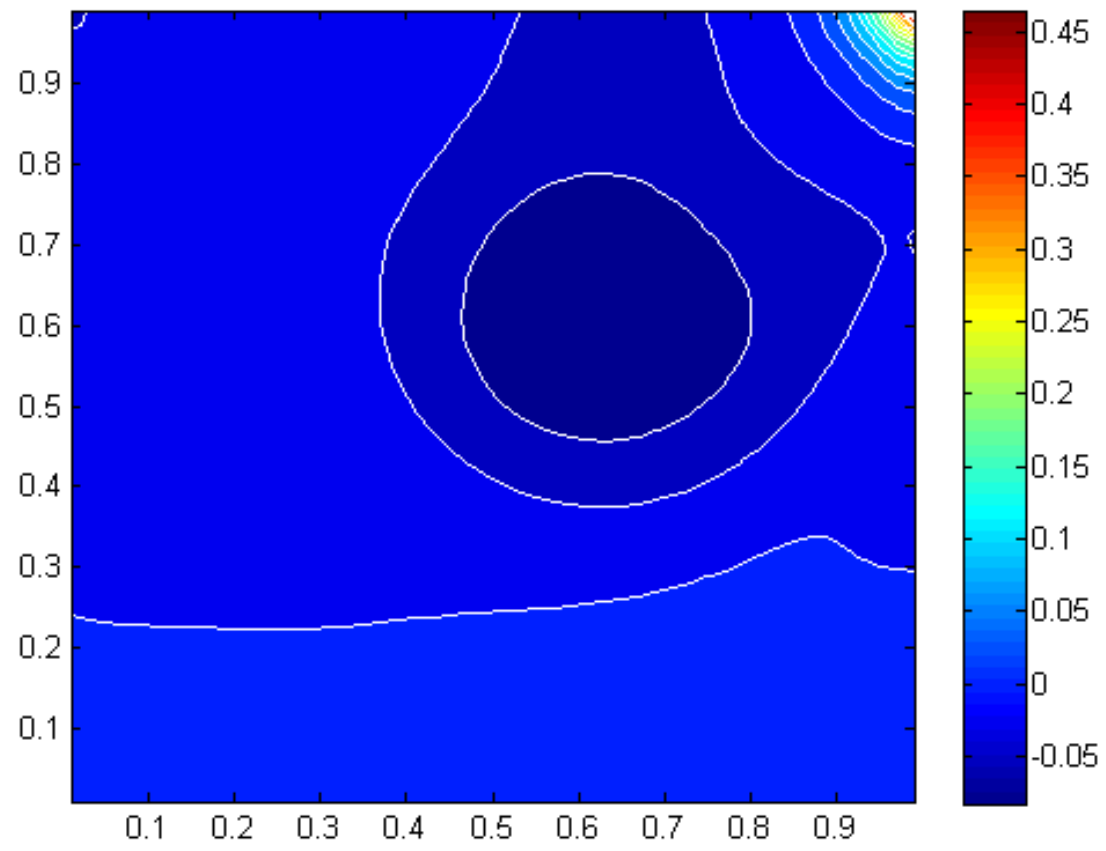

Figure 17 Lid-driven pressure field, $t=8, \mathbf{R e}=\mathbf{1 0 0 0}$

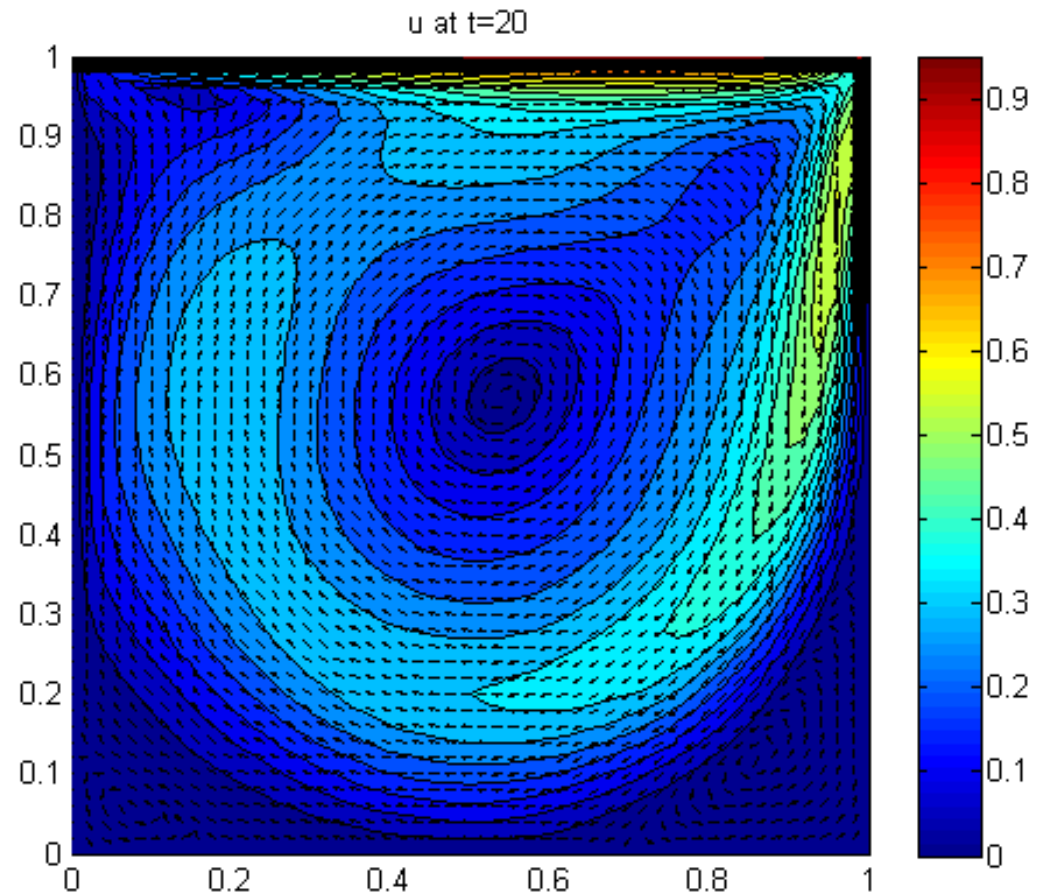

Figure 18 Lid-driven velocity field, $t=\mathbf{2 0}, \mathbf{R e}=\mathbf{1 0 0 0}$ 


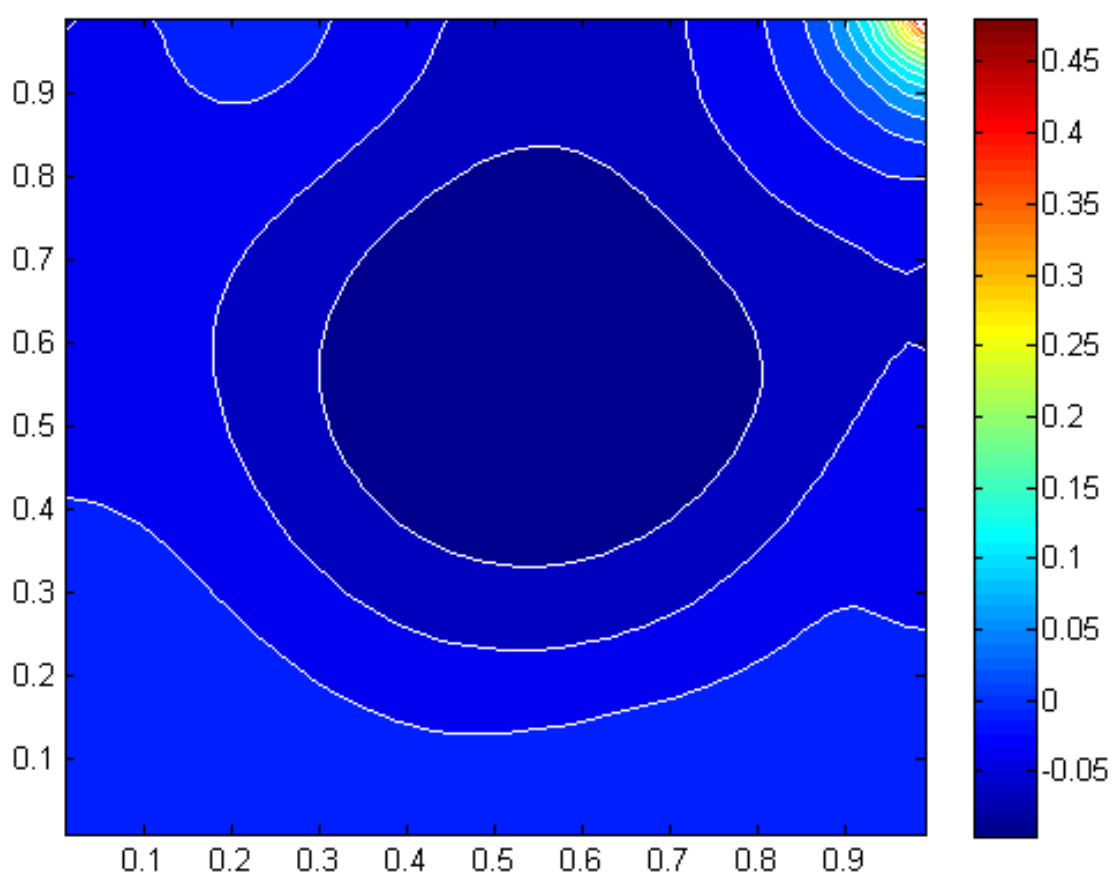

Figure 19 Lid-driven pressure field, $t=20, \operatorname{Re}=1000$

The vertical velocity on midline for steady state solution is compared with reference data found in literature (Ghia U. 1982). And the results show good consistency with reference data as is shown in Figure 20.

$\operatorname{Re} 1000$

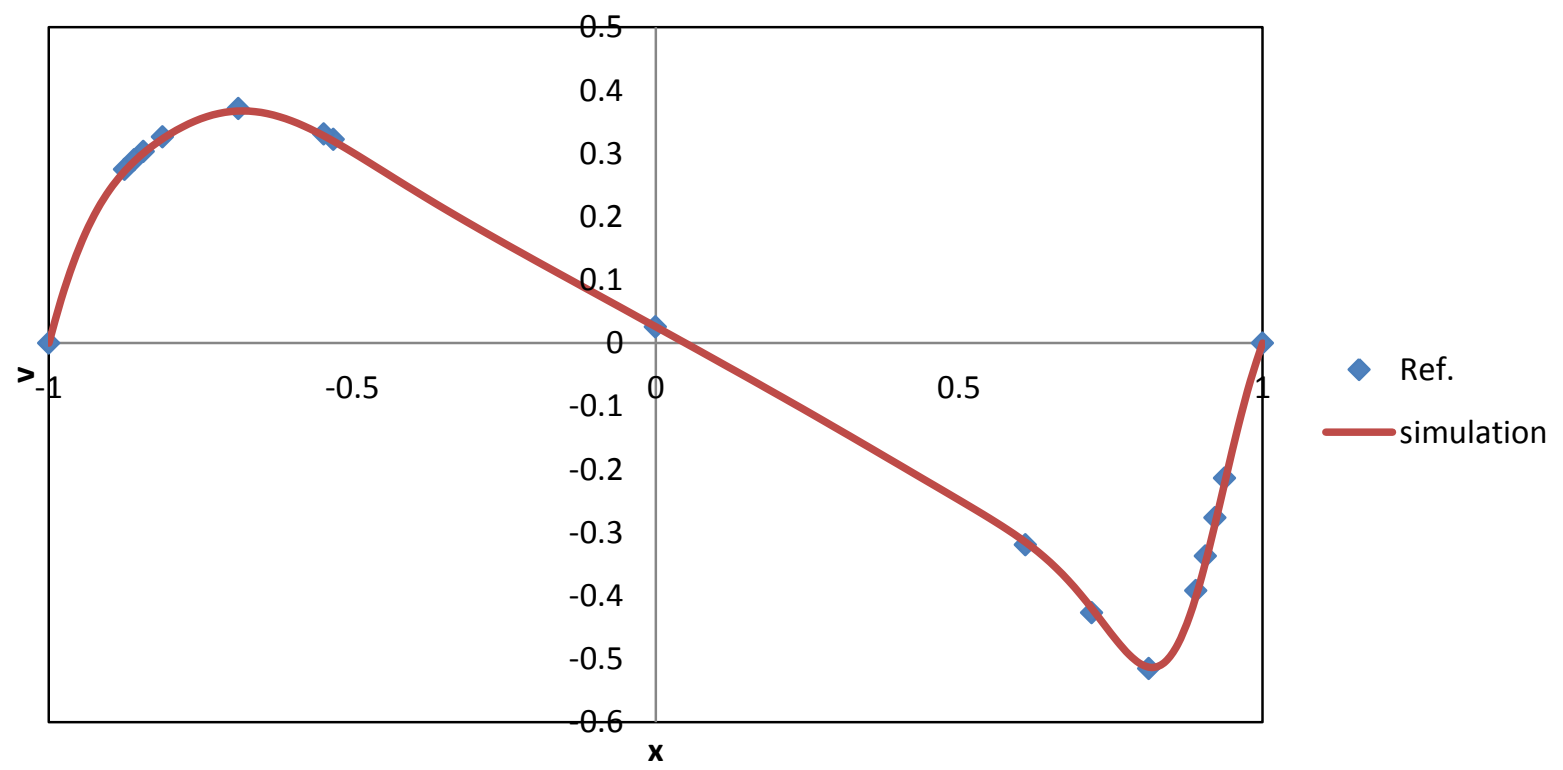

Figure $20 \mathrm{v}$ velocity along horizontal midline shows consistency with reference data, Re is 1000 , resolution is $100 * 100$ 


\section{3: Fracture geometry after flow back}

When the concentration of proppant in fracture reaches threshold value, proppant particles will jam and form irregular packing. Because of fluid leak-off during injection or flow back afterward, the fluid pressure will decrease and thus the proppant pack will be compressed by fracture walls. This will reduce the fracture width and permeability. The decrease of fracture width and proppant pack permeability depends on proppant elastic properties and closure stress. Experiments (Barree, 2003) show that fracture width can be reduced by about $16 \%$ from 0 closure stress to 8000 psi closure stress. However, when closure stress is below 4000 psi, the decrease of fracture width due to closure stress can be neglected.

White Sand (16/30) $2 \# / \mathrm{ft}^{2}$



Figure 21 Pack width versus stress for 16/30 white sand (Barree, 2003) 
White Sand (20/40) $2 \# / \mathrm{ft}^{2}$

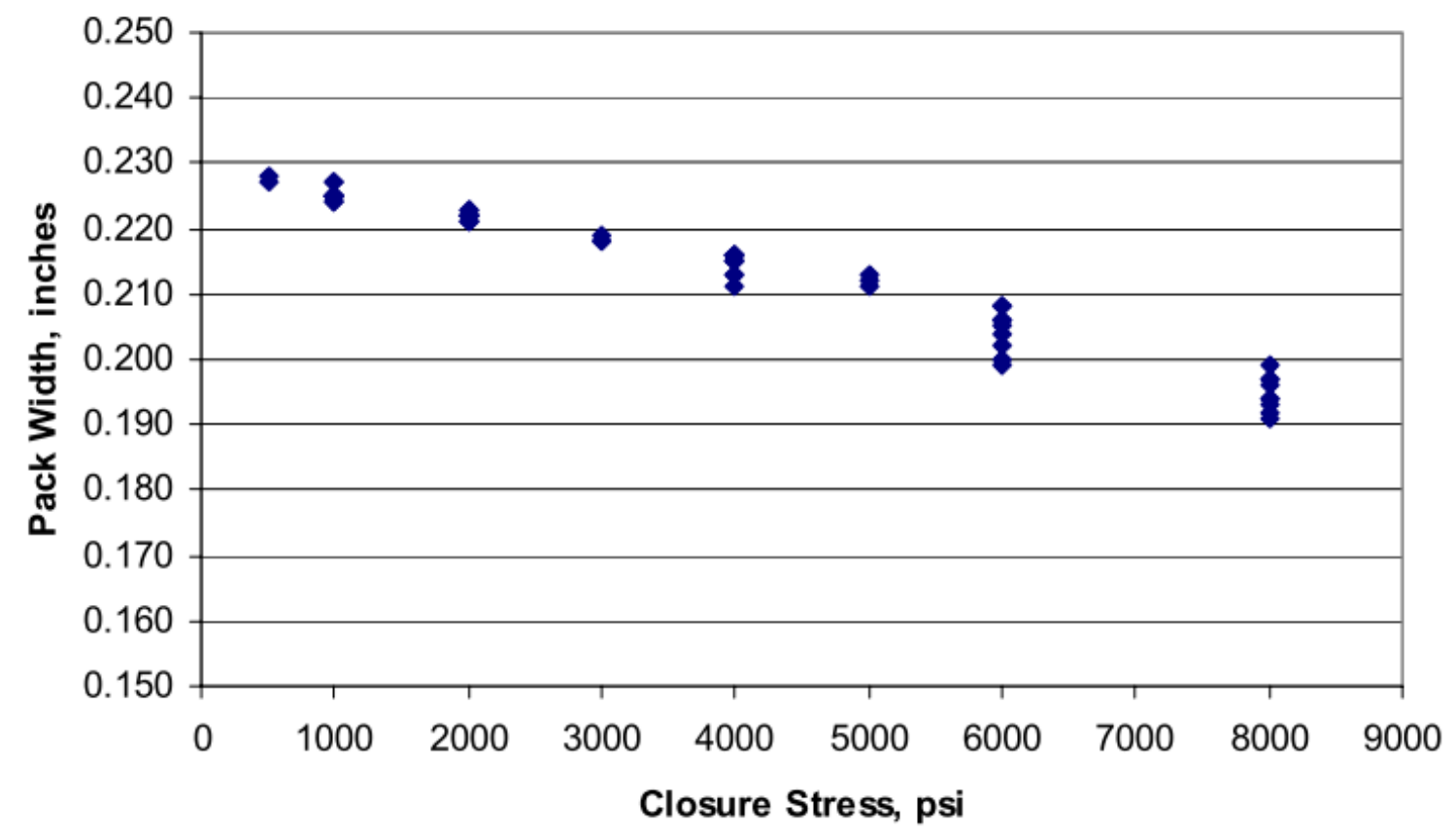

Figure 22 Pack width versus stress for 20/40 white sand (Barree, 2003)

The overall decrease rate of fracture width of white sand is $2.1 \%\left(/ 10^{3} \mathrm{psi}\right)$. The fracture width at 0 closure stress can be obtained using proppant concentration and original fracture width after injection.

$$
w_{f}^{\prime}=\mathrm{w} \frac{\mathrm{c}}{\mathrm{c}_{\max }}
$$


Where, $w$ is original fracture width after injection, $c$ is proppant concentration and $c_{\max }$ is maximum proppant concentration. Based on this equation the area where proppant concentration reaches the maximum value will hold the original fracture width, while the area where proppant concentration doesn't reach the maximum value will have smaller fracture width. This equation gives a simple estimation of fracture width after injection.

\section{4: Numerical simulation of fluid flow in fractures during production}

Fracture is filled with compact proppant pack after flow back. Proppant pack is uncemented porous media. Fluid flow in proppant pack is governed with same mass and momentum governing equations for fluid flow in porous media. Here both slightly compressible fluid and compressible fluid flow are considered for frac fluid production and gas production from the reservoir.

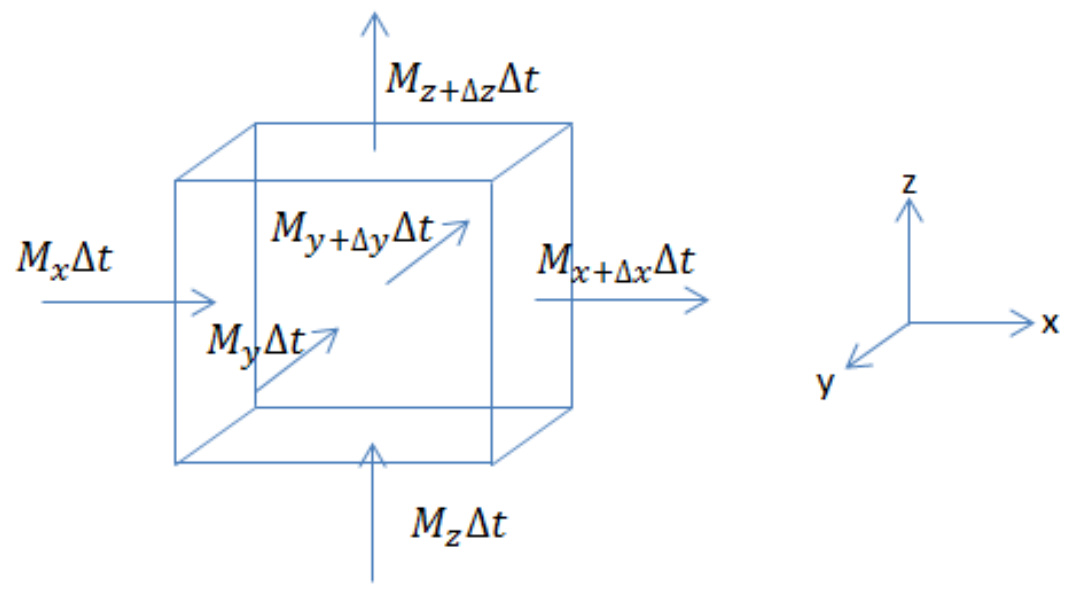

Figure 23 Mass conservation of porous media flow

The conservation equation of fluid flow in porous media is defined as following:

$$
\begin{gathered}
{\left[M_{x} \Delta t+M_{y} \Delta t+M_{z} \Delta t\right]-\left[M_{x+\Delta x} \Delta t+M_{y+\Delta y} \Delta t+M_{z+\Delta z} \Delta t\right]+Q \Delta t} \\
=(\Delta x \Delta y \Delta z \emptyset s \rho)_{t+\Delta t}-(\Delta x \Delta y \Delta z \emptyset s \rho)_{t}
\end{gathered}
$$

Where $M$ is the amount of mass entering or leaving at each moment

$$
\begin{aligned}
& M_{x}=m_{x} \Delta y \Delta z \\
& M_{y}=m_{y} \Delta x \Delta z
\end{aligned}
$$




$$
M_{z}=m_{z} \Delta x \Delta y
$$

Where mass flow $m$ is defined as following

$$
\begin{aligned}
& m_{x}=\rho v_{x} \\
& m_{y}=\rho v_{y} \\
& m_{z}=\rho v_{z}
\end{aligned}
$$

Substitute the definition of mass flow into mass flow rate $M$ and get

$$
\begin{aligned}
& M_{x}=\rho v_{x} \Delta y \Delta z=\rho v_{x} A_{x} \\
& M_{y}=\rho v_{y} \Delta x \Delta z=\rho v_{y} A_{y} \\
& M_{z}=\rho v_{z} \Delta x \Delta y=\rho v_{z} A_{z}
\end{aligned}
$$

$A$ represents area in each direction perpendicular to the flow. Rewrite the conservation equation considering the cross section area:

$-\left[\left(\rho v_{x} A_{x}\right)_{x+\Delta x}-\left(\rho v_{x} A_{x}\right)_{x}+\left(\rho v_{y} A_{y}\right)_{y+\Delta y}-\left(\rho v_{y} A_{y}\right)_{y}+\left(\rho v_{z} A_{z}\right)_{z+\Delta z}-\left(\rho v_{z} A_{z}\right)_{z}-\mathrm{Q}=\right.$ $\frac{\left(\Delta x \Delta y \Delta z \emptyset_{s} \rho\right)_{t+\Delta t}-(\Delta x \Delta y \Delta z \emptyset s \rho)_{t}}{\Delta t}$

Divide both side of the equation by $\Delta x \Delta y \Delta z$

$$
-\frac{\Delta\left(\rho v_{x}\right)}{\Delta x}-\frac{\Delta\left(\rho v_{y}\right)}{\Delta y}-\frac{\Delta\left(\rho v_{z}\right)}{\Delta z}+\frac{Q}{v_{b}}=\frac{(\emptyset s \rho)_{t+\Delta t}-(\emptyset s \rho)_{t}}{\Delta t}
$$

At the limit when time goes to zero we have:

$$
-\frac{\Delta\left(\rho v_{x}\right)}{\Delta x}-\frac{\Delta\left(\rho v_{y}\right)}{\Delta y}-\frac{\Delta\left(\rho v_{z}\right)}{\Delta z}+\frac{Q}{v_{b}}=\frac{\partial(\varnothing s \rho)}{\partial t}
$$

Where

$$
\begin{gathered}
Q=q \rho_{s c} \\
v=-\frac{k k_{r}}{\mu} \frac{\partial \Phi}{\partial l} \\
\Phi=\mathrm{p}-\frac{1}{144} \rho D
\end{gathered}
$$




$$
\begin{gathered}
\rho=\frac{\rho_{s c}}{B} \\
v_{b}=\Delta x \Delta y \Delta z
\end{gathered}
$$

Where $B$ is formation volume factor and $\mathrm{D}$ is the depth:

$$
\frac{\partial}{\partial x}\left(\frac{k_{x} A_{x}}{\mu B} \frac{\partial \Phi}{\partial x}\right) \Delta x+\frac{\partial}{\partial y}\left(\frac{k_{y} A_{y}}{\mu B} \frac{\partial \Phi}{\partial y}\right) \Delta y+\frac{\partial}{\partial z}\left(\frac{k_{z} A_{z}}{\mu B} \frac{\partial \Phi}{\partial z}\right) \Delta z+q=v_{b} \frac{\partial}{\partial t}\left(\frac{s \emptyset}{B}\right)
$$

\subsubsection{Slightly compressible system}

Pore compressibility for slightly compressible system is expressed as following:

$$
\operatorname{comp}=-\frac{1}{v}\left(\frac{\partial v}{\partial p}\right)
$$

Where v is pore volume; Substitute $v=\frac{m}{\rho}$ into the above equation pore compressibility can be written in terms of density as follow:

$$
\operatorname{comp}=\frac{1}{\rho}\left(\frac{\partial \rho}{\partial p}\right)
$$

Integration of above equation leads to:

$$
\begin{gathered}
\int_{p_{s c}}^{p} \operatorname{comp} d p=\int_{p_{s c}}^{p} \frac{1}{\rho} d \rho \\
\operatorname{comp}\left(p-p_{s c}\right)=\ln \frac{\rho_{s c}}{\rho} \\
e^{\operatorname{com} p\left(p-p_{s c}\right)}=\frac{\rho_{s c}}{\rho} \cong 1+\operatorname{comp}\left(p-p_{s c}\right)
\end{gathered}
$$

Then $\frac{1}{B} \cong 1+\operatorname{comp}\left(p-p_{s c}\right)$

Assuming single phase flow, $\emptyset=\emptyset(x, y, z)$, and ignoring gravity effect the governing Equation 36 can be written as following:

$$
\frac{\partial}{\partial x}\left(\frac{k_{x} A_{x}}{\mu B} \frac{\partial \Phi}{\partial x}\right) \Delta x+\frac{\partial}{\partial y}\left(\frac{k_{y} A_{y}}{\mu B} \frac{\partial \Phi}{\partial y}\right) \Delta y+\frac{\partial}{\partial z}\left(\frac{k_{z} A_{z}}{\mu B} \frac{\partial \Phi}{\partial z}\right) \Delta z+q=v_{b} \emptyset \frac{\partial p}{\partial t}
$$


Although viscosity and formation volume factor are functions of pressure, in slightly compressible fluid, they can be safely assumed constant.

$$
\frac{\partial}{\partial x}\left(k_{x} A_{x} \frac{\partial \mathrm{p}}{\partial x}\right) \Delta x+\frac{\partial}{\partial y}\left(k_{y} A_{y} \frac{\partial \mathrm{p}}{\partial y}\right) \Delta y+\frac{\partial}{\partial z}\left(k_{z} A_{z} \frac{\partial \mathrm{p}}{\partial z}\right) \Delta z+\mu B q=\mu B v_{b} \emptyset \frac{\partial p}{\partial t}
$$

Next, central difference approximation for space derivative can be used.

$$
\begin{aligned}
{\left[\left(\frac{k_{x} A_{x}}{\Delta x}\right)_{i+1 / 2, j, k}\right.} & \left.\left(p_{i+1, j, k}-p_{i, j, k}\right)-\left(\frac{k_{x} A_{x}}{\Delta x}\right)_{i-1 / 2, j, k}\left(p_{i, j, k}-p_{i-1, j, k}\right)\right] \\
+ & {\left[\left(\frac{k_{y} A_{y}}{\Delta y}\right)_{i, j+1 / 2, k}\left(p_{i, j+1, k}-p_{i, j, k}\right)-\left(\frac{k_{y} A_{y}}{\Delta y}\right)_{i, j-1 / 2, k}\left(p_{i, j, k}-p_{i, j-1, k}\right)\right] } \\
+ & {\left[\left(\frac{k_{z} A_{z}}{\Delta z}\right)_{i, j, k+1 / 2}\left(p_{i, j, k+1}-p_{i, j, k}\right)-\left(\frac{k_{z} A_{z}}{\Delta z}\right)_{i, j, k-1 / 2}\left(p_{i, j, k}-p_{i, j, k-1}\right)\right] } \\
+ & \mu B q_{i, j, k}=\mu B\left(v_{b} \emptyset\right)_{i, j, k} \frac{\partial p}{\partial t}
\end{aligned}
$$

Organizing the above equation results in following:

$$
\begin{gathered}
a_{e}\left(p_{i+1, j, k}-p_{i, j, k}\right)-a_{w}\left(p_{i, j, k}-p_{i-1, j, k}\right)+a_{n}\left(p_{i, j+1, k}-p_{i, j, k}\right)-a_{s}\left(p_{i, j, k}-p_{i, j-1, k}\right) \\
+a_{a}\left(p_{i, j, k+1}-p_{i, j, k}\right)-a_{b}\left(p_{i, j, k}-p_{i, j, k-1}\right)+\mu B q_{i, j, k}=\mu B\left(v_{b} \emptyset\right)_{i, j, k} \frac{\partial p}{\partial t} \\
a_{e} p_{i+1, j, k}+a_{n} p_{i, j+1, k}+a_{a} p_{i, j, k+1}-\left(a_{e}+a_{w}+a_{n}+a_{s}+a_{a}+a_{b}\right) p_{i, j, k}+a_{w} p_{i-1, j, k} \\
+a_{s} p_{i, j-1, k}+a_{b} p_{i, j, k-1}+\mu B q_{i, j, k}=\mu B\left(v_{b} \emptyset\right)_{i, j, k} \frac{\partial p}{\partial t}
\end{gathered}
$$

Replacing the transient term with forward finite difference approximation above equation can be written in implicit form as follow:

$$
\begin{gathered}
a_{e} p_{i+1, j, k}^{n+1}+a_{n} p_{i, j+1, k}^{n+1}+a_{a} p_{i, j, k+1}^{n+1}-\left(a_{e}+a_{w}+a_{n}+a_{s}+a_{a}+a_{b}+a_{c}\right) p_{i, j, k}^{n+1}+a_{w} p_{i-1, j, k}^{n+1} \\
+a_{s} p_{i, j-1, k}^{n+1}+a_{b} p_{i, j, k-1}^{n+1}=-a_{c} p_{i, j, k}^{n}-\mu B q_{i, j, k}^{n+1}
\end{gathered}
$$

For a steady problem transient term can be neglected, i.e., $\frac{\partial p}{\partial t}=0$, 


$$
\begin{gathered}
a_{e} p_{i+1, j, k}+a_{n} p_{i, j+1, k}+a_{a} p_{i, j, k+1}-\left(a_{e}+a_{w}+a_{n}+a_{s}+a_{a}+a_{b}\right) p_{i, j, k} \\
+a_{w} p_{i-1, j, k}+a_{s} p_{i, j-1, k}+a_{b} p_{i, j, k-1}=-\mu B q_{i, j, k}
\end{gathered}
$$

Where $a_{c}=\frac{\mu B\left(v_{b} \emptyset\right)_{i, j, k}}{\Delta t}$, and the cell face values, $a_{e}, a_{w}, a_{n}, a_{s}, a_{a}$ and $a_{b}$ can be obtained using Harmonic Mean as following

$$
\begin{aligned}
& a_{e}=\frac{2}{\frac{1}{a_{E}}+\frac{1}{a_{C}}}=\frac{2}{\frac{1}{\left(\frac{k_{x} A_{x}}{\Delta x}\right)_{i+1, j, k}}+\frac{1}{\left(\frac{k_{x} A_{x}}{\Delta x}\right)_{i, j, k}}} \\
& a_{w}=\frac{2}{\frac{1}{a_{W}}+\frac{1}{a_{C}}}=\frac{2}{\frac{1}{\left(\frac{k_{x} A_{x}}{\Delta x}\right)_{i-1, j, k}}+\frac{1}{\left(\frac{k_{x} A_{x}}{\Delta x}\right)_{i, j, k}}} \\
& a_{n}=\frac{2}{\frac{1}{a_{N}}+\frac{1}{a_{C}}}=\frac{\frac{1}{\left(\frac{k_{y} A_{y}}{\Delta y}\right)_{i, j+1, k}}+\frac{1}{\left(\frac{k_{y} A_{y}}{\Delta y}\right)_{i, j, k}}}{2} \\
& a_{s}=\frac{2}{\frac{1}{a_{S}}+\frac{1}{a_{C}}}=\frac{\frac{1}{\left(\frac{k_{y} A_{y}}{\Delta y}\right)_{i, j-1, k}}+\frac{1}{\left(\frac{k_{y} A_{y}}{\Delta y}\right)_{i, j, k}}}{2} \\
& a_{b}=\frac{2}{\frac{1}{a_{S}}+\frac{1}{a_{C}}}=\frac{\left.\frac{k_{z} A_{z}}{\Delta z}\right)_{i, j, k}}{\frac{1}{a_{A}}+\frac{1}{a_{C}}}
\end{aligned}
$$




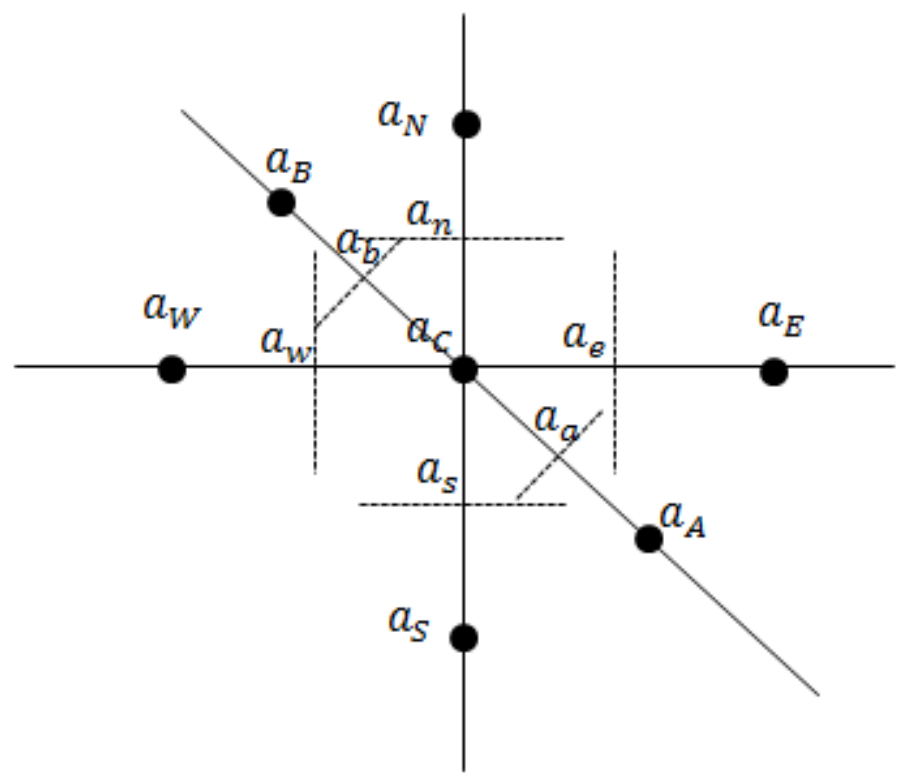

Figure 24 illustration of finite volume coefficients

\subsubsection{Compressible system}

For a compressible fluid flow and assuming single phase flow, $s=1$, Equation 36 can be simplified as,

$$
\frac{\partial}{\partial x}\left(\frac{k_{x} A_{x}}{\mu B} \frac{\partial \Phi}{\partial x}\right) \Delta x+\frac{\partial}{\partial y}\left(\frac{k_{y} A_{y}}{\mu B} \frac{\partial \Phi}{\partial y}\right) \Delta y+\frac{\partial}{\partial z}\left(\frac{k_{z} A_{z}}{\mu B} \frac{\partial \Phi}{\partial z}\right) \Delta z+q=v_{b} \frac{\partial}{\partial t}\left(\frac{\emptyset}{B}\right)
$$

Where

$$
\begin{aligned}
& \frac{\partial \Phi}{\partial x}=\frac{\partial \mathrm{P}}{\partial x}-\gamma_{g} \frac{\partial \mathrm{Z}}{\partial x} \\
& \frac{\partial \Phi}{\partial y}=\frac{\partial \mathrm{P}}{\partial y}-\gamma_{g} \frac{\partial \mathrm{Z}}{\partial y} \\
& \frac{\partial \Phi}{\partial z}=\frac{\partial \mathrm{P}}{\partial z}-\gamma_{g} \frac{\partial \mathrm{Z}}{\partial z}
\end{aligned}
$$

Substituting the corresponding terms in the governing Equation 41 as

$$
\begin{aligned}
\frac{\partial}{\partial x}\left(\frac { k _ { x } A _ { x } } { \mu B } \left(\frac{\partial \mathrm{P}}{\partial x}\right.\right. & \left.\left.-\gamma_{g} \frac{\partial \mathrm{Z}}{\partial x}\right)\right) \Delta x+\frac{\partial}{\partial y}\left(\frac{k_{y} A_{y}}{\mu B}\left(\frac{\partial \mathrm{P}}{\partial y}-\gamma_{g} \frac{\partial \mathrm{Z}}{\partial y}\right)\right) \Delta y+\frac{\partial}{\partial z}\left(\frac{k_{z} A_{z}}{\mu B}\left(\frac{\partial \mathrm{P}}{\partial z}-\gamma_{g} \frac{\partial \mathrm{Z}}{\partial z}\right)\right) \Delta z+q \\
& =v_{b} \frac{\partial}{\partial t}\left(\frac{\emptyset}{B}\right)
\end{aligned}
$$


Neglecting the gravity effect, the governing equation for compressible flow can be solved using finite difference approach in Cartesian coordinates as follow:

$$
\begin{aligned}
{\left[\left(\frac{k_{x} A_{x}}{\mu B \Delta x}\right)_{i+1 / 2, j, k}\left(p_{i+1, j, k}-p_{i, j, k}\right)-\left(\frac{k_{x} A_{x}}{\mu B \Delta x}\right)_{i-1 / 2, j, k}\left(p_{i, j, k}-p_{i-1, j, k}\right)\right] } & {\left[\left(\frac{k_{y} A_{y}}{\mu B \Delta y}\right)_{i, j+1 / 2, k}\left(p_{i, j+1, k}-p_{i, j, k}\right)-\left(\frac{k_{y} A_{y}}{\mu B \Delta y}\right)_{i, j-1 / 2^{, k}}\left(p_{i, j, k}-p_{i, j-1, k}\right)\right] } \\
+ & {\left[\left(\frac{k_{z} A_{z}}{\mu B \Delta z}\right)_{i, j, k+1 / 2}\left(p_{i, j, k+1}-p_{i, j, k}\right)-\left(\frac{k_{z} A_{z}}{\mu B \Delta z}\right)_{i, j, k-1 / 2}\left(p_{i, j, k}-p_{i, j, k-1}\right)\right]+q_{i, j, k} } \\
= & \left(v_{b}\right)_{i, j, k} \frac{\partial}{\partial t}\left(\frac{\emptyset}{B}\right)
\end{aligned}
$$

Considering the right side of the equation:

$$
\left(v_{b}\right)_{i, j, k} \frac{\partial}{\partial t}\left(\frac{\emptyset}{B}\right)=\frac{\left(v_{b}\right)_{i, j, k}}{\Delta t}\left(\frac{\emptyset_{i, j, k}^{n+1}}{B_{i, j, k}^{n+1}}-\frac{\emptyset_{i, j, k}^{n}}{B_{i, j, k}^{n}}\right)
$$

Where the rock compressibility is employed

$$
\emptyset_{i, j, k}^{n+1}=\emptyset_{i, j, k}^{n}\left(1+c_{i, j, k}\left(p_{i, j, k}^{n+1}-p_{i, j, k}^{n}\right)\right)
$$

We can have:

$$
\begin{aligned}
\left(v_{b}\right)_{i, j, k} & \frac{\partial}{\partial t}\left(\frac{\emptyset}{B}\right)=\frac{\left(v_{b}\right)_{i, j, k}}{\Delta t} \emptyset_{i, j, k}^{n}\left(\frac{1+c_{i, j, k}\left(p_{i, j, k}^{n+1}-p_{i, j, k}^{n}\right)}{B_{i, j, k}^{n+1}}-\frac{1}{B_{i, j, k}^{n}}\right) \\
\left(v_{b}\right)_{i, j, k} \frac{\partial}{\partial t}\left(\frac{\emptyset}{B}\right) & =\frac{\left(v_{b}\right)_{i, j, k}}{\Delta t}\left(\frac{\emptyset_{i, j, k}^{n} c_{i, j, k}}{B_{i, j, k}^{n+1}}\left(p_{i, j, k}^{n+1}-p_{i, j, k}^{n}\right)+\frac{\emptyset_{i, j, k}^{n}}{B_{i, j, k}^{n}}\left(\frac{B_{i, j, k}^{n}}{B_{i, j, k}^{n+1}}-1\right)\right) \\
= & \frac{\left(v_{b}\right)_{i, j, k}}{\Delta t}\left(\frac{\emptyset_{i, j, k}^{n} c_{i, j, k}}{B_{i, j, k}^{n+1}}+\frac{\frac{\emptyset_{i, j, k}^{n}}{B_{i, j, k}^{n}}\left(\frac{B_{i, j, k}^{n}}{B_{i, j, k}^{n+1}}-1\right)}{\left(p_{i, j, k}^{n+1}-p_{i, j, k}^{n}\right)}\right)\left(p_{i, j, k}^{n+1}-p_{i, j, k}^{n}\right) \\
= & \Gamma_{i, j, k}^{n+1}\left(p_{i, j, k}^{n+1}-p_{i, j, k}^{n}\right)
\end{aligned}
$$

Where $\square$ is defined as: 


$$
\Gamma_{i, j, k}^{n+1}=\frac{\left(v_{b}\right)_{i, j, k}}{\Delta t}\left(\frac{\emptyset_{i, j, k}^{n} c_{i, j, k}}{B_{i, j, k}^{n+1}}+\frac{\frac{\emptyset_{i, j, k}^{n}}{B_{i, j, k}^{n}}\left(\frac{B_{i, j, k}^{n}}{B_{i, j, k}^{n+1}}-1\right)}{\left(p_{i, j, k}^{n+1}-p_{i, j, k}^{n}\right)}\right)
$$

Then governing equation can be solved using central difference approximation in space and implicit method in time becomes

$$
\begin{aligned}
{\left[\left(\frac{k_{x} A_{x}}{\mu B \Delta x}\right)_{i+1 / 2, j, k}\left(p_{i+1, j, k}^{n+1}-p_{i, j, k}^{n+1}\right)-\left(\frac{k_{x} A_{x}}{\mu B \Delta x}\right)_{i-1 / 2, j, k}\left(p_{i, j, k}^{n+1}-p_{i-1, j, k}^{n+1}\right)\right] } \\
+\left[\left(\frac{k_{y} A_{y}}{\mu B \Delta y}\right)_{i, j+1 / 2, k}\left(p_{i, j+1, k}^{n+1}-p_{i, j, k}^{n+1}\right)-\left(\frac{k_{y} A_{y}}{\mu B \Delta y}\right)_{i, j-1 / 2, k}\left(p_{i, j, k}^{n+1}-p_{i, j-1, k}^{n+1}\right)\right] \\
+\left[\left(\frac{k_{z} A_{z}}{\mu B \Delta z}\right)_{i, j, k+1 / 2}\left(p_{i, j, k+1}^{n+1}-p_{i, j, k}^{n+1}\right)-\left(\frac{k_{z} A_{z}}{\mu B \Delta z}\right)_{i, j, k-1 / 2}\left(p_{i, j, k}^{n+1}-p_{i, j, k-1}^{n+1}\right)\right]+q_{i, j, k} \\
=\Gamma_{i, j, k}^{n+1}\left(p_{i, j, k}^{n+1}-p_{i, j, k}^{n}\right)
\end{aligned}
$$

Use explicit transmissibility we have:

$$
\begin{aligned}
& a_{e}=\frac{2}{\frac{1}{a_{E}}+\frac{1}{a_{C}}}=\frac{2}{\frac{1}{\left(\frac{k_{x} A_{x}}{\mu B \Delta x}\right)_{i+1, j, k}^{n}}+\frac{1}{\left(\frac{k_{x} A_{x}}{\mu B \Delta x}\right)_{i, j, k}^{n}}} \\
& a_{w}=\frac{2}{\frac{1}{a_{W}}+\frac{1}{a_{C}}}=\frac{2}{\frac{1}{\left(\frac{k_{x} A_{x}}{\mu B \Delta x}\right)_{i-1, j, k}^{n}}+\frac{1}{\left(\frac{k_{x} A_{x}}{\mu B \Delta x}\right)_{i, j, k}^{n}}} \\
& a_{n}=\frac{2}{\frac{1}{a_{N}}+\frac{1}{a_{C}}}=\frac{2}{\frac{1}{\left(\frac{k_{y} A_{y}}{\mu B \Delta y}\right)_{i, j+1, k}^{n}}+\frac{1}{\left(\frac{k_{y} A_{y}}{\mu B \Delta y}\right)_{i, j, k}^{n}}} \\
& a_{s}=\frac{2}{\frac{1}{a_{S}}+\frac{1}{a_{C}}}=\frac{1}{\frac{1}{\left(\frac{k_{y} A_{y}}{\mu B \Delta y}\right)_{i, j-1, k}^{n}}+\frac{1}{\left(\frac{k_{y} A_{y}}{\mu B \Delta y}\right)_{i, j, k}^{n}}}
\end{aligned}
$$




$$
\begin{gathered}
a_{a}=\frac{2}{\frac{1}{a_{A}}+\frac{1}{a_{C}}}=\frac{2}{\frac{1}{\left(\frac{k_{z} A_{z}}{\mu B \Delta z}\right)_{i, j, k+1}^{n}}+\frac{1}{\left(\frac{k_{z} A_{z}}{\mu B \Delta}\right)_{i, j, k}^{n}}} \\
a_{b}=\frac{2}{\frac{1}{a_{S}}+\frac{1}{a_{C}}}=\frac{2}{\frac{1}{\left(\frac{k_{z} A_{z}}{\mu B \Delta z}\right)_{i, j, k-1}^{n}}+\frac{1}{\left(\frac{k_{z} A_{z}}{\mu B \Delta z}\right)_{i, j, k}^{n}}} \\
a_{c}=\Gamma_{i, j, k}^{n+1}
\end{gathered}
$$

Since in gas reservoir, flow rate is much higher than oil reservoir, non-Darcy flow is not negligible, especially in near well region and hydraulic fractures. Forchheimer equation is used here to calculate apparent permeability.

$$
\frac{1}{k_{\text {app }}}=\frac{1}{k}+3.238 * 10^{-8} \frac{\rho \beta \nu}{\mu}
$$

Where $\beta$ is Non-Darcy factor or Forchheimer factor. It is recommended by Lee and Wattenbarger to use the following correlation to calculate Non-Darcy factor (M. Armenta, 2003),

$$
\beta=1.88 * 10^{10} k^{-1.47} \emptyset^{-0.53}
$$

where $k$ is permeability and $\emptyset$ is porosity.

$$
\begin{gathered}
a_{e} p_{i+1, j, k}^{n+1}+a_{n} p_{i, j+1, k}^{n+1}+a_{a} p_{i, j, k+1}^{n+1}-\left(a_{e}+a_{w}+a_{n}+a_{s}+a_{a}+a_{b}+a_{c}\right) p_{i, j, k}^{n+1} \\
+a_{w} p_{i-1, j, k}^{n+1}+a_{s} p_{i, j-1, k}^{n+1}+a_{b} p_{i, j, k-1}^{n+1}=-a_{c} p_{i, j, k}^{n}-q_{i, j, k}^{n+1}
\end{gathered}
$$

\subsubsection{Model Validation}

To verify the simulator describing the compressible fluid flow through the reservoir, results of the numerical simulator are compared with analytical solution of volumetric gas reservoir material balance.

The material balance equation for a gas reservoir can be written as:

$$
G\left(B_{g}-B_{g i}\right)+G B_{g i} \frac{\left(c_{w} S_{w i}+c_{f}\right)}{1-S_{w i}} \Delta \bar{p}+W_{e}=G_{g} B_{g}+B_{w} W_{p}
$$

Where $\mathrm{G}$ is original gas in place, $G_{g}$ is cumulative gas production, $B_{g i}$ is initial gas formation factor, $B_{w}$ is water formation factor, $W_{p}$ is cumulative water production, $W_{e}$ is water flux from 
aquifer or injection well, $c_{w}$ and $c_{f}$ are water and rock compressibility respectively. Water and rock compressibility is negligible in compare to gas compressibility, also considering no water influx or injection, the above equation can be simplified to:

$$
G\left(B_{g}-B_{g i}\right)=G_{g} B_{g}
$$

Using compressibility equation of state for real gases:

$$
P V=n z R T
$$

Gas formation volume factor $B_{g}$ can be expressed in term of pressure, $P$, gas compressibility, $z$ and temperature, $T$,

$$
B_{g}=\frac{p_{s c} z T}{T_{s c} p}
$$

Substitute the Equation 48 into the material balance Equation 46

$$
G\left(\frac{p_{s c} z T}{T_{s c} p}-\frac{p_{s c} z T_{i}}{T_{s c} p_{i}}\right)=G_{g} \frac{p_{s c} z T}{T_{s c} p}
$$

Fluid flow in reservoir can be assumed as an isothermal process, then,

$$
\frac{p}{Z}=-\frac{p_{i}}{z_{i}} \frac{G_{g}}{G}+\frac{p_{i}}{z_{i}}
$$

Where $p_{i}$ and $z_{i}$ is pressure and gas compressibility at initial condition. Equation 49 therefore describes a linear relationship between $\frac{p}{z}$ and $\frac{G_{g}}{G}$ with slope of $-\frac{p_{i}}{z_{i}}$ and intercept of $\frac{p_{i}}{z_{i}}$ (Craft, B. C. and M. F. Hawkins , 1990).

We applied our numerical solution to simulate gas production from a reservoir with initial parameters defined in Table 3. The model parameters and gas properties is listed in the following tables. The simulation results is plotted against analytical solution by comparing the $\frac{p}{z}$ vs. $\frac{G_{g}}{G}$, where $G$ is calculated using volumetric method. The results of reservoir simulation match the analytical solution perfectly. 
Table 3 Model parameters used for validation

\begin{tabular}{lr}
\hline Initial reservoir pressure(psi) & 4000.00 \\
Reservoir Size(cf) & $250 * 250 * 10$ \\
Bottom hole pressure(psi) & 2000.00 \\
Porosity (\%) & 1.00 \\
Permeability(mD) & 1.00 \\
\hline
\end{tabular}

Table 4 Gas properties used for simulation

\begin{tabular}{rlr}
\hline$p$ (psia) & \multicolumn{1}{l}{$z$} & $\mu(c p)$ \\
\hline 1.00 & 1.00 & 0.01 \\
400.00 & 0.93 & 0.01 \\
800.00 & 0.85 & 0.01 \\
1200.00 & 0.79 & 0.01 \\
1600.00 & 0.74 & 0.02 \\
2000.00 & 0.71 & 0.02 \\
2400.00 & 0.71 & 0.02 \\
2800.00 & 0.72 & 0.02 \\
3200.00 & 0.75 & 0.03 \\
3600.00 & 0.79 & 0.03 \\
4000.00 & 0.84 & 0.03 \\
4400.00 & 0.88 & 0.03 \\
4800.00 & 0.93 & 0.04 \\
5000.00 & 0.95 & 0.04 \\
\hline
\end{tabular}




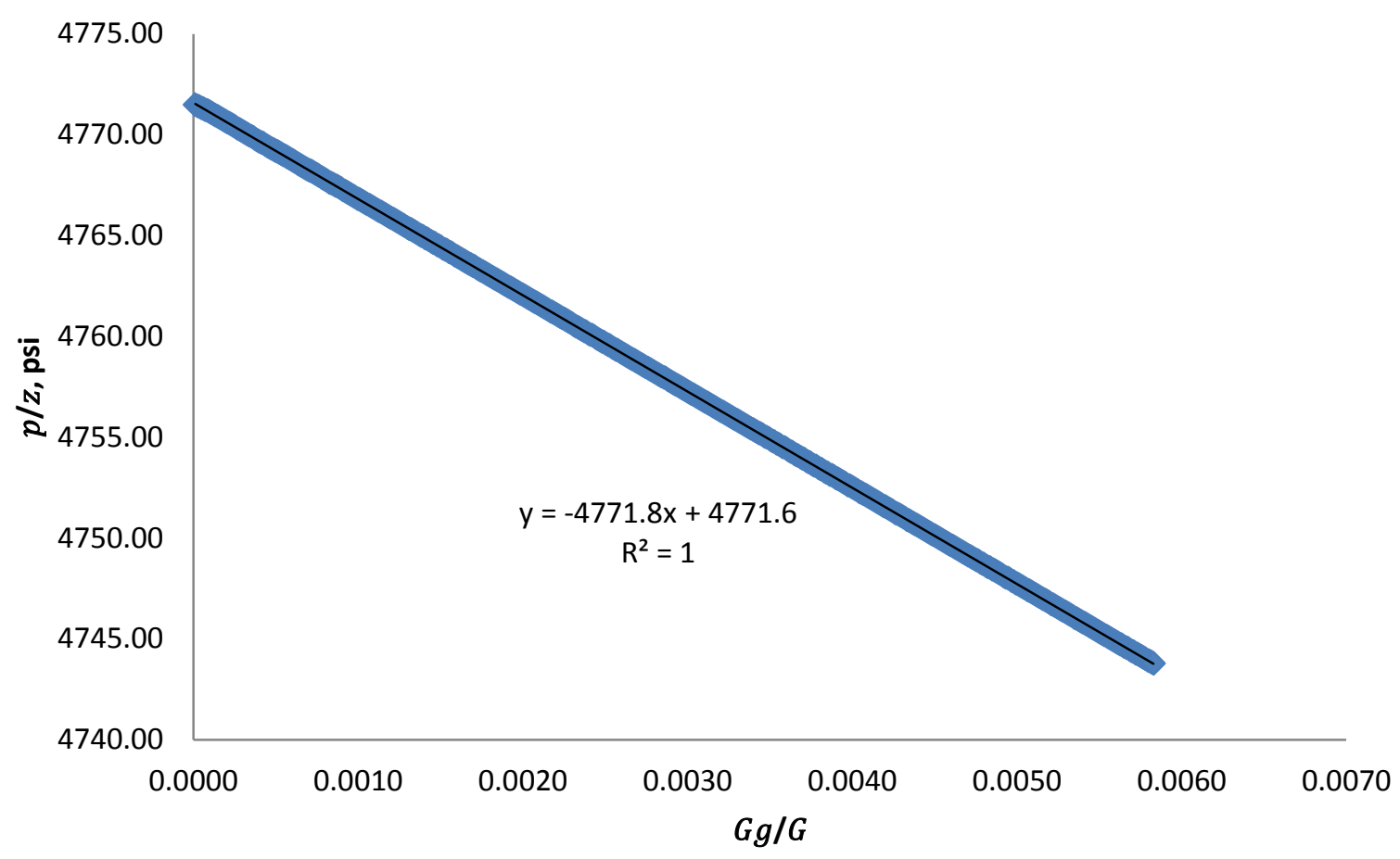

Figure 25 Material balance of a gas reservoir. the results show an agreement with the theory.

\section{5: Fracture performance evaluation during production}

The purpose of hydraulic fracturing is to create a highly conductive flow path connecting reservoir and wellbore which can economically increase hydrocarbon production. Quantifying the effectiveness and efficiency of hydraulic fracturing stimulation using direct methods are tedious if not impossible. Therefore, it is common to use fracture conductivity and productivity index to evaluate the hydraulic fracturing performance.

In reality, all fractures are finite conductivity fractures. The conductivity of a fracture is a good indicator of how easy it allows fluid to flow through it. Fracture conductivity is defined as the product of fracture width and proppant pack permeability. Fracture width and fluid type have great influence on fracture conductivity, but the most important factor that influence conductivity is proppant (Palisch T,2007, CE C.1973 ). According to Palisch T, et al (Palisch T,2007), there are three methods to determine fracture conductivity which are conductivity testing in a laboratory, well testing and field result. The first one is the most common method, and the test 
procedure can be found in many literatures (Palisch T,2007, CE C.1973 ). However, literatures and studies (Pearson C.,2001) show that fracture conductivity overestimates the importance of proppant pack permeability. So, dimensionless fracture conductivity is more common nowadays. The dimensionless fracture conductivity is defined as $\mathrm{C}_{\mathrm{fd}}=\mathrm{k}_{\mathrm{f}} \mathrm{w}_{\mathrm{f}} / \mathrm{kx}_{\mathrm{f}}$. Dimensionless conductivity can reflect the effective performance of hydraulic fractures more accurately since it considers fracture length and formation permeability. Researches show that when dimensionless conductivity exceeds a certain value (10, before correction), formation permeability limits the overall flow resistivity more than proppant permeability that means further increase in proppant permeability will not impact the flow. Conductivity is a good indication to quantify the performance of proppant pack if homogeneous concentration of proppant pack is assumed; otherwise, conductivity is unable to evaluate the performance of hydraulic fracture.

Well productivity index can also be used to evaluate the effectiveness of hydraulic fracturing treatment. Productivity index is defined as a ratio of well production rate to pressure difference between reservoir and well. Usually, dimensionless productivity (Romero D, 2003) index is defined as

$$
\frac{q}{p-p_{w f}}=\frac{k h}{\alpha_{r} B \mu} J_{D}
$$

Where $\alpha_{\mathrm{r}}$ is unit transfer factor, $\mathrm{h}$ is formation thickness, $\mathrm{k}$ is formation permeability, $\mathrm{B}$ is formation factor, $\mu$ is fluid viscosity

For a gas reservoir, the productivity index is defined as:

$$
J_{g}=\frac{q \mu z}{\bar{p}_{r}^{2}-p_{w f}^{2}}
$$


Where $\mathrm{J}_{\mathrm{g}}$ is the productivity index of gas reservoir, $\mathrm{z}$ is the gas compressibility factor, $\mu$ is the gas viscosity, $\mathrm{q}$ is the gas flow rate in standard conditions, $\overline{\mathrm{p}}_{\mathrm{r}}$ is the reservoir average pressure, and $\mathrm{p}_{\mathrm{wf}}$ is the flowing bottom hole pressure.

Productivity index depends on both the geometry of hydraulic fractures and fracture conductivity, (McGuire W J,1991, Romero D,2003, Diyashev I,2006),. Consequently, productivity index can reflect the performance of hydraulic fractures more comprehensively.

However, both fracture conductivity and productivity index usually assume homogeneous and isotropic formation condition, regular fracture geometry and uniform proppant distribution in the fracture. To investigate the influence of different proppant distribution pattern in fracture on hydraulic fracturing treatment effectiveness, numerical simulation of fluid production rate from fractured formation is desired. For each fractured formation with certain proppant distribution pattern, Fracture-Production model can simulate the fluid flow rate and pressure. Then this flow rate and pressure can be used to calculate productivity, which is a good indication of hydraulic fracturing performance.

\section{CHAPTER: 3: SENSITIVITY ANALYSIS AND OPTIMIZATION}

In this chapter, using previously developed simulators for proppant transport and production performance analysis in chapter 2 will be used to perform a linear screening analysis to determine the most important factors impacting our simulation results "heavy-hitters" and if necessary perform a comprehensive analysis to understand the non-linear behavior of the "heavy-hitters" and finally generate a response surfaces.. The effects of proppant settling and Non-Darcy flow effect will be discussed first. Then, single variable sensitivity analysis is implemented on proppant size, fracture width and fracturing fluid viscosity. The effects of all the main variables affecting hydraulic fracturing performance are studied using Placket Burman experiment design. Multi-proppant size combination treatment is optimized using the same simulator.

\section{1: Simulation of base cases}

\subsubsection{Base case}




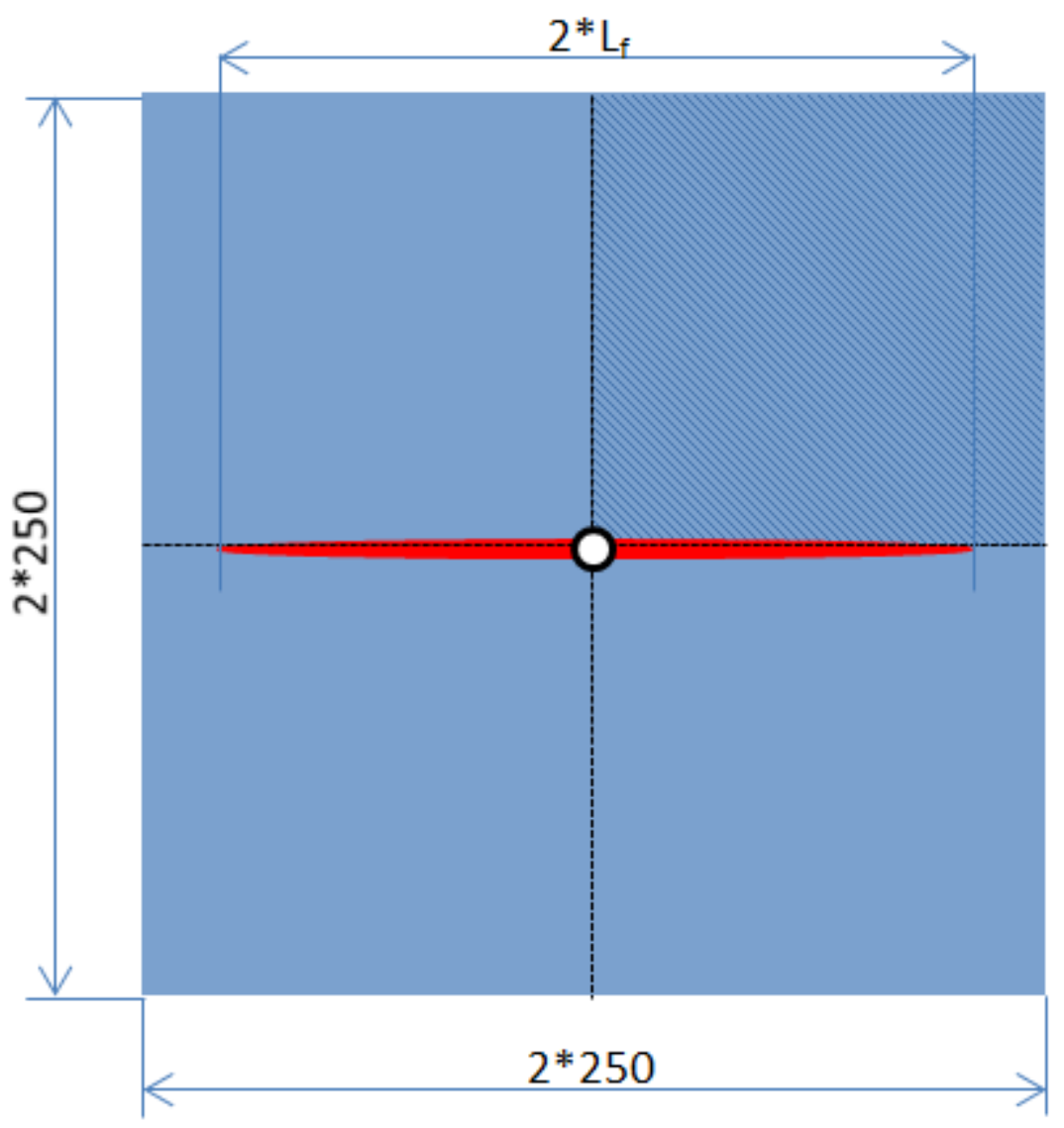

Figure 26 Overlook of the gas reservoir model for simulation 
The reservoir model used here is a square gas reservoir. The size of this reservoir is $500 * 500 * 10$ $\mathrm{cf}$ as is shown in the figure. The production well locates at the center of the reservoir. Location of the hydraulic fracture with half-length of Lf is shown in the figure too. Since homogeneous and isotropic reservoir properties are assumed simulation will be performed on quarter five spot pattern as illustrated by shaded region in Figure 26.

The range of proppant size is very important. Typical proppant sizes are generally between 8 and 140 mesh (106 $\mu \mathrm{m}-2.36 \mu \mathrm{m})$, for example 16-30 mesh $(600 \mu \mathrm{m}-1180 \mu \mathrm{m}), 20-40$ mesh (420 $\mu \mathrm{m}-840 \mu \mathrm{m}), 30-50$ mesh $(300 \mu \mathrm{m}-600 \mu \mathrm{m}), 40-70$ mesh $(212 \mu \mathrm{m}-420 \mu \mathrm{m})$ or 70-140 mesh $(106 \mu \mathrm{m}-212 \mu \mathrm{m})$. When describing frac sand, the product is frequently referred to as simply the sieve cut, i.e. 20/40 sand. Here, for demonstration, proppant size of $0.2 \mathrm{~mm}$ is used. The matrix permeability is $100 \mathrm{nD}$.

If proppant settling during injection is not considered, the proppant will distribute uniformly in the hydraulic fracture. The permeability distribution is shown in the following Figure 27.

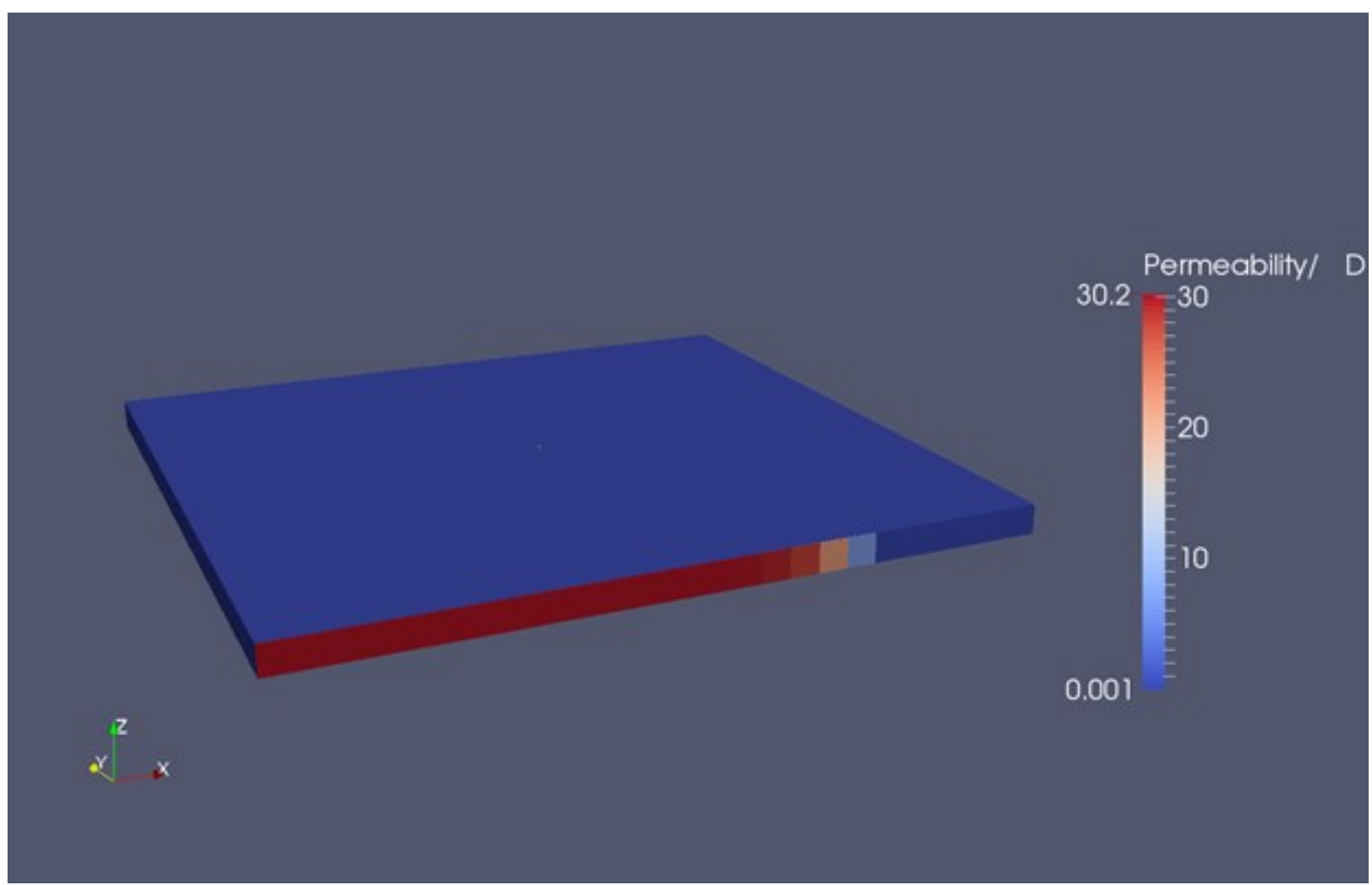

Figure 27 Permeability of reservoir and hydraulic fracture, considering non-settling of proppant, proppant is distributed uniformly in the hydraulic fracture 
And the pressure distribution after 2 days in the fracture and matrix are shown in Figure 28,



Figure 28 pressure field of reservoir and hydraulic fracture during production, considering non-settling of proppant 
If considering proppant settling in hydraulic fracture, proppant particles will settle down to the fracture bottom, causing heterogeneous proppant distribution in the hydraulic fracture as clearly illustrated in Figure 29.

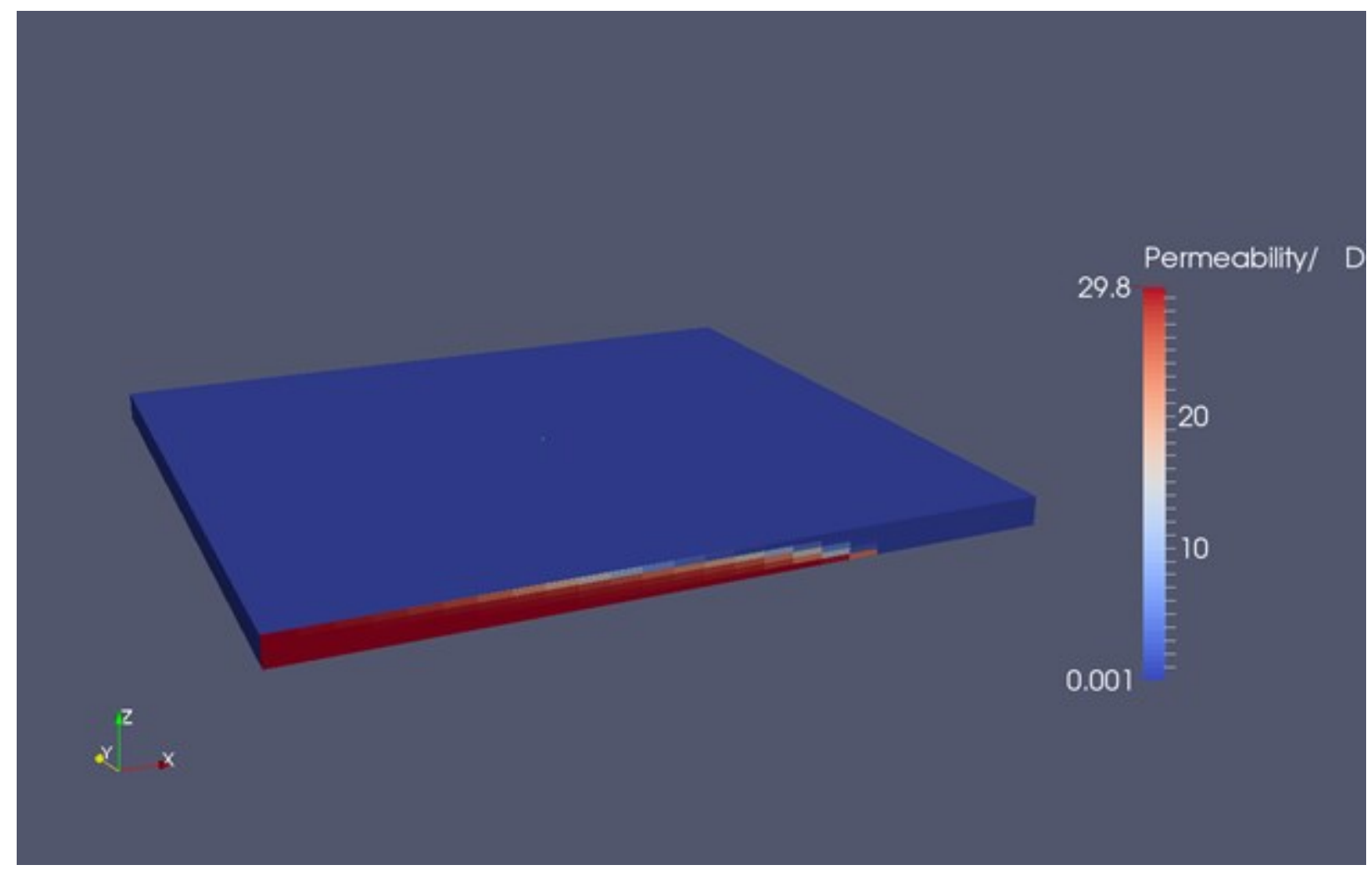

Figure 29 Permeability of reservoir and hydraulic fracture, considering settling of proppant, proppant is distributed nonuniformly in the hydraulic fracture 
Then pressure distribution after 2 days of gas production in matrix and fracture can be obtained, Figure 30.

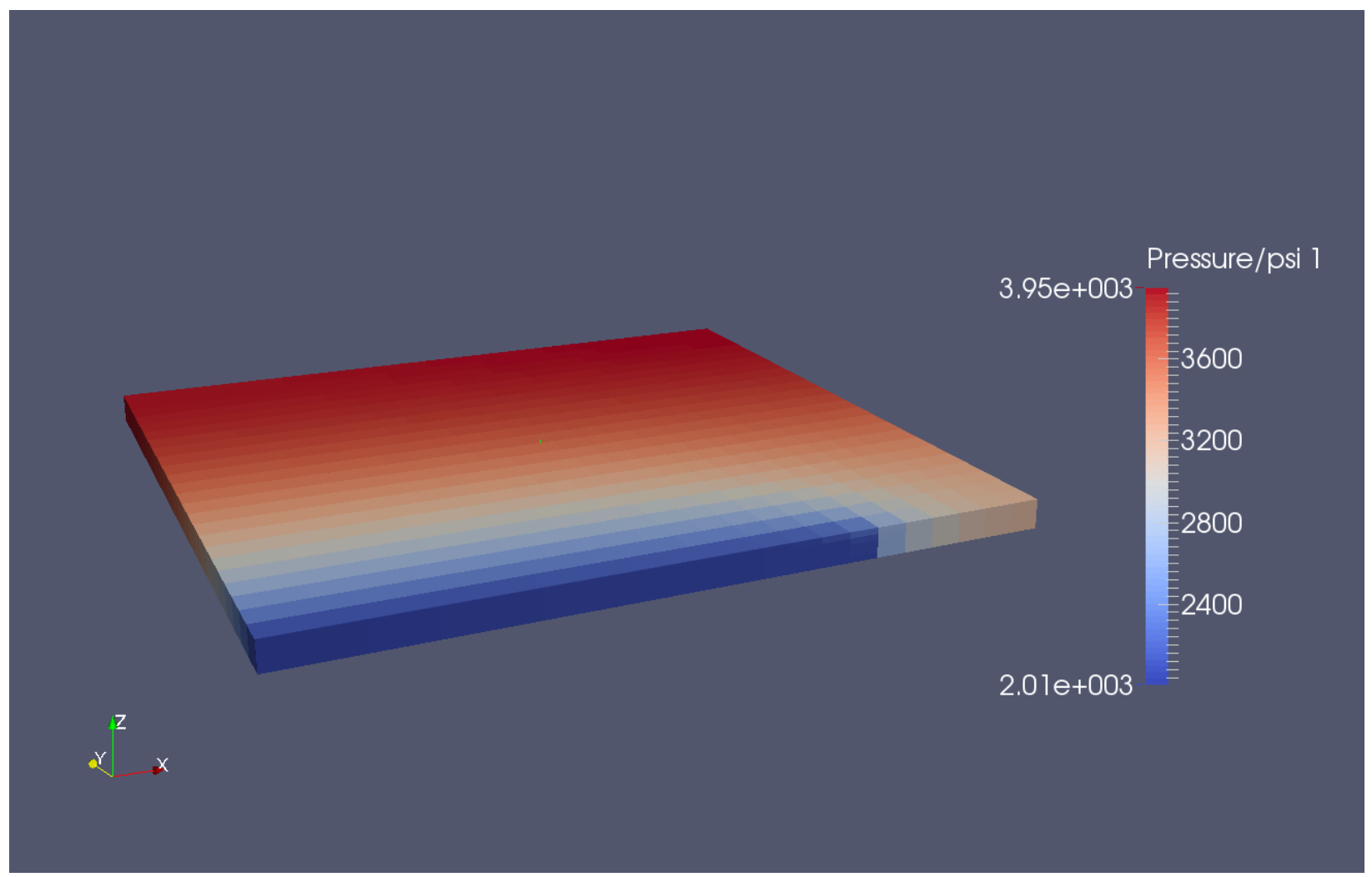

Figure 30 pressure field of reservoir and hydraulic fracture during production, considering settling of proppant 
Further discussion on the differences between models including proppant settling and ignoring proppant settling will be presented in the next section.

Non-Darcy effect is also an important parameter needs to be considered in simulation of gas production. This can be highly impacted by the ratio of apparent horizontal permeability to rock absolute permeability. Figure 31 illustrates this change from gas reservoir with properties presented in Table 3

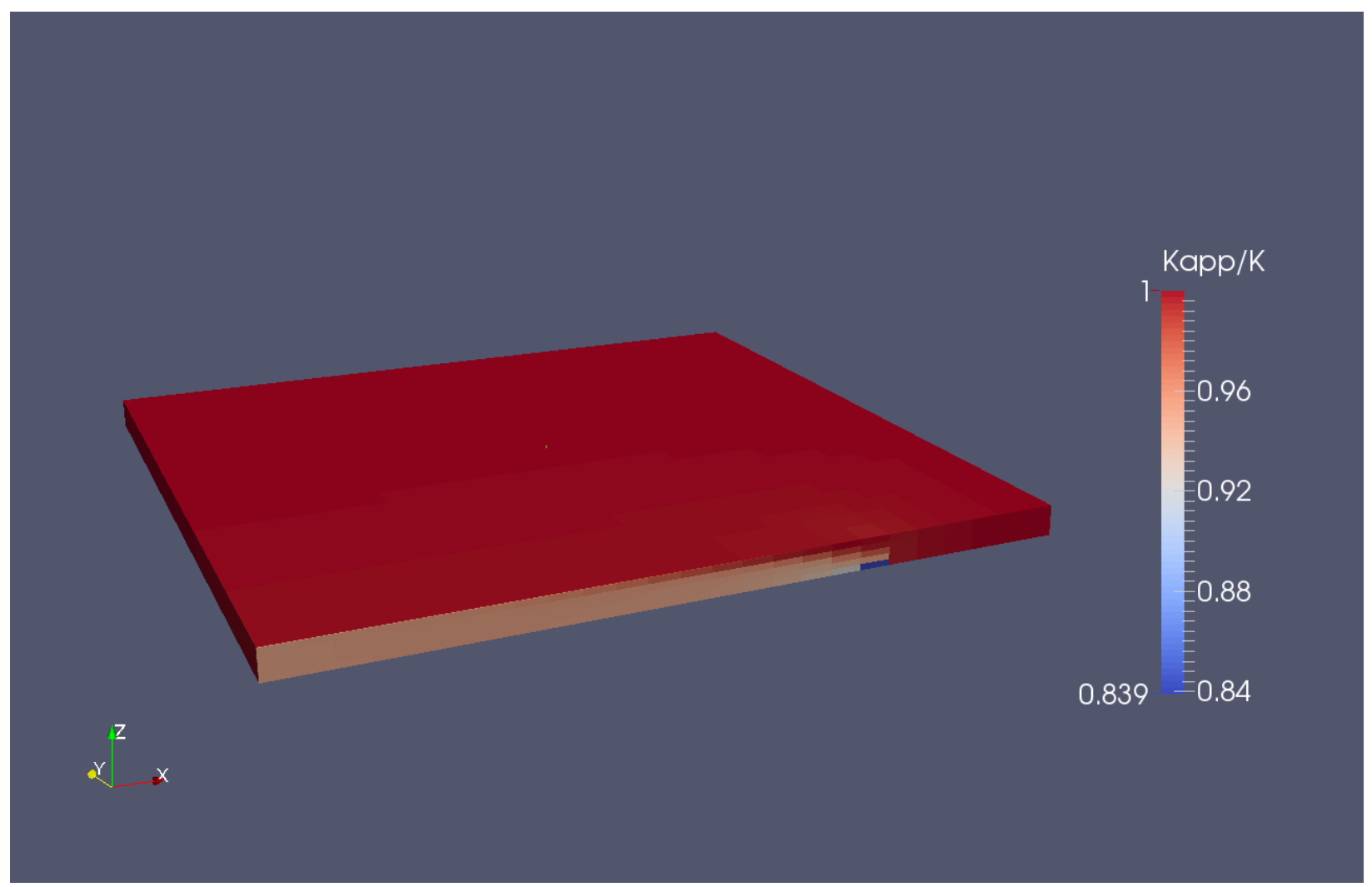

Figure 31 the ratio of apparent permeability over absolute permeability considering non-Darcy flow

Figure 31 clearly shows that most non-Darcy effect happens in the hydraulic fracture. Further discussion on non-Darcy effect in gas production is in the next section.

\subsubsection{Effect of proppant settling on gas transport in hydraulic fractures}

In this section, the result of simulations with and without considering proppant settling on dimensionless productivity index is compared and the effects on hydraulic fracturing performance is discussed. For the base case the proppant size equal to $0.6 \mathrm{~mm}$ is considered. Our simulation results show that ignoring the effect of proppant settling leads to more than $12 \%$ overestimation 
on dimensionless productivity index. This effect would be more pronounced using larger proppant sizes. As an example simulation results for $1.8 \mathrm{~mm}$ proppant size results in over $20 \%$ change in dimensionless productivity index. Thus, it is crucial to take into account of the effect proppant settling and proppant distribution performance analysis of hydraulic fractures. Figure 32depicts the difference between the estimation of dimensionless productivity index with and without proppant settling effects for wide range of reservoir matrix permeabilities.

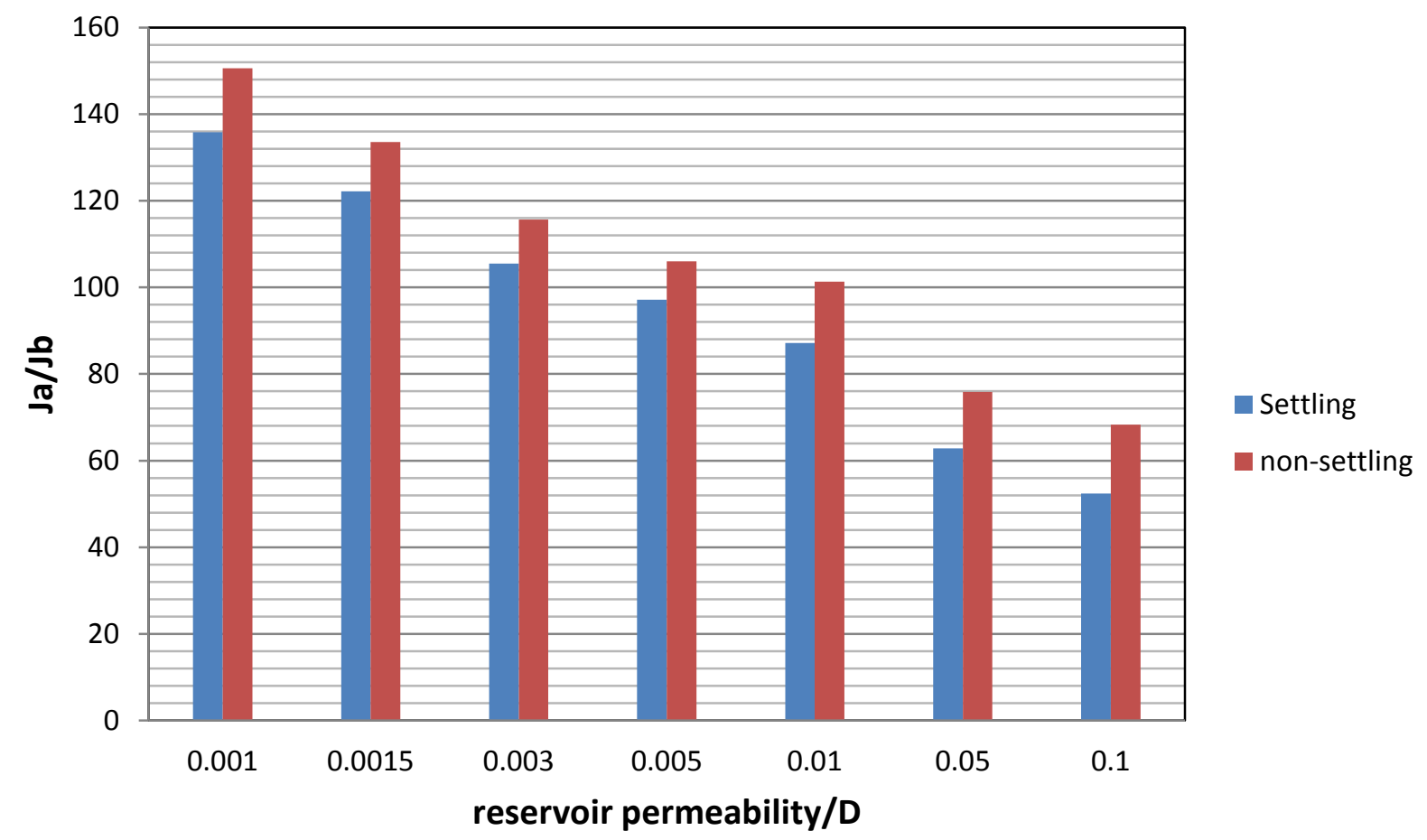

Figure 32 Influence of proppant settling on dimensionless productivity index, the proppant size is $0.6 \mathrm{~mm}$.

\subsubsection{Effect of Non-Darcy flow on reservoir performance}

During the production of gas reservoir, gas flow rate is very high especially in the near well region and hydraulic fracture. The gas flow rate in those areas can results in turbulence flow. Therefore, it is necessary to consider Non-Darcy effect on gas flow in hydraulic fractures and near wellbore area. To investigate the impact of Non-Darcy effect on hydraulic fracturing performance here we compare the simulation results with and without Non-Darcy effect on dimensionless productivity index. In this simulation, initial reservoir pressure is assumed to be $4000.0 \mathrm{psi}$, bottom hole pressure is $2000.0 \mathrm{psi}$, and the proppant size is $0.3 \mathrm{~mm}$. Simulation results are 
presented in Figure 33 that shows Non-Darcy effects leads to more than $9 \%$ reduction in dimensionless productivity index for wide range of reservoir matrix permeability.

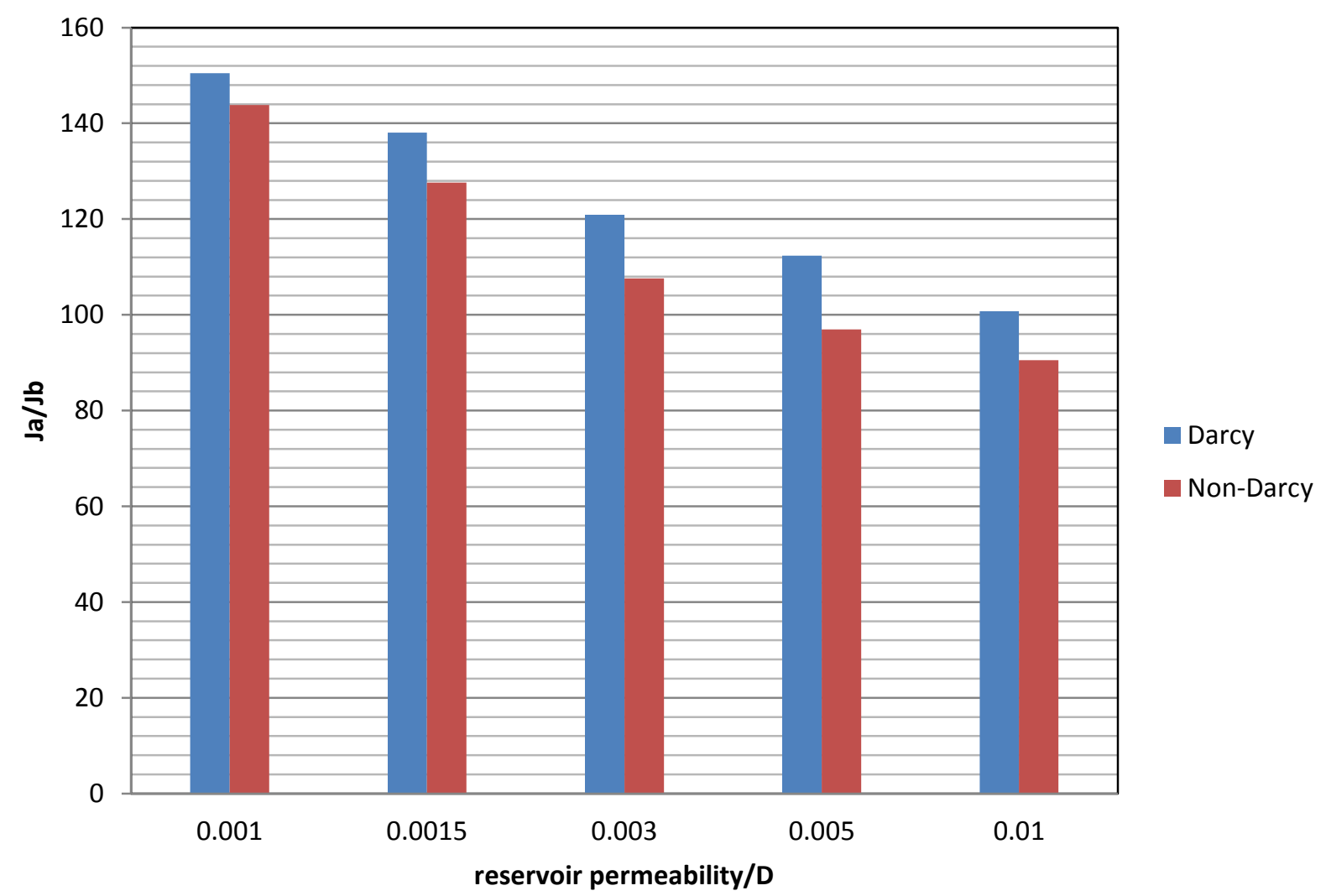

Figure 33 Influence of Non-Darcy flow on dimensionless productivity index, the proppant size is $0.6 \mathrm{~mm}$.

\subsubsection{Different proppant size injection effects on hydraulic fracturing performance}

Higher pressure gradient near the well bore causes largest gas flow rate in that area. To maintain this high flow rate multiple size of proppants are used for hydraulic fracturing to increase the fracture conductivity near the wellbore region. Usually, smaller size proppant is first injected to reach as close as fracture tip in the hydraulic fracture to maximize fracture area after flow back, and then larger size proppant is injected to build up in near wellbore area to create higher conductivity flow paths. In this research, two size of proppant combination is studied. For demonstration, combination of proppant of $0.2 \mathrm{~mm}$ and $0.6 \mathrm{~mm}$ is simulated. The $0.6 \mathrm{~mm}$ proppant takes $25 \%$ of the overall proppant volume. The absolute permeability distribution is shown in Figure 34 . 


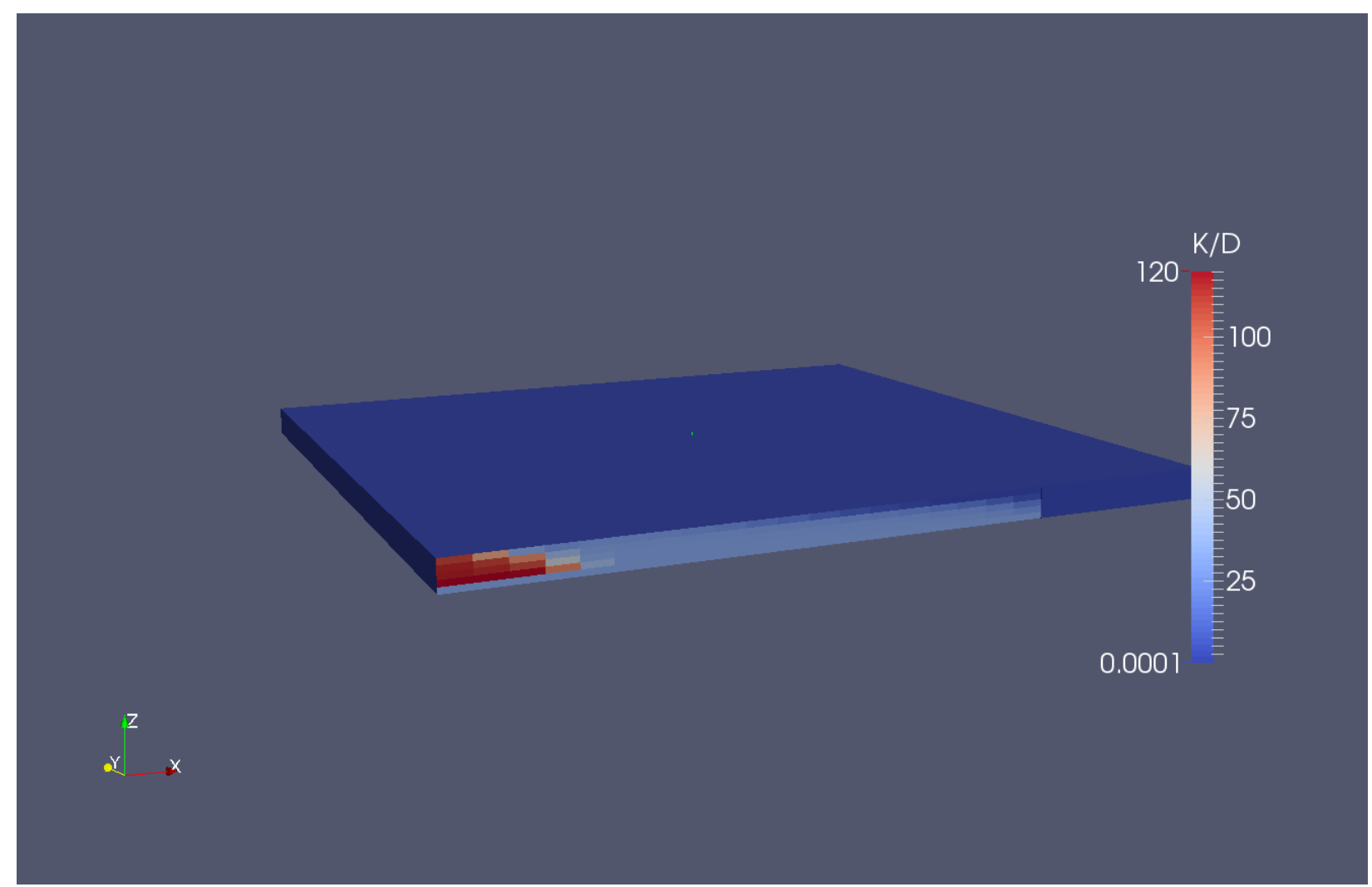

Figure 34 Permeability distribution of reservoir and hydraulic fracture of Two-proppant size $(0.2 \mathrm{~mm}$ and $0.6 \mathrm{~mm})$ combination 


\section{2: Single variable sensitivity analysis}

\subsubsection{Proppant size sensitivity analysis}

Proppant size has major influence on the settling velocity and proppant pack permeability. Larger proppant leads to larger fracture permeability which is beneficial; however, it will also cause higher settling velocity. Higher settling velocity means proppant will settle down much faster in the hydraulic fracture and builds up sand bank from the bottom of the fracture, instead of distributing uniformly. This will compromise effective fracture area and thus the performance of hydraulic fracture. The balance between increasing fracture permeability and decreasing fracture area is the key element of hydraulic fracturing optimization. Here for different reservoir permeability, the influence of proppant size on dimensionless productivity index is studied. Reservoir permeability range is from $1 \mathrm{mD}$ to $100 \mathrm{mD}$, and the proppant size range is $0.1 \mathrm{~mm}$ to $0.8 \mathrm{~mm}$. The ratio of productivity index after and before stimulation is used. Results show that for high permeability reservoir, the relation between proppant size and productivity index is simple, which is the larger the proppant, the better the performance. However, for low permeability reservoir, the relation is more complex. Along the increase of proppant size, productivity index will first increase and then decrease and become steady. This clearly shows that critical value exist for proppant size selection leading to maximum productivity index in low permeability reservoirs, such as shale gas. 


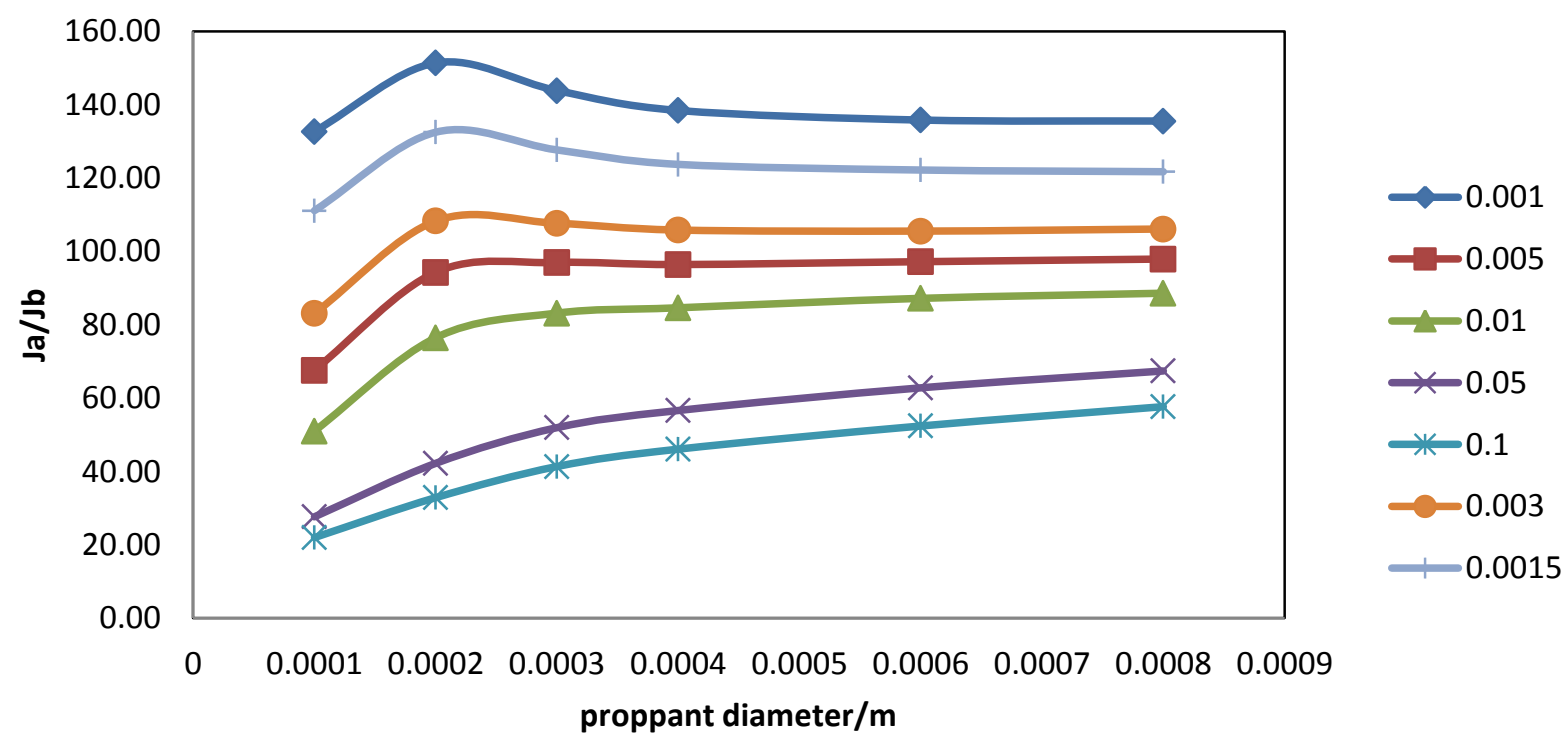

Figure 35 the effect of proppant size on dimensionless productivity for different permeability reservoir 


\subsubsection{Fracture width sensitivity analysis}

Fracture width during pumping can influence proppant settling velocity and fracture conductivity. Larger fracture width will cause higher proppant settling velocity (see Equation 14) as well as higher fracture conductivity. Here in this section, different fracture width in reservoirs with wide range of permeability is simulated and the comparison of the results show that impact of original fracture width is not significant, see Figure 36.

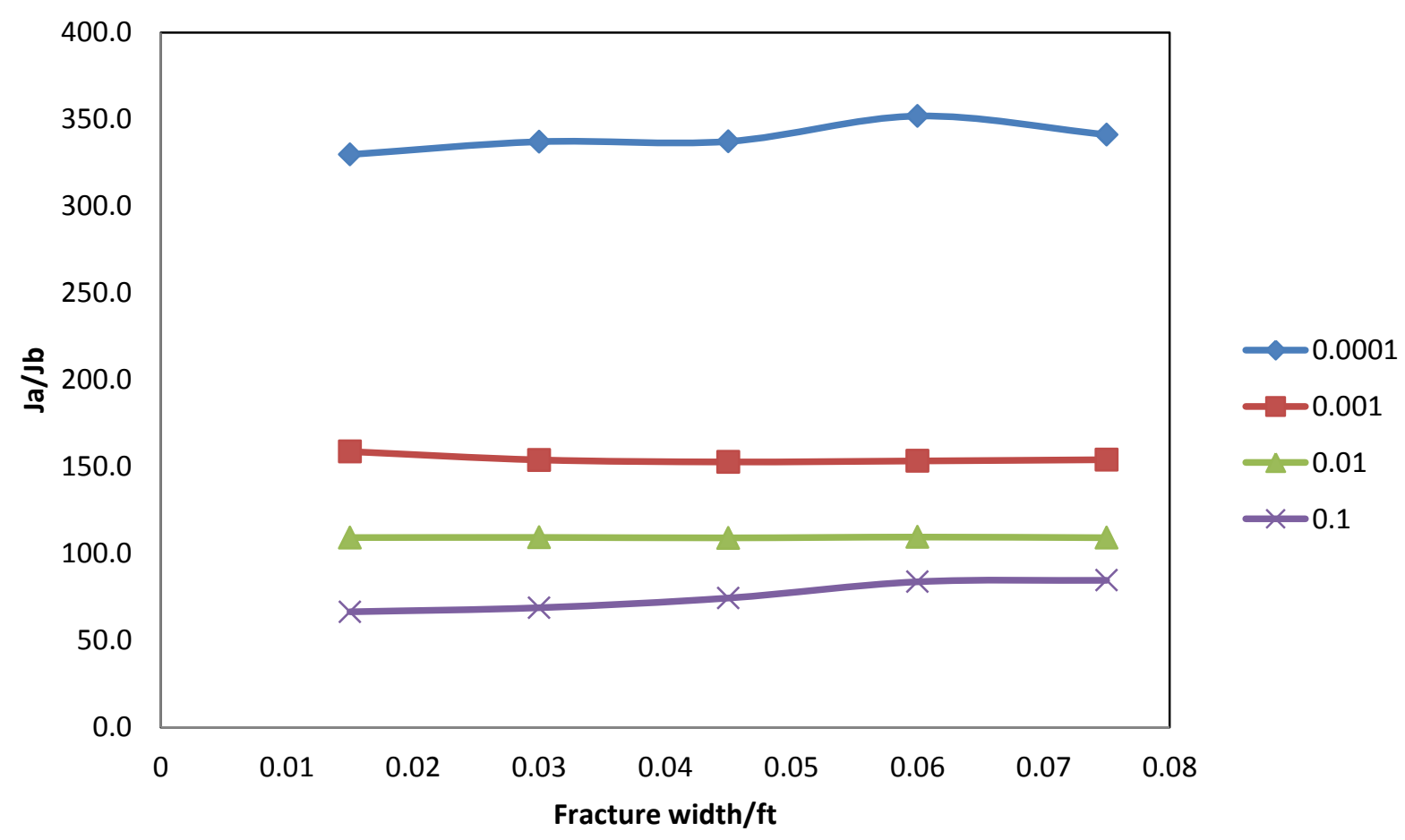

Figure 36 the effect of original fracture width on dimensionless productivity for different permeability reservoir 


\subsubsection{Fracturing fluid viscosity sensitivity analysis}

Our simulator can handle different frac fluid with different density and viscosities. Fracturing fluid is usually a mixture of water, proppant, acid, friction reducer and other chemicals that can be treated as non-Newtonian fluid. Eiler's equation introduces a correction on the viscosity of base fracturing fluid without proppant. Here, sensitivity analysis is made on the base Newtonian fluid with proppant size equal to $0.5 \mathrm{~mm}$. Simulation results show a minor increase of productivity along the increase of base fluid viscosity, Figure 37.

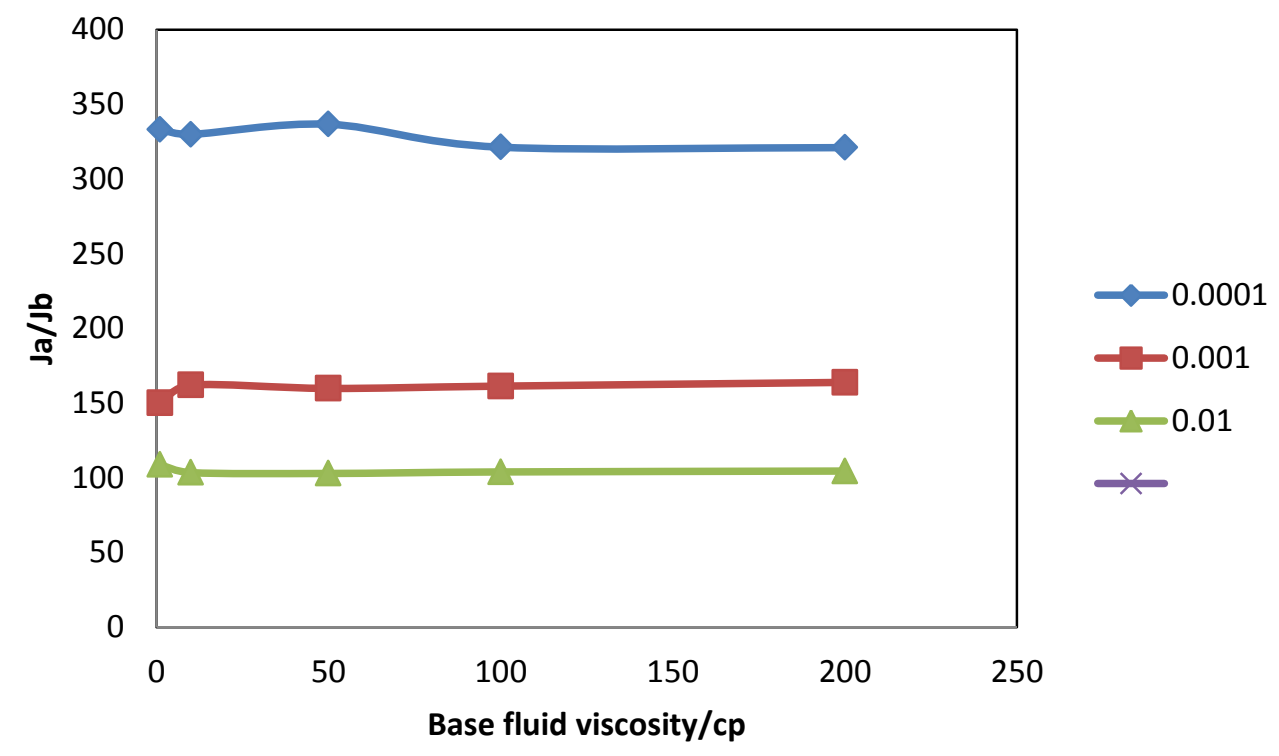

Figure 37 The effect of base fluid viscosity on dimensionless productivity for different permeability reservoir 


\subsubsection{Two size proppant combination optimization}

Multi size proppant combination can maintain relatively large fracture area as well as high fracture permeability in the near wellbore region. In this section, different proppant combinations, i.e., different volume portion and different proppant size combinations are simulated and their performance is compared with each other. The reservoir permeability is $0.1 \mathrm{mD}$ and the smaller proppant size is $0.2 \mathrm{~mm}$. A series of different larger proppant sizes and its volume portion are simulated. The results are shown in the following figure.

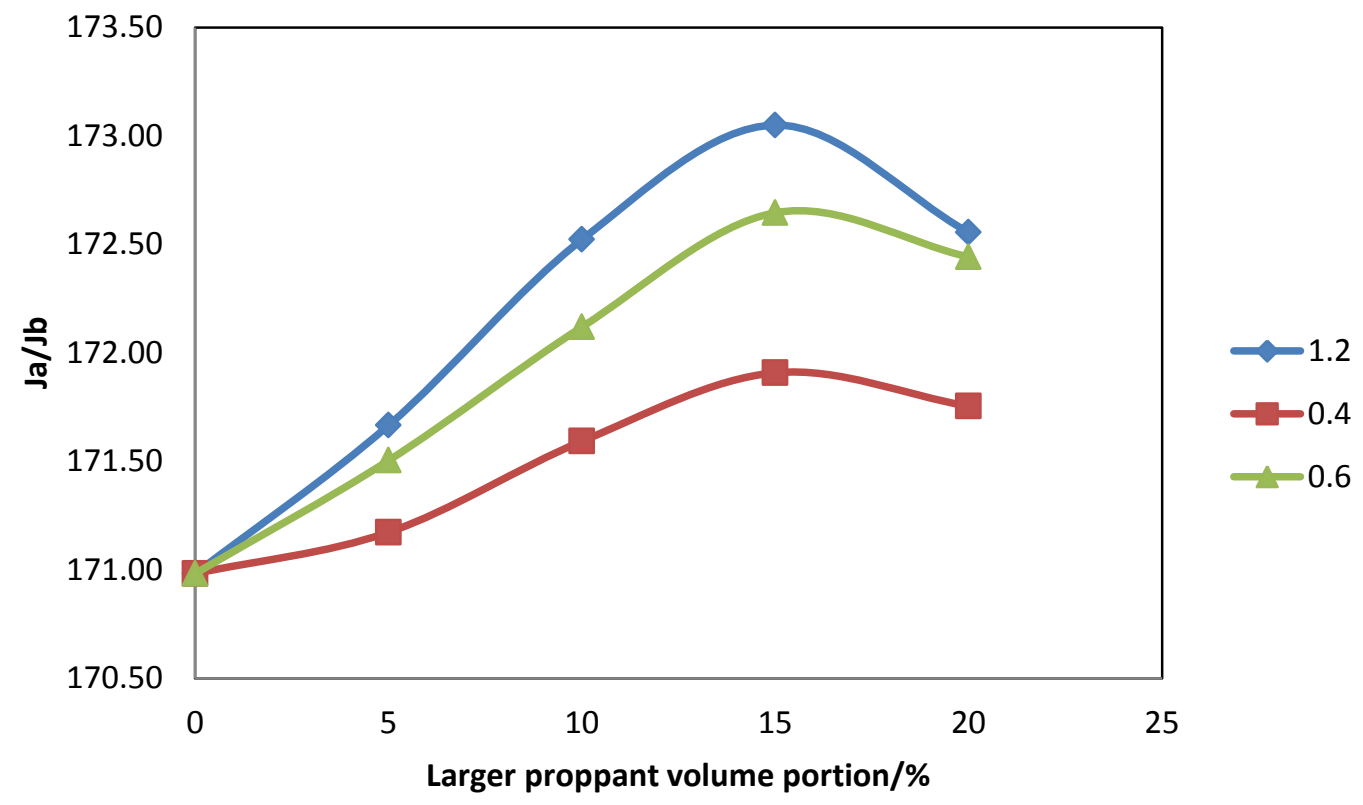

Figure 38 The effect of proppant size and volume portion combination on dimensionless productivity

Simulation results show that larger size of the later injected proppant leads to a better performance. Also, there exist an optimum volume portion for the later injected proppant, and the portion is about $15 \%$ to $20 \%$ depending on the proppant size.

\section{3: Experimental design}

Due to the fact that many different variables like reservoir permeability, proppant size, injection rate and fluid viscosity contribute in the hydraulic fracture performance, it is very hard to identify the specific role played by each one of these parameters using one variable at a time approach (OVAT) due to correlation exist between these parameters, such as viscosity density or proppant 
size and density relations. Design of experiment technique will be used in this research to quantify the contribution of each candidate parameters and their interactions

\subsubsection{Design of experiments}

Single variable sensitivity analysis is a good tool to study how the system responds to the variable when limited number of independent variables is considered. This technique requires a change in one variable while other variables are constant. In the case that we have more variables and they are correlated in some extent, new techniques have been developed to study their effects and interaction with limited number of runs while being able to capture the major future of interactions between different variables. These techniques can also be used for uncertainty analysis of the process when lacking the knowledge of the process and sufficient precision in obtaining the parameters of interest and control on interaction between different parameters of the process. Based on the number of variables and their levels of change, different experimental design techniques are introduced. Usually two or three levels of changes of variables are considered. In the case of variables with two levels change experiment, higher and lower boundaries for each variable is picked based on OVAT studies and +1 and -1 will be assigned to those values for representation purpose in experimental design structure; three levels of changes have an additional middle level or zero level in the experimental design structure. The most accurate method is full factorial design which considers all possible combinations of the variables. The total number of full factorial design is given by $\mathrm{L}^{\mathrm{N}}$ where $\mathrm{L}$ denotes the number of levels for each variable and $\mathrm{N}$ is the number of variables. This method is very accurate but at the same time very time consuming. A lot of attempt has been made to minimize the number of runs while maintain the resolution as high as possible. In this research, Plackett-Burman design (PB) is used. PB is two-level factorial experiment design that allows us to investigate large number of factors inexpensively. Plackett-Burman designs can be used to identify the most important factors early in the experimentation phase. They are generally used with eight or more (up to 47) factors. In Plackett-Burman designs, main effects have complicated confounding relationship with twofactor interactions. Therefore, these designs should be used mainly to study main effects, when two-way interactions can be assumed negligible. Plackett-Burman designs always have a run number that is a multiple of four (12 to 48). The number of factors must be less than the number of runs. For example, a design with 12 runs allows you to estimate the main effects for up to 11 factors. Plackett-Burman experiment can identify the most important main effects and then use 
response surface designs to optimize the process. The PB design settings are listed in Table 5 and Table 6.

Table 5 Parameter setting of PB design

\begin{tabular}{|c|c|c|c|}
\hline Parameter & -1 & 1 & unit \\
\hline A:Fluid viscosity & 1 & 10 & $\mathrm{cp}$ \\
\hline B:Proppant size & 0.1 & 2 & $\mathrm{~mm}$ \\
\hline $\begin{array}{c}\text { C:Relative } \\
\text { density }\end{array}$ & 1.5 & 3.5 & 1 \\
\hline D:Injection rate & 0.2 & 1 & $\mathrm{ft} / \mathrm{s}$ \\
\hline E:Fracture width & 0.017 & 0.2 & $\mathrm{ft}$ \\
\hline F:Permeability & 0.1 & 100 & $\mathrm{mD}$ \\
\hline G:Prop volume & 0.45 & 0.9 & 1 \\
\hline
\end{tabular}

Table 6 PB matrix for 7 variables, $-1=$ low value; $+1=$ high value

\begin{tabular}{|c|c|c|c|c|c|c|c|c|}
\hline & Factor 1 & Factor 2 & Factor 3 & Factor 4 & Factor 5 & Factor 6 & Factor 7 & Response \\
\hline $\begin{array}{c}\text { R } \\
\text { un }\end{array}$ & $\begin{array}{c}\text { A:Fluid } \\
\text { viscosity }\end{array}$ & $\begin{array}{c}\text { B:Proppa } \\
\text { nt size }\end{array}$ & $\begin{array}{c}\text { C:Relative } \\
\text { density }\end{array}$ & $\begin{array}{c}\text { D:Injectio } \\
\text { n rate }\end{array}$ & $\begin{array}{c}\text { E:Fracture } \\
\text { width }\end{array}$ & $\begin{array}{c}\text { F:Perme } \\
\text { ability }\end{array}$ & $\begin{array}{c}\text { G:Prop } \\
\text { volume }\end{array}$ & $\begin{array}{c}\text { Dimension } \\
\text { less PI }\end{array}$ \\
\hline & cp & mm & 1 & s & in & D & & \\
\hline 1 & 1 & 1 & -1 & 1 & 1 & -1 & 1 & $2.11 \mathrm{E}+02$ \\
\hline 2 & 1 & 1 & 1 & -1 & 1 & 1 & -1 & $4.15 \mathrm{E}+01$ \\
\hline 3 & 1 & 1 & -1 & 1 & -1 & -1 & -1 & $2.07 \mathrm{E}+02$ \\
\hline 4 & -1 & 1 & -1 & -1 & -1 & 1 & 1 & $1.01 \mathrm{E}+02$ \\
\hline 5 & 1 & -1 & 1 & -1 & -1 & -1 & 1 & $4.14 \mathrm{E}+02$ \\
\hline 6 & 1 & -1 & 1 & 1 & -1 & 1 & -1 & $2.69 \mathrm{E}+01$ \\
\hline 7 & -1 & 1 & 1 & -1 & 1 & -1 & -1 & $2.57 \mathrm{E}+02$ \\
\hline 8 & -1 & 1 & 1 & 1 & -1 & 1 & 1 & $9.02 \mathrm{E}+01$ \\
\hline 9 & -1 & -1 & -1 & -1 & -1 & -1 & -1 & $2.66 \mathrm{E}+02$ \\
\hline 10 & -1 & -1 & -1 & 1 & 1 & 1 & -1 & $2.72 \mathrm{E}+01$ \\
\hline 11 & 1 & -1 & -1 & -1 & 1 & 1 & 1 & $2.77 \mathrm{E}+01$ \\
\hline 12 & -1 & -1 & 1 & 1 & 1 & -1 & 1 & $4.12 \mathrm{E}+02$ \\
\hline
\end{tabular}

\subsubsection{Experiment design analysis}

In this research, Pareto chart, normal plot of the standardized effects and 3D surface response will be used for analysis. The Pareto chart displays the relative size of the effects and present the contribution of the parameters. It uses dimensionless statistics to scale the effects in terms of standard deviations. These are t-value obtained from t-test and p-value using statistical significance. In this design Pareto chart analyzes the uncertainty into three different classes. The 
variable has certainly significant impact in simulation response if it falls above $90 \%$ line defined by $\square=0.1$ and has no significant impact on simulation results if it falls below the line. . From the following Pareto chart we can tell that reservoir permeability, proppant volume and proppant density have significant influence on the dimensionless productivity index while proppant size, fluid viscosity, injection rate and fracture width having minimal impact.

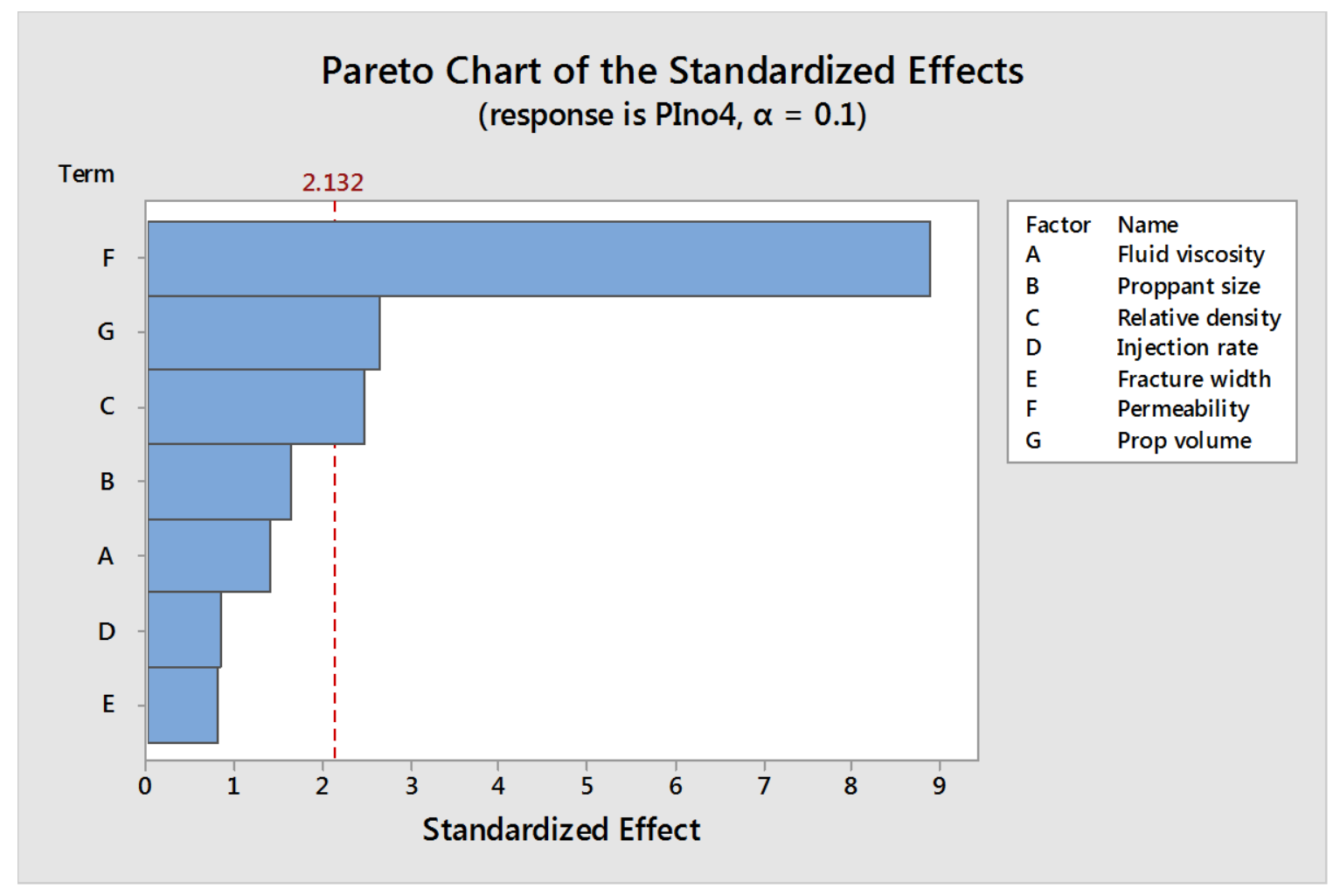

Figure 39 Pareto chart shows the importance of parameters evaluated on the t-value of original case

In the normal probability plot of the effects, points that do not fall near the line usually indicate important effects. Important effects are larger and generally further from the fitted line than unimportant effects. Unimportant effects tend to be smaller and centered on zero. Also, normal plot can tell the effect polarity of each variable. For example, the standard effect of reservoir permeability is negative, which means small permeability reservoir tend to have better improvement from hydraulic fracturing treatment. Figure 40 clearly shows that reservoir matrix permeability has the highest negative impact on simulation response and prop volume and then relative density of proppant to frac fluid has the highest positive impact on dimensionless productivity index. 


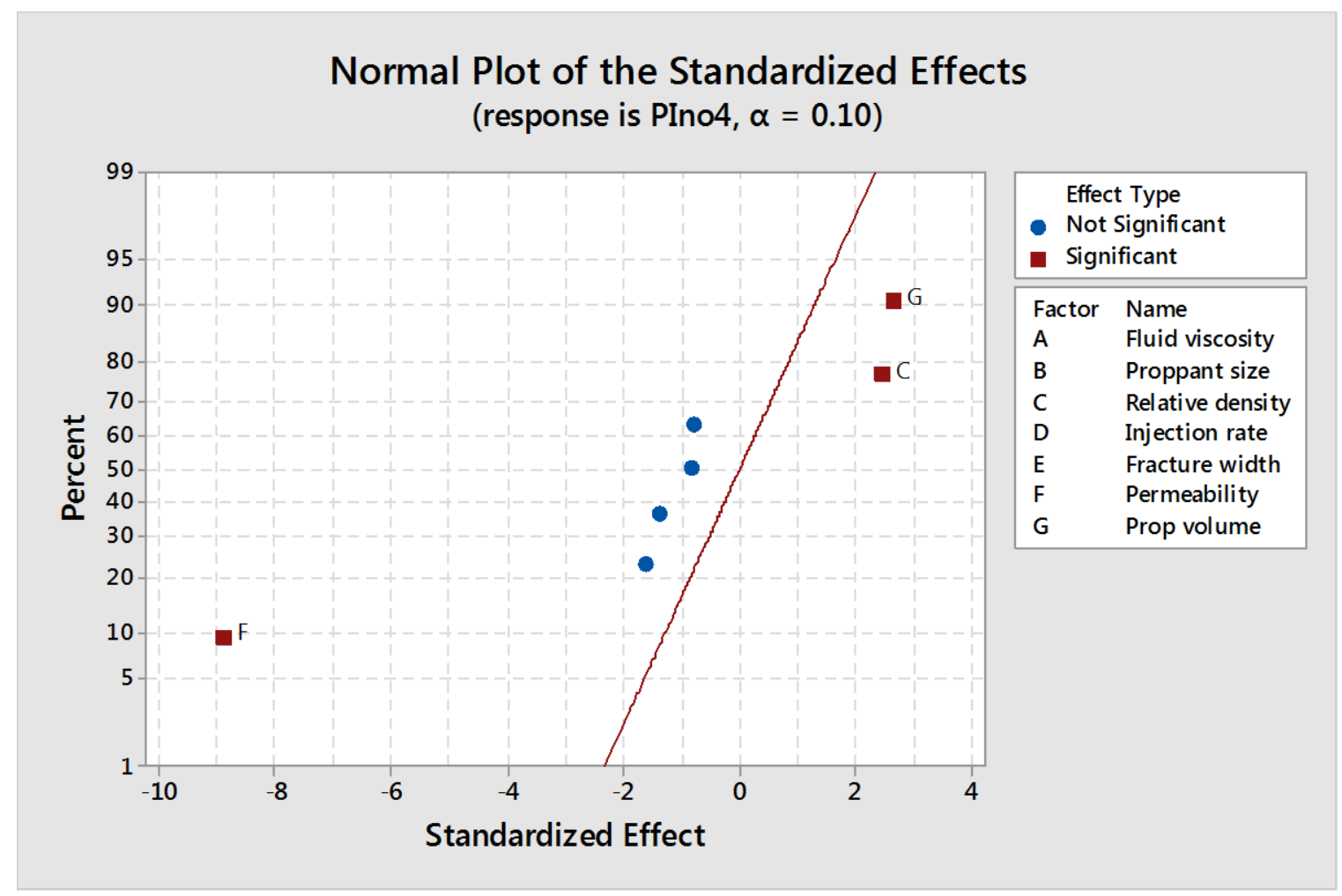

Figure 40 Normal plot of the standardized effects of original case shows the importance of parameters

The alias structure of PB design is complex. All main effects have two-factor, three-factor and more interaction alias chains. To minimize the error, we can do full fold-over design to eliminate the entire two-factor interaction alias from main effects. Full fold-over design means to switch the signs in all columns of the original design as shown in Table 6: 
Table 7 full fold-over PB matrix for 7 variables, $-1=$ low value; $+1=$ high value

\begin{tabular}{|c|c|c|c|c|c|c|c|c|}
\hline $\begin{array}{c}\text { R } \\
\text { un }\end{array}$ & $\begin{array}{c}\text { Factor 1 } \\
\text { viscosity }\end{array}$ & $\begin{array}{c}\text { Factor 2 } \\
\text { nt size }\end{array}$ & $\begin{array}{c}\text { Factor 3 } \\
\text { density }\end{array}$ & $\begin{array}{c}\text { Factor 4 } \\
\text { n rate }\end{array}$ & $\begin{array}{c}\text { Factor 5 } \\
\text { E:Fracture } \\
\text { width }\end{array}$ & $\begin{array}{c}\text { Factor 6 } \\
\text { ability }\end{array}$ & $\begin{array}{c}\text { Factor 7 } \\
\text { G:Prop } \\
\text { volume }\end{array}$ & $\begin{array}{c}\text { Dimensionse } \\
\text { less PI }\end{array}$ \\
\hline & $\mathrm{cp}$ & $\mathrm{mm}$ & 1 & $\mathrm{~s}$ & in & D & & \\
\hline 1 & -1 & -1 & 1 & -1 & -1 & 1 & -1 & $2.68 \mathrm{E}+01$ \\
\hline 2 & -1 & -1 & -1 & 1 & -1 & -1 & 1 & $4.14 \mathrm{E}+02$ \\
\hline 3 & -1 & -1 & 1 & -1 & 1 & 1 & 1 & $2.76 \mathrm{E}+01$ \\
\hline 4 & 1 & -1 & 1 & 1 & 1 & -1 & -1 & $2.85 \mathrm{E}+02$ \\
\hline 5 & -1 & 1 & -1 & 1 & 1 & 1 & -1 & $5.26 \mathrm{E}+01$ \\
\hline 6 & -1 & 1 & -1 & -1 & 1 & -1 & 1 & $3.56 \mathrm{E}+02$ \\
\hline 7 & 1 & -1 & -1 & 1 & -1 & 1 & 1 & $2.74 \mathrm{E}+01$ \\
\hline 8 & 1 & -1 & -1 & -1 & 1 & -1 & -1 & $2.86 \mathrm{E}+02$ \\
\hline 9 & 1 & 1 & 1 & 1 & 1 & 1 & 1 & $1.65 \mathrm{E}+02$ \\
\hline 10 & 1 & 1 & 1 & -1 & -1 & -1 & 1 & $3.91 \mathrm{E}+02$ \\
\hline 11 & -1 & 1 & 1 & 1 & -1 & -1 & -1 & $2.64 \mathrm{E}+02$ \\
\hline 12 & 1 & 1 & -1 & -1 & -1 & 1 & -1 & $5.80 \mathrm{E}+01$ \\
\hline
\end{tabular}

The Pareto chart after full fold-over design shows the same order as obtained before fold over, i.e., matrix permeability, prop volume and relative density) however it shows proppant size and fluid viscosity also might have higher impacts than what has been obtained earlier. 


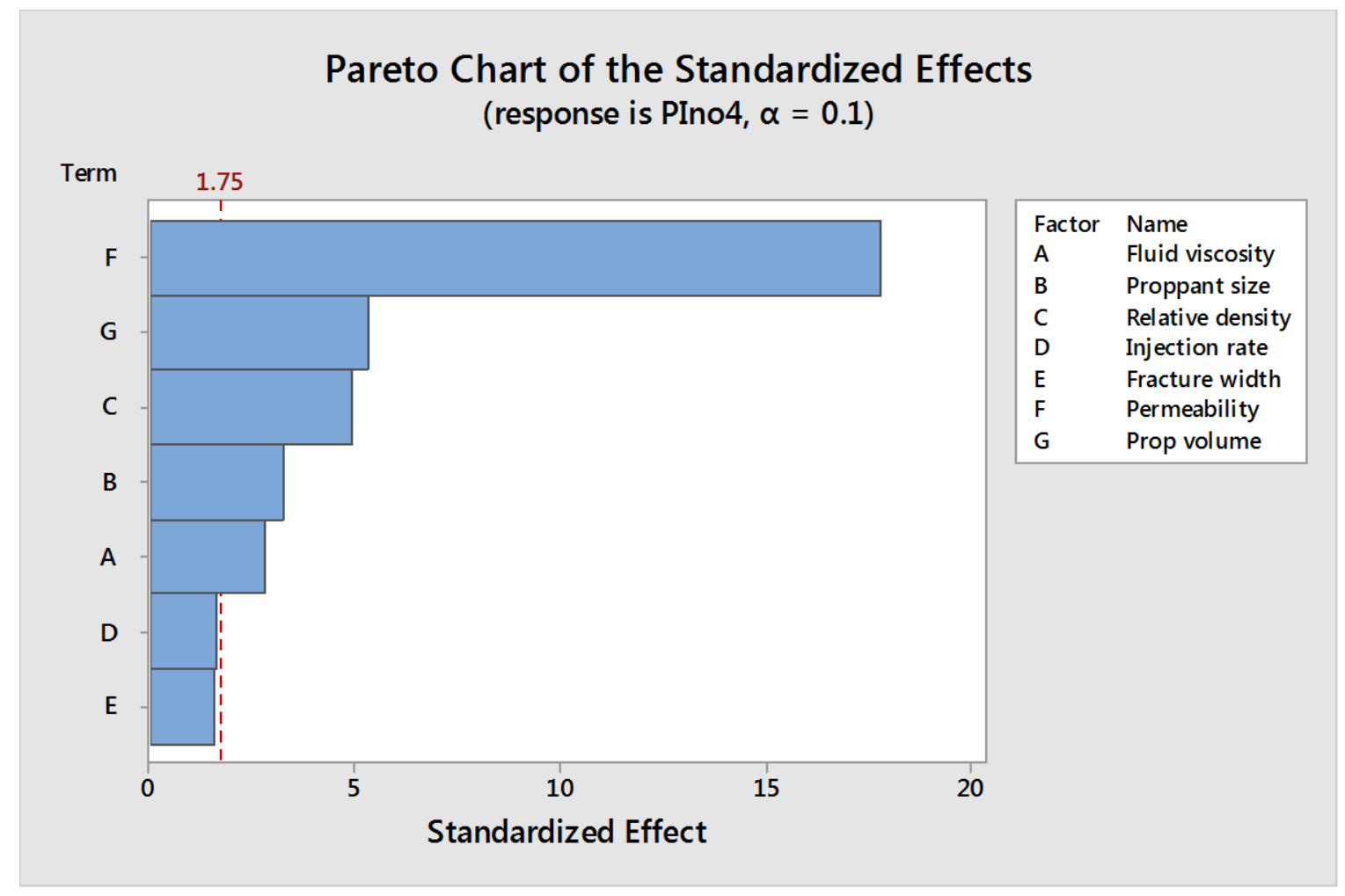

Figure 41 Pareto chart shows the importance of parameters evaluated on the t-value of fold-over case

The 3D surface plot of dimensionless productivity index vs. proppant size and proppant density, Figure $423 \mathrm{D}$ surface generated to visualize the magnitude and trend of the effect of proppant size and relative density on dimensionless productivity, shows the effect of proppant size and density on productivity index in a more clear way. 


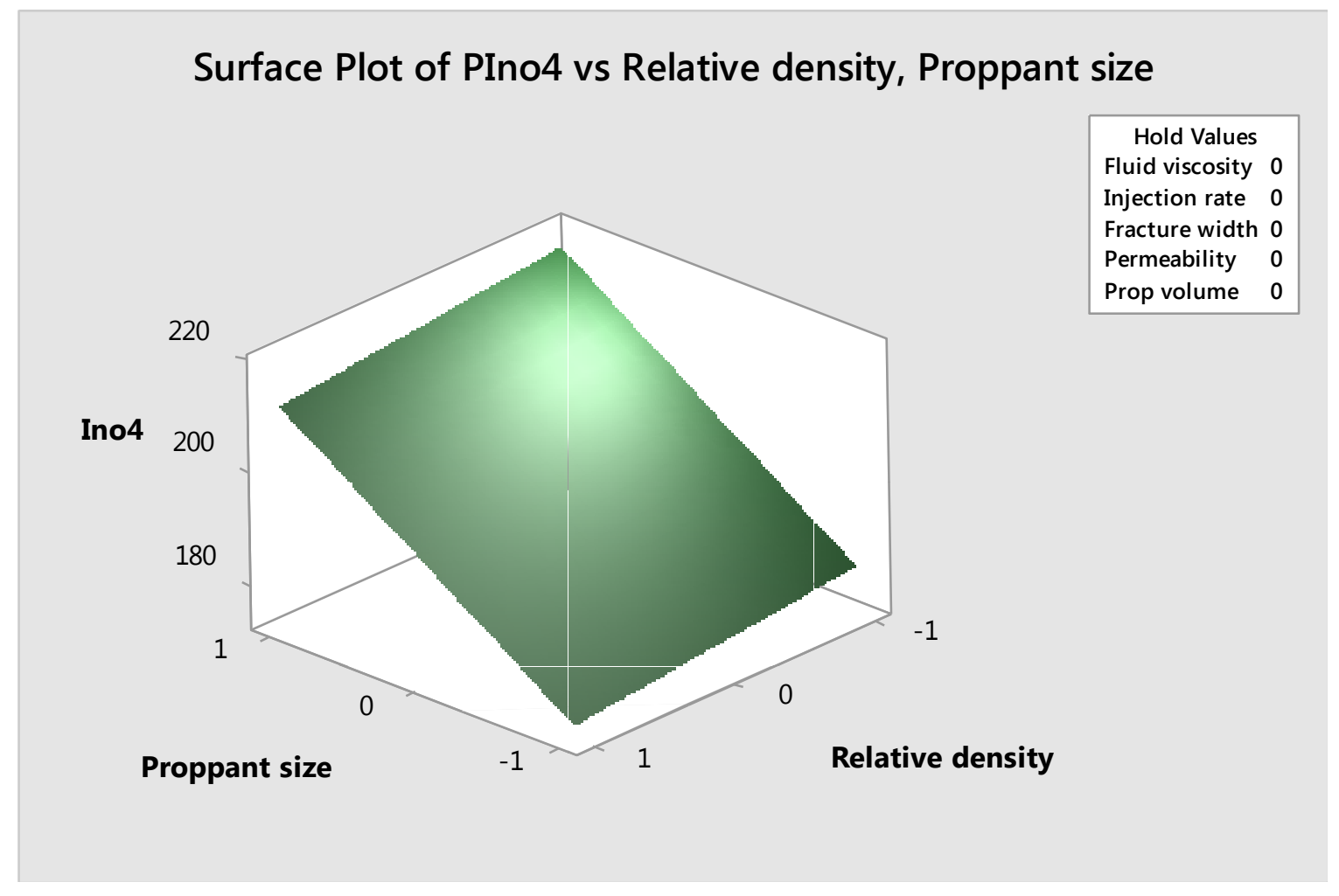

Figure 42 3D surface generated to visualize the magnitude and trend of the effect of proppant size and relative density on dimensionless productivity 


\section{CHAPTER: 4 CONCLUSIONS}

A numerical simulator based on finite differencing method is built using Fortran 90 including three major parts: fluid and proppant transport in hydraulic fracture during injection, which is based on staggered grid system; hydraulic fracture geometry calculation after flow back; hydraulic fractured gas reservoir production simulator in 3D. These three modules work in series in which the output of one will be an input for next module. Final hydraulic fracture geometry uses the proppant concentration profile provided by fluid and proppant transport simulation, then the fracture geometry and proppant pack properties are passed to the gas reservoir production simulator to simulate the pressure transient and production rate. In this study different parameters impacting proppant settling velocity such as non-Newtonian flow, fracture width and proppant concentration effect are considered.

Next, sensitivity analysis is implemented to quantify the impact of different parameters such as proppant size, proppant density, prop volume, matrix permeability and injection rate on dimensionless productivity index. Also, by using design of experiment technique, important factors are ranked based on their impact on the dimensionless productivity index.

Sensitivity analysis shows that proppant settling can cause heterogeneous distribution of proppant and further more reduce the production by $12 \%$ or more. Non-Darcy effect is severe in gas reservoir especially in hydraulic fracture, and it also decreases the production rate. Among the parameters which can affect proppant settling, proppant size is most sensitive. Sensitivity of proppant size shows different pattern in different permeability reservoir. In low permeability reservoir, small proppant is better suited because it can reduce the settling velocity and lead to a larger flowing area; in a high permeability reservoir, larger proppant can cause better performance because high permeability flow channel is more granted. Through the design of experiment, the effect of each variable is identified and ranked. It is shown that reservoir permeability determines the hydraulic fracturing treatment performance the most.

Also, two proppant size combination treatments are studied in this research. Relatively smaller size proppant plug followed by larger size proppant plug can improve the treatment effectiveness, depending on their volume ratio. 


\section{REFERENCES}

1. Abousleiman, Y. N. "A poroelastic PKN model with pressure dependent leakoff and formation permeability determination". Diss. University of Delaware, 1992.

2. Abe, H., Keer, L. M. and Mura ,T. "Growth rate of a penny shaped crack in hydraulic fracturing of rocks, 2." Journal of Geophysical Research 81.35 (1976): 6292-6298.

3. $\quad$ Adachi, J., Siebrits, E., Peirce, A., "Computer simulation of hydraulic fractures." International Journal of Rock Mechanics and Mining Sciences 44.5 (2007): 739-757.

4. Armenta, M., \& Wojtanowicz, A. K. (2003, January 1). Rediscovering Non-Darcy Flow Effect In Gas Reservoir. Society of Petroleum Engineers. doi:10.2118/84071-MS

5. Asmolov, E. S. "The inertial lift on a small particle in a weak-shear parabolic flow." Physics of Fluids (1994-present) 14.1 (2002): 15-28.

6. Barree, R. D. and Conway, M. W. "Experimental and numerical modeling of convective proppant transport." JPT. Journal of petroleum technology 47.3 (1995): 216-222.

7. Brown, D. L., Cortez, R. and Michael L. M. "Accurate projection methods for the incompressible Navier-Stokes equations." Journal of Computational Physics 168.2 (2001): 464-499.

8. Bird, R. B., Warren E. S., and Edwin N. L. Transport phenomena. John Wiley \& Sons, 2007.

9. Carter, R. D. "Derivation of the general equation for estimating the extent of the fractured area." Appendix I of "Optimum Fluid Characteristics for Fracture Extension,” Drilling and Production Practice, GC Howard and CR Fast, New York, New York, USA, American Petroleum Institute (1957): 261-269.

10. Craft, B. C., Murray F. H., and Ronald, E. T. Applied petroleum reservoir engineering. Vol. 199. Englewood Cliffs, NJ: Prentice-Hall, 1959.

11. Chorin, A. J. "Numerical solution of the Navier-Stokes equations." Mathematics of computation 22.104 (1968): 745-762.

12. Clifton, R. J., \& Wang, J.-J. (1988, January 1). Multiple Fluids, Proppant Transport, and Thermal Effects in Three-Dimensional Simulation of Hydraulic Fracturing. Society of Petroleum Engineers. doi:10.2118/18198-MS 
13. Clark, P. E., \& Quadir, J. A. (1981, January 1). Prop Transport In Hydraulic Fractures: A Critical Review Of Particle Settling Velocity Equations. Society of Petroleum Engineers. doi:10.2118/9866-MS

14. Cooke, C. E. "Conductivity of fracture proppants in multiple layers." Journal of Petroleum Technology 25.09 (1973): 1-101.

15. Chaikin, P. "Random thoughts." Physics Today 60.6 (2007): 8-9.

16. Daneshy, A. A. and Crichlow, H. B. Numerical solution of sand transport in hydraulic fracturing. No. CONF-800242-5. Halliburton Services, Duncan, OK, 1980.

17. Diyashev, I. R., \& Economides, M. J. (2006, August 1). The Dimensionless Productivity Index as a General Approach to Well Evaluation. Society of Petroleum Engineers. doi:10.2118/94644-PA

18. Fjær, E. "Mechanics of hydraulic fracturing." Developments in Petroleum Science 53 (2008): 369-390.

19. Griffith, A. A. "VI. The Phenomena of Rupture and Flow in Solids." Phil. Trans. Roy. Soc.(Lon.) A 221 (1920): 163-198.

20. Ghia, U. K. N. G., Ghia, K. N. and Shin, C. T. "High-Re solutions for incompressible flow using the Navier-Stokes equations and a multigrid method." Journal of computational physics 48.3 (1982): 387-411.

21. Geertsma, J. and Klerk, F. D. "A rapid method of predicting width and extent of hydraulically induced fractures." Journal of Petroleum Technology 21.12 (1969): 1-571.

22. Gidley, J. L. (1991, November 1). A Method for Correcting Dimensionless Fracture Conductivity for Non-Darcy Flow Effects. Society of Petroleum Engineers. doi:10.2118/20710-PA

23. Gardner, M. New mathematical diversions from Scientific American. Simon and Schuster, 1966.

24. Gadde, P. B., Liu, Y., Norman, J., Bonnecaze, R., \& Sharma, M. M. (2004, January 1). Modeling Proppant Settling in Water-Fracs. Society of Petroleum Engineers. doi:10.2118/89875-MS

25. Hudson, D. R. "Density and packing in an aggregate of mixed spheres." Journal of Applied Physics 20.2 (2004): 154-162. 
26. Hopkins, A. B., Frank H. S. and Salvatore T. "Densest binary sphere packings." Physical Review E 85.2 (2012): 021130.

27. Harris, P. C., Morgan, R. G., \& Heath, S. J. (2005, January 1). Measurement of Proppant Transport of Frac Fluids. Society of Petroleum Engineers. doi:10.2118/95287-MS

28. Howard, G. C. and Fast, C. R. "Optimum fluid characteristics for fracture extension." Drilling and Production Practice (1957).

29. Khristianovic, S. and Zheltov, Y. "Formation of vertical fractures by means of highly viscous fluids." Proceedings of the 4th world petroleum congress, Rome. Vol. 2. 1955.

30. Unwin, A. T., \& Hammond, P. S. (1995, January 1). Computer Simulations of Proppant Transport in a Hydraulic Fracture. Society of Petroleum Engineers. doi:10.2118/29649MS

31. Marshall, G. W. and Toby S. H. "Dense binary sphere packings." Contributions to Algebra and Geometry 51.2 (2010): 337-344.

32. McGuire, W. J. and Sikora,V. J. "The effect of vertical fractures on well productivity." Journal of Petroleum Technology 12.10 (1960): 72-74.

33. Morales, R. H., \& Abou-Sayed, A. S. (1989, February 1). Microcomputer Analysis of Hydraulic Fracture Behavior With a Pseudo-Three-Dimensional Simulator. Society of Petroleum Engineers. doi:10.2118/15305-PA

34. Novotny, E. J. (1977, January 1). Proppant Transport. Society of Petroleum Engineers. doi:10.2118/6813-MS

35. Nordgren, R. P. "Propagation of a vertical hydraulic fracture." Society of Petroleum Engineers Journal 12.04 (1972): 306-314.

36. Ouyang, S., Carey, G. F. and Yew, C. H. "An adaptive finite element scheme for hydraulic fracturing with proppant transport." International journal for numerical methods in fluids 24.7 (1997): 645-670.

37. Palisch, T. T., Duenckel, R. J., Bazan, L. W., Heidt, J. H., \& Turk, G. A. (2007, January 1). Determining Realistic Fracture Conductivity and Understanding its Impact on Well Performance - Theory and Field Examples. Society of Petroleum Engineers. doi:10.2118/106301-MS

38. Pearson, C. M. "Dimensionless fracture conductivity: Better input values make better wells." Journal of petroleum technology 53.01 (2001): 59-63. 
39. Perkins, T. K. and Kern, L. R. "Widths of hydraulic fractures." Journal of Petroleum Technology 13.09 (1961): 937-949.

40. Petty, N. A. and Xu, G. "The Effects of Proppant Concentration on the Rheology of Slurries for Hydraulic Fracturing-A Review." Undergraduate Research Journal (2011): 45.

41. Roodhart, L. P. (1985, January 1). Proppant Settling in Non-Newtonian Fracturing Fluids. Society of Petroleum Engineers. doi:10.2118/13905-MS

42. Rubey, W. W. "Settling velocity of gravel, sand, and silt particles." American Journal of Science 148 (1933): 325-338.

43. Romero, D. J., Valko, P. P., \& Economides, M. J. (2003, February 1). Optimization of the Productivity Index and the Fracture Geometry of a Stimulated Well With Fracture Face and Choke Skins. Society of Petroleum Engineers. doi:10.2118/81908-PA

44. Shah, S.N.: "Proppant Settling Correlations for Non-Newtonian Fluids Under Static and Dynamic Conditions," Soc. Pet. Eng. J. (April 1982) 164-70.

45. Song, C., Wang, P. and Hernán A. M. "A phase diagram for jammed matter." Nature 453.7195 (2008): 629-632.

46. Smith, M. B., Bale, A., Britt, L. K., Hainey, B. W., \& Klein, H. K. (2001, February 1). Enhanced 2D Proppant-Transport Simulation: The Key To Understanding Proppant Flowback and Post-Frac Productivity. Society of Petroleum Engineers. doi:10.2118/69211-PA

47. Sweby, P. K. "High resolution schemes using flux limiters for hyperbolic conservation laws." SIAM journal on numerical analysis 21.5 (1984): 995-1011.

48. Settari, A. "Simulation of hydraulic fracturing processes." Society of Petroleum Engineers Journal 20.06 (1980): 487-500.

49. Seibold, B. "A compact and fast Matlab code solving the incompressible Navier-Stokes equations on rectangular domains." Massachusetts Institute of Technology (2008).

50. Yu, W., \& Sepehrnoori, K. (2013, November 5). Simulation of Proppant Distribution Effect on Well Performance in Shale Gas Reservoirs. Society of Petroleum Engineers. doi:10.2118/167225-MS

51. Tsai, K., Degaleesan, S. S., Fonseca, E. R., \& Lake, E. (2012, January 1). Advanced Computational Modeling of Proppant Settling in Water Fractures for Shale Gas Production. Society of Petroleum Engineers. doi:10.2118/151607-MS 
52. Takbiri Borujeni, A. Multi-scale Modeling of Inertial Flows through Propped Fractures. Diss. Louisiana State University, 2013.

53. Valkó, P. and Economides, M. J. Hydraulic fracture mechanics. Chichester, UK: Wiley, 1995.

54. Yamamoto, K., Shimamoto, T., \& Maezumi, S. (1999, January 1). Development of a True 3D Hydraulic Fracturing Simulator. Society of Petroleum Engineers. doi:10.2118/54265MS

55. Zong, C. "From deep holes to free planes." Bulletin of the American Mathematical Society 39.4 (2002): 533-555. 